\title{
MARCELO KATZ
}

\section{Valor prognóstico dos peptídeos natriuréticos BNP e}

NT-proBNP na estratificação de risco dos pacientes com

\author{
estenose aórtica grave
}

Tese apresentada à Faculdade de Medicina da Universidade de São Paulo para obtenção do título de Doutor em Ciências

Área de concentração: Cardiologia

Orientador: Prof. Dr. Flávio Tarasoutchi 


\section{Dados Internacionais de Catalogação na Publicação (CIP)}

Preparada pela Biblioteca da

Faculdade de Medicina da Universidade de São Paulo

Creprodução autorizada pelo autor

\section{Katz, Marcelo}

Valor prognóstico dos peptídeos natriuréticos BNP e NT-proBNP na estratificação de risco dos pacientes com estenose aórtica grave / Marcelo Katz. -São Paulo, 2009.

Tese(doutorado)--Faculdade de Medicina da Universidade de São Paulo. Departamento de Cardio-Pneumologia.

Área de concentração: Cardiologia.

Orientador: Flávio Tarasoutchi.

Descritores: 1.Estenose da valva aórtica 2.Peptídeo natriurético encefálico 3.Marcadores biológicos 4.Prognóstico

USP/FM/SBD-183/09 
"O único lugar onde o sucesso vem antes do trabalho é no dicionário." ALBERT EINSTEIN

"A persistência é o caminho do êxito." CHARLES CHAPLIN 
À minha maior incentivadora, minha esposa Thaísa, você é o melhor presente que eu poderia receber nessa vida.

Aos meus pais, Elizabeth e Ieoschua, que sempre me incentivaram, torceram e vibraram. Tenho muito orgulho em tê-los como pais.

Aos meus irmãos Marcio e Michele, pela amizade mais sincera e lealdade incondicional.

Às minhas avós Sarah e Lea, por terem sido tão próximas esses anos todos.

Aos meus avôs Gerszon (in memorian) e Marcos (in memorian) por sua sabedoria e conselhos, e pela oportunidade que tive de conviver com vocês.

Aos meus sogros, Ruth e Alberto, que desde sempre me receberam tão bem.

Aos meus cunhados Adriana, Flávia, Marcel e Jairo pela amizade e carinho. 


\section{AGRADECIMENTOS}

Ao Prof. Dr. Flávio Tarasoutchi, orientador e amigo, exemplo de ser humano e médico, pela oportunidade, por todo o incentivo, e pelos ensinamentos desses anos todos de convívio.

Ao Prof. Dr. Max Grinberg, Diretor da Unidade de Cardiopatias Valvares do InCor-HCFMUSP, por abrir as portas do Departamento, dando-me a oportunidade de me desenvolver na pesquisa.

Ao Dr. Guilherme Sobreira Spina, pelo apoio fundamental na realização deste projeto.

Ao Dr. Roney Orismar Sampaio, pelos bons conselhos recebidos.

À Secretária Monica Udo Junqueira Kondo e à Técnica de Pesquisa Rute Mello Diniz Ribeiro por todo seu apoio e incentivo durante a minha passagem pela Unidade de Cardiopatias Valvares do InCor.

Aos colegas da equipe de Cardiopatias Valvares, Dr. Tarso Accorsi, Dr. Luiz Francisco Cardoso, Dr. Eduardo Rossi, Dra. Solange Avakian, Dr. Paulo Lavitola, Dr. Nelson Elias, Dra. Berta Boer e Dr. Marcelo Nigri (in memorian).

Ao Dr. Marcelo Luiz Campos Vieira, pela ajuda na avaliação ecocardiográfica dos pacientes deste projeto.

À Prof. Dra. Célia Maria Strunz, por viabilizar a realização do projeto em sua fase laboratorial.

À Técnica de Laboratório Marli Rafael da Silva Cruz, sempre disposta a ajudar, muito obrigado.

À Dra Leila Antonangelo e à Dra Aline Cora, pelo apoio fundamental na realização do projeto. 
Ao Dr. Francisco Laurindo, pelo apoio na finalização desta Tese.

Ao Dr. Antonio Eduardo Pesaro, colega e amigo, por compartilhar todas as etapas deste projeto, muito obrigado.

A todos os funcionários do laboratório do InCor, que participaram direta ou indiretamente da realização deste projeto.

A todos os funcionários do ambulatório de cardiopatias valvares do InCor que participarem direta ou indiretamente da realização deste projeto.

Ao Serviço de pós-graduação do InCor, Neusa, Juliana e Eva, muito obrigado pelo apoio.

Aos pacientes que espontânea e gentilmente participaram desta Tese, meus sinceros agradecimentos. 
Esta tese está de acordo com as seguintes normas:

Referências: adaptado de International Committee of Medical Journal Editors (Vancouver)

Universidade de São Paulo. Faculdade de Medicina. Serviço de Biblioteca e Documentação. Guia de apresentação de dissertações, teses e monografias. Elaborado por Anneliese Carneiro da Cunha, Maria Julia de A. L. Freddi, Maria F. Crestana, Marinalva de Souza Aragão, Suely Campos Cardoso, Valéria Vilhena. $2^{\mathrm{a}}$ Ed. São Paulo: Serviço de Biblioteca e Documentação; 2005.

Abreviaturas dos títulos dos periódicos de acordo com List of Journals Indexed in Index Medicus. 


\section{SUMÁRIO}

\section{LISTA DE ABREVIATURAS E SIGLAS}

LISTA DE QUADROS

LISTA DE TABELAS

LISTA DE FIGURAS

RESUMO

SUMMARY

1. INTRODUÇÃO ........................................................................... 1

1.1 Estenose da valva aórtica: questão de saúde pública ......................... 2

1.2 Estenose da valva aórtica: aspectos relevantes ................................ 4

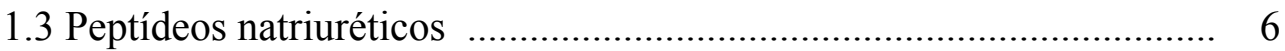

1.4 Peptídeo natriurético tipo B ......................................................... 7

1.4.1 Estrutura molecular, síntese e secreção ..................................... 7

1.4.2 Receptores, mecanismos de ação e depuração ........................... 9

1.5 Peptídeo natriurético tipo B na estenose aórtica: o racional para sua utilização .................................................................................... 12

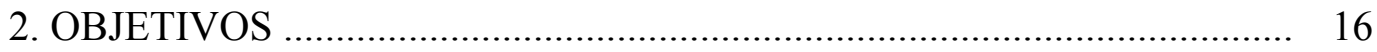

2.1 Objetivo primário …...................................................................... 17

2.2 Objetivos secundários ............................................................ 17

3. MATERIAIS E MÉTODOS …........................................................... 18

3.1 Casuística ….............................................................. 19

3.2 Critérios de exclusão .................................................................... 19

3.3 Protocolo de seguimento .......................................................... 20

3.4 Dosagem do BNP ................................................................. 23

3.5 Dosagem do NT-proBNP ............................................................... 25 
3.6 Ecocardiografia 27

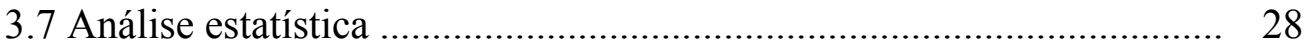

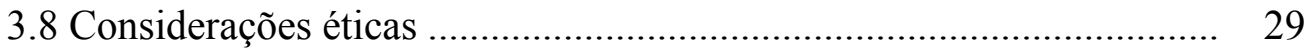

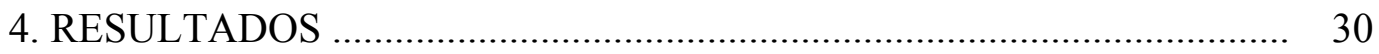

4.1 Dados clínicos ....................................................................... 31

4.2 Dados evolutivos dos pacientes .................................................. 33

4.3 Níveis de BNP e sintomas dos pacientes na inclusão ....................... 35

4.3.1 Comparação dos níveis de BNP entre assintomáticos e sintomáticos ........................................................................ $\quad 35$

4.3.2 BNP e classe funcional (NYHA) ....................................... 36

4.4 BNP como preditor de classe funcional III e IV na inclusão .............. 38

4.5 BNP como preditor de sobrevida ................................................. 39

4.6 Níveis de NT-proBNP e sintomas dos pacientes na inclusão ............ 42

4.6.1 Comparação dos níveis de NT-proBNP entre assintomáticos e sintomáticos ....................................................................... 42

4.6.2 NT-proBNP e classe funcional (NYHA) ................................ 43

4.7 NT-proBNP como preditor de classe funcional III e IV na inclusão.. 45

4.8 NT-proBNP como preditor de sobrevida ........................................ 46

4.9 Correlação entre os parâmetros ecocardiográficos e nível sérico de BNP

4.10 Correlação entre os parâmetros ecocardiográficos e nível sérico de NT-proBNP.....

4.11 Comparação dos níveis de BNP e NT-proBNP no pré e pósoperatório.

4.12 Comparação entre os níveis de BNP e NT-proBNP e classe funcional (NYHA) após a cirurgia . 
4.13 Comparação dos níveis de BNP e NT-proBNP entre pacientes assintomáticos na inclusão vs. pacientes no pós-operatório

4.14 Evolução ecocardiográfica durante o estudo. 58

4.15 BNP vs. NT-proBNP 60

5. DISCUSSÃO 62

5.1 Valores considerados "normais" para o BNP e NT-proBNP 63

5.2 BNP e NT-proBNP para avaliação de status funcional 65

5.3 BNP e NT-proBNP como marcadores prognósticos de sobrevida ...... 68

5.4 BNP e NT-proBNP e parâmetros ecocardiográficos .......................... 72

5.5 BNP e NT-proBNP no período pós-operatório ................................ 74

5.6 Evolução ecocardiográfica dos pacientes ........................................ 75

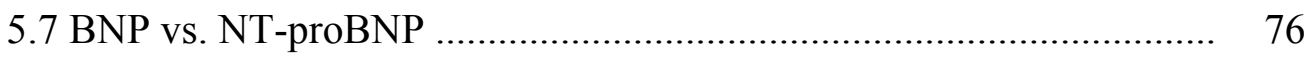

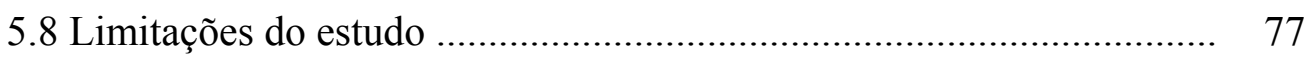

5.9 Considerações finais .................................................................. 77

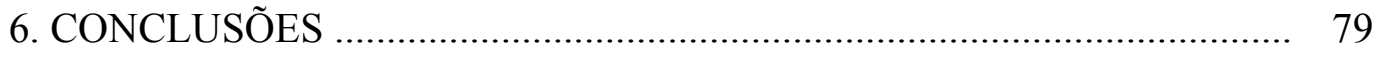

7. REFERÊNCIAS BIBLIOGRÁFICAS ….............................................. 81 APÊNDICE 


\section{LISTA DE ABREVIATURAS E SIGLAS}

\%D Fração de encurtamento do ventrículo esquerdo

$\boldsymbol{\mu} \mathbf{L} \quad$ Microlitro

$\mathrm{ACC}$

American College of Cardiology

$\mathbf{A E}$

Átrio esquerdo

AHA

American Heart Association

ANP

Peptídeo natriurético do tipo A

AO

Aorta

BNP

Peptídeo natriurético tipo B - BNP ativo

C

Carbono

CF

Classe funcional

CI

Confidence interval

cm

Centímetro

CNP

Peptídeo natriurético do tipo $\mathrm{C}$

DD

Diâmetro diastólico do ventrículo esquerdo

DNP Peptídeo natriurético do tipo D

DP Desvio-padrão da média

DS

Diâmetro sistólico do ventrículo esquerdo

EAo Estenose valvar aórtica

ECO Ecocardiograma

EDTA Ácido etilenediaminotetraacético

et al et alii $-\mathrm{e}$ outros

FC Frequência cardíaca

FE Fração de ejeção do ventrículo esquerdo 
GMPc

G. médio

G. pico

HAS

HCFMUSP

HVE

IAO

IBGE

IC

ICC

IMI

IMVE

InCor

Kd

$\mathrm{Kg} / \mathrm{m}^{2}$

Log

$\mathbf{m} / \mathbf{s}$

mg/dL

$\mathbf{m m H g}$

MMII

$\mathbf{N}$

$\mathbf{N}$

NYHA
Monofosfato de guanosina cíclica

Gradiente médio de pressão transvalvar aórtico

Gradiente de pressão transvalvar aórtico no pico da sístole

Hipertensão arterial sistêmica

Hospital das Clínicas da Faculdade de Medicina da

Universidade de São Paulo

Hipertrofia ventricular esquerda

Insuficiência aórtica

Instituto Brasileiro de Geografia e Estatística

Intervalo de confiança

Insuficiência cardíaca congestiva

Insuficiência mitral

Índice de massa do ventrículo esquerdo

Instituto do Coração

Kilodálton

Kilograma por metro quadrado

Logaritmo

Metro por segundo

Miligrama por decilitro

Milímetro de mercúrio

Membros inferiores

Número de pacientes

Nitrogênio

New York Heart Association 


$\begin{array}{ll}\text { NT-proBNP } & \text { Fragmento amino-terminal do proBNP } \\ { }^{\mathbf{O} C} & \text { Graus Celsius } \\ \text { OR } & \text { Odds ratio - razão de chances } \\ \text { PA } & \text { Pressão arterial } \\ \text { pg/mL } & \text { Picograma por mililitro } \\ \text { PN } & \text { Peptídeos natriuréticos } \\ \text { PP } & \text { Parede posterior do ventrículo esquerdo } \\ \text { ROC } & \text { Receiver operating curve characteristic } \\ \text { RPN } & \text { Receptor para peptídeo natriurético } \\ \text { S } & \text { Septo interventricular } \\ \text { SNS } & \text { Sistema nervoso simpático } \\ \text { SRAA } & \text { Sistema renina-angiotensina-aldosterona } \\ \text { Sup corp } & \text { Superfície corpórea } \\ \text { VNP } & \text { Peptídeo natriurético do tipo V } \\ \text { Vs. } & \end{array}$




\section{LISTA DE QUADROS}

Quadro 1 - BNP vs. NT-proBNP

Quadro 2 - BNP vs. classe funcional (NYHA) na inclusão 37

Quadro 3 - BNP vs. classe funcional (NYHA) na inclusão 38

Quadro 4 - NT-proBNP vs. classe funcional (NYHA) na inclusão 44

Quadro 5 - NT-proBNP vs. classe funcional (NYHA) na inclusão 45

Quadro 6 - BNP vs. classe funcional (NYHA) no pós-operatório 57

Quadro 7 - NT-proBNP vs. classe funcional (NYHA) no pós-operatório 57

Quadro 8 - Exemplos de estudos envolvendo PN e prognóstico 69 


\section{LISTA DE TABELAS}

Tabela 1 - Classificação da gravidade da estenose aórtica

Tabela 2 - Valores de normalidade do BNP em pg/mL 25

Tabela 3 - Valores de normalidade do NT-proBNP em pg/mL

Tabela 4 - Características dos pacientes

Tabela 5 - Frequências absolutas e relativas das medicações utilizadas

Tabela 6 - Características dos óbitos

Tabela 7 - BNP em assintomáticos vs. sintomáticos na inclusão do protocolo......

Tabela 8 - NT-proBNP em assintomáticos vs. sintomáticos na inclusão do protocolo

Tabela 9 - Correlação de Pearson entre $\log$ (BNP) e parâmetros ecocardiográficos no grupo todo (sintomáticos e assintomáticos)

Tabela 10 - Correlação de Pearson entre $\log$ (BNP) e parâmetros ecocardiográficos no grupo assintomáticos

Tabela 11 - Correlação de Pearson entre log (BNP) e parâmetros ecocardiográficos no grupo sintomáticos

Tabela 12 - Correlação de Pearson entre log (NT-proBNP) e parâmetros ecocardiográficos no grupo todo (sintomáticos e assintomáticos)

Tabela 13 - Correlação de Pearson entre log (NT-proBNP) e parâmetros ecocardiográficos no grupo assintomáticos

Tabela 14 - Correlação de Pearson entre $\log$ (NT-proBNP) e parâmetros ecocardiográficos no grupo sintomáticos

Tabela 15 - BNP e NT-proBNP pré e pós-operatório de pacientes sintomáticos 
Tabela 16 - BNP em assintomáticos na inclusão vs. pós-operatório 58

Tabela 17 - NT-proBNP em assintomáticos na inclusão vs. pós-operatório 58

Tabela 18 - Comparação entre Ecocardiograma inicial e no final do acompanhamento de pacientes operados

Tabela 19 - Comparação entre Ecocardiograma inicial e no final do acompanhamento de pacientes não operados 


\section{LISTA DE FIGURAS}

Figura 1. Pirâmide populacional brasileira no ano de 2000

Figura 2. Pirâmide populacional brasileira projetada para o ano de 2050

Figura 3. Síntese do BNP e NT-proBNP

Figura 4. Efeitos sistêmicos do BNP

Figura 5. Ficha de avaliação inicial utilizada na inclusão dos pacientes 22

Figura 6. Fluxo de atendimento dos pacientes incluídos

Figura 7. Dados evolutivos dos pacientes durante o acompanhamento

Figura 8. BNP vs. classe funcional (NYHA) na inclusão

Figura 9. Curva ROC para BNP e classe funcional III e IV

Figura 10. Curva de sobrevida dos pacientes (total) em relação ao $\mathrm{BNP}<105$ $\mathrm{pg} / \mathrm{mL}(\mathrm{n}=35)$ e $\geq 105 \mathrm{pg} / \mathrm{mL}(\mathrm{n}=29)$

Figura 11. Curva de sobrevida dos pacientes (total) em relação aos valores de BNP em tercis

Figura 12. Curva de sobrevida dos pacientes sintomáticos em relação ao BNP $<105 \mathrm{pg} / \mathrm{mL}(\mathrm{n}=25)$ e $\geq 105 \mathrm{pg} / \mathrm{mL}(\mathrm{n}=24)$.

Figura 13. NT-proBNP vs. classe funcional (NYHA) na inclusão 44

Figura 14. Curva ROC para NT-proBNP e classe funcional III e IV 46

Figura 15. Curva de sobrevida dos pacientes (total) em relação ao NTproBNP $<1500 \mathrm{pg} / \mathrm{mL}(\mathrm{n}=43)$ e $\geq 1500 \mathrm{pg} / \mathrm{mL}(\mathrm{n}=21)$

Figura 16. Curva de sobrevida dos pacientes (total) em relação aos valores de NT-proBNP em tercis

Figura 17. Curva de sobrevida dos pacientes sintomáticos em relação ao NTproBNP $<1500 \mathrm{pg} / \mathrm{mL}(\mathrm{n}=30)$ e $\geq 1500 \mathrm{pg} / \mathrm{mL}(\mathrm{n}=19)$. 
Figura 18. Correlação entre os níveis de BNP e NT-proBNP 60

Figura 19. Curva ROC de BNP vs. NT-proBNP como preditores de mortalidade 
Katz M. Valor prognóstico dos peptídeos natriuréticos BNP e NT-proBNP na estratificação de risco dos pacientes com estenose aórtica grave [tese]. São Paulo: Faculdade de Medicina, Universidade de São Paulo; 2009. 95p.

INTRODUÇÃO: A estenose aórtica, doença valvar de grande prevalência, tem na avaliação clínica e ecocardiográfica as principais ferramentas para avaliação dos pacientes. Ferramentas auxiliares de avaliação são desejáveis e neste contexto surgem os peptídeos natriuréticos. Os peptídeos natriuréticos BNP e NT-proBNP podem ser usados como marcadores diagnósticos e prognósticos em diversas situações clínicas. Postulamos que os peptídeos pudessem ter papel diagnóstico, mas principalmente valor prognóstico em pacientes com estenose aórtica grave. OBJETIVO: primariamente, definir o papel prognóstico de sobrevida dos peptídeos natriuréticos BNP e NT-proBNP no acompanhamento prospectivo de uma população de pacientes com estenose aórtica grave. Secundariamente, comparar os níveis séricos de BNP e NT-proBNP entre pacientes com EAo grave assintomáticos e sintomáticos. MÉTODOS: Foram incluídos de forma consecutiva 66 pacientes com estenose aórtica grave, definida pela presença de gradiente médio de pressão transvalvar aórtica maior que $40 \mathrm{mmHg}$. Os critérios de exclusão foram fibrilação atrial, outra valvopatia, cardiopatia associada, infecções ativas, neoplasias, doenças auto-imunes ou inflamatórias, insuficiência renal e obesidade. Dos 66 pacientes incluídos, $76 \%$ eram sintomáticos (50/66). Os sintomas foram definidos como dispnéia aos esforços, síncope ou angina. $\mathrm{Na}$ inclusão, todos os pacientes foram submetidos à avaliação clínica inicial, realização de ecocardiograma e dosagem de BNP e NT-proBNP. Os pacientes sintomáticos recebiam a indicação de tratamento cirúrgico e os pacientes assintomáticos eram conduzidos clinicamente. Os pacientes foram acompanhados prospectivamente. O desfecho clínico avaliado foi óbito cardiovascular, definido por morte súbita, morte por insuficiência cardíaca e óbito peri-operatório. RESULTADOS: Os pacientes foram acompanhados por $869 \pm 397$ dias. Houve 11 óbitos durante o acompanhamento. Na inclusão, os níveis de BNP e NT-proBNP foram similares em assintomáticos e sintomáticos: BNP 72 (41-175) pg/mL versus 104 (46-270) pg/mL; $\mathrm{p}=0,275$ e NT-proBNP 676 (235-1356) pg/mL vs. 871 (310-2230) $\mathrm{pg} / \mathrm{mL} ; \mathrm{p}=0,226$. Houve diferença entre os níveis de BNP e NT-proBNP e classe funcional ( $\mathrm{p}<0,001 \mathrm{e} \mathrm{p}<0,001$, respectivamente). Através da curva ROC foi determinado um valor de corte de BNP $(105 \mathrm{pg} / \mathrm{mL})$ e NT-proBNP $(1500 \mathrm{pg} / \mathrm{mL})$ capazes de predizer classe funcional III e IV (New York Heart Association), com área sob a curva de 0,806 e 0,786 respectivamente. BNP e NT-proBNP foram preditores de mortalidade ( $\mathrm{p}=0,007 \mathrm{e} \mathrm{p}=0,001$ respectivamente). $\mathrm{BNP} \geq 105 \mathrm{pg} / \mathrm{mL}$ aumentou $\mathrm{o}$ risco de óbito cardiovascular de forma independente [OR=6,3 (IC95\%: 1,36 - 29,25)]. NT-proBNP $\geq 1500 \mathrm{pg} / \mathrm{mL}$ aumentou o risco de óbito cardiovascular de forma independente $[\mathrm{OR}=6,5$ (IC95\%: 1,73 - 24,63)]. CONCLUSÃO: O BNP e o NTproBNP foram preditores independentes de mortalidade em pacientes com estenose aórtica grave em um acompanhamento de quatro anos. O BNP e o NT-proBNP foram preditores de classe funcional III e IV (New York Heart Association) em pacientes com estenose aórtica grave. O BNP e o NT-proBNP não permitiram diferenciar pacientes sintomáticos de assintomáticos.

Descritores: estenose da valva aórtica, BNP, NT-proBNP, prognóstico. 
Katz M. Prognostic value of natriuretic peptides BNP and NT-proBNP in risk stratification of patients with severe aortic stenosis [thesis]. São Paulo: "Faculdade de Medicina, Universidade de São Paulo"; 2009. 95p.

BACKGROUND: Aortic valve stenosis is a high prevalent cardiac valve disease, in which clinical and echocardiographic parameters are the most common approach of diagnosis and risk evaluation. Complementary methods are desirable and the natriuretic peptides BNP and NT-proBNP, both diagnostic and prognostic markers in multiple clinical situations, could improve patient assessment. We postulate that these peptides may have diagnostic purpose, but mainly a prognostic value in patients with severe aortic stenosis. OBJECTIVE: primarily, define the survival prognostic role of natriuretic peptides BNP and NT-proBNP in monitoring a population of patients with severe aortic stenosis prospectively. Secondarily, compare the serum levels of BNP and NT-proBNP among patients with symptomatic and asymptomatic severe aortic stenosis. METHODS: 66 consecutive patients with severe aortic stenosis, defined by the presence of gradient mean transvalvular aortic pressure greater than $40 \mathrm{mmHg}$ were included. Exclusion criteria were concomitant atrial fibrillation, other valve disease, other myocardiopathies, active infections, autoimmunity diseases, inflammatory diseases, neoplasia, renal failure or obesity. $76 \%$ of patients were symptomatic (50/66), defined as dyspnea on exertion, syncope or angina. All patients underwent initial clinical evaluation, echocardiography and BNP and NT-proBNP measurement. Symptomatic patients were referred for surgical treatment and asymptomatic patients were clinically managed. (Patients were followed up prospectively). The clinical outcome was cardiovascular death, defined by sudden death, death from heart failure and peri-operative death. RESULTS: Patients were followed up for $869 \pm 397$ days. There were 11 deaths during followup. On admission, levels of BNP and NT-proBNP were similar in asymptomatic and symptomatic individuals: BNP 72 (41-175) pg / $\mathrm{mL}$ vs. 104 (46-270) pg / mL, p = 0.275 and NT-proBNP 676 (235-1356) pg / mL vs. 871 (310-2230) pg / ml, p = 0.226 . There were differences between the levels of BNP and NT-proBNP and functional class ( $\mathrm{p}<0.001 \mathrm{p}<0.001$, respectively). ROC-curve analysis demonstrated a cut-off value of BNP (105 pg / mL) and NT-proBNP (1500 pg / mL) capable of predicting NYHA functional class III and IV, with an area under the curve of 0.806 and 0.786 respectively. BNP and NT-proBNP could predict mortality $(\mathrm{p}=0.007$ and $\mathrm{p}=0.001$ respectively). $\mathrm{BNP} \geq 105 \mathrm{pg} / \mathrm{mL}$ independently increased the risk of cardiovascular death $[\mathrm{OR}=6.3(95 \% \mathrm{CI}: 1.36$ to 29.25$)]$. NT-proBNP $\geq 1500 \mathrm{pg} / \mathrm{mL}$ independently increased the risk of cardiovascular death [OR $=6.5(95 \% \mathrm{CI}: 1.73$ to 24.63)]. CONCLUSION: BNP and NT-proBNP were independent predictors of mortality in patients with severe aortic stenosis after a follow up of 4 years. BNP and NT-proBNP were predictors of NYHA functional class III and IV in patients with severe aortic stenosis. BNP and NT-proBNP alone did not distinguish symptomatic from asymptomatic patients.

Descriptors: aortic valve stenosis, BNP, NT-proBNP, prognosis. 


\section{INTRODUÇÃO}

\subsection{Estenose da valva aórtica: questão de saúde pública}

O envelhecimento da população é um fenômeno mundial. No Brasil, de acordo com censos populacionais e projeções realizadas pelo Instituto Brasileiro de Geografia

e Estatística (IBGE) ${ }^{1}$, estima-se que, em cinquenta anos, a população acima de 75 anos represente aproximadamente $10 \%$ do total populacional. Como efeito de comparação, no ano de 2000 esta faixa etária correspondia a apenas $2 \%$ do total de brasileiros. As Figuras 1 e 2 ilustram as mudanças populacionais projetadas para o período de 2000 a 2050

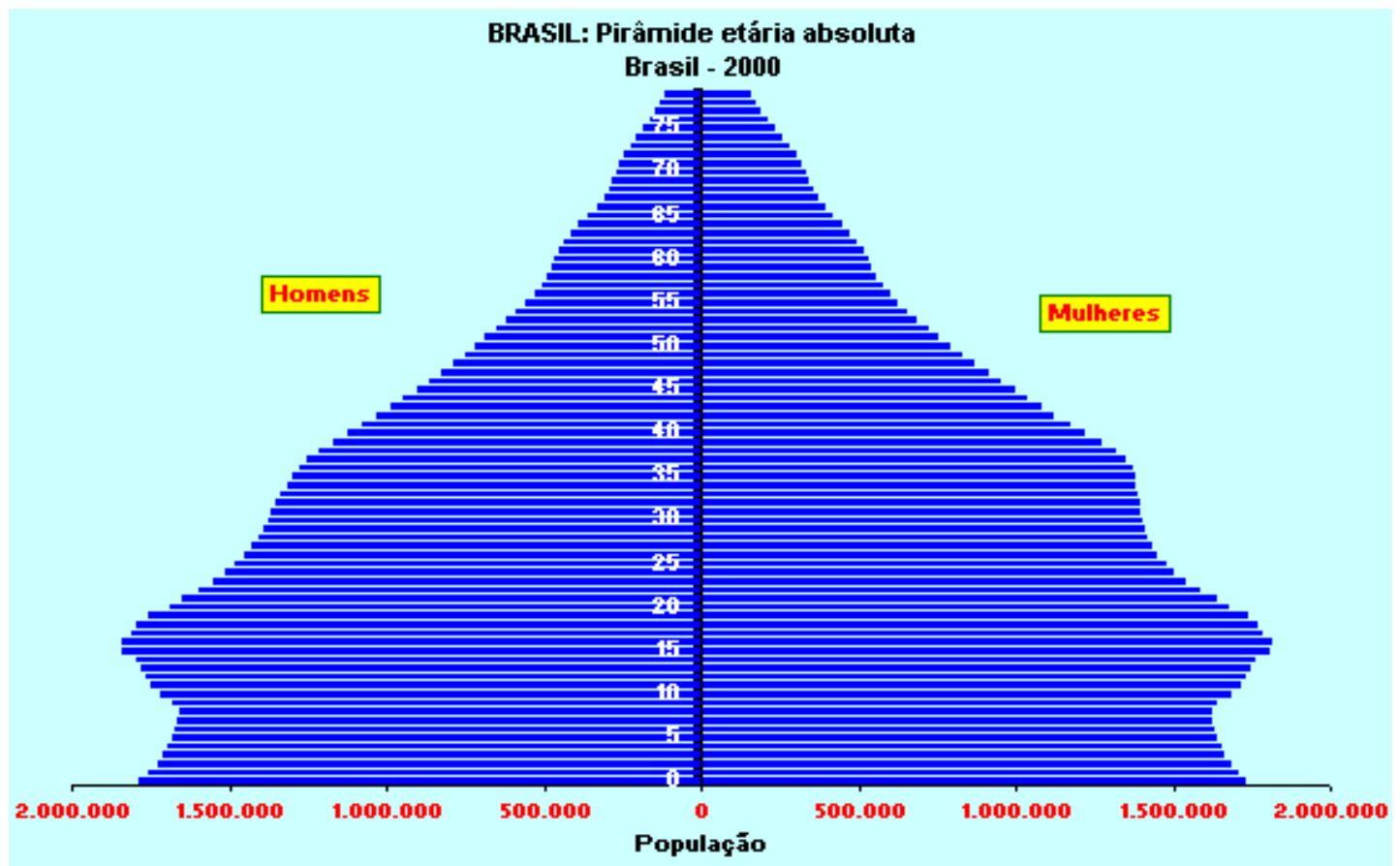

Figura 1. Pirâmide populacional brasileira no ano de 2000

Fonte IBGE: Projeção da População do Brasil 2000-2050

http://www.ibge.gov.br/home/estatistica/populacao/projecao_da_populacao/piramide/piramide.shtm 


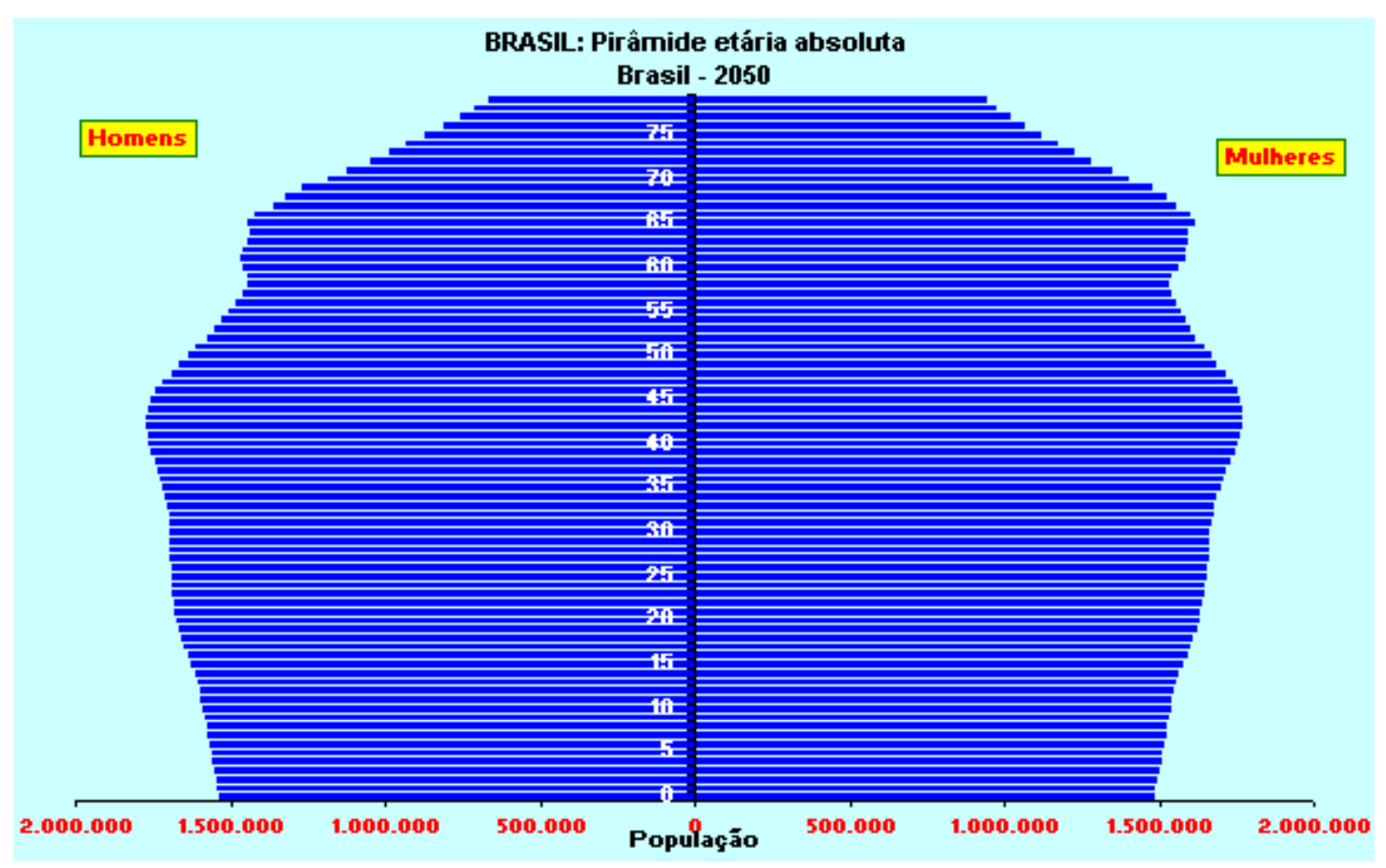

Figura 2. Pirâmide populacional brasileira projetada para o ano de 2050

Fonte IBGE: Projeção da População do Brasil 2000-2050

http://www.ibge.gov.br/home/estatistica/populacao/projecao_da_populacao/piramide/piramide.shtm

Aproximadamente 3\% da população acima de 75 anos de idade apresenta estenose aórtica (EAo) grave de etiologia degenerativa ${ }^{2}$. Ao projetarmos um cenário populacional para o ano de 2050, considerando as estimativas do IBGE, teremos um total populacional de 260.000.000 de habitantes, sendo que destes, aproximadamente $10 \%$, ou 26.000.000, serão pessoas acima de 75 anos de idade. Considerando o estudo de Lindroos et $\mathrm{al}^{2}$, teremos 800.000 pessoas acima de 75 anos de idade com EAo grave degenerativa. Somando estes pacientes àqueles portadores de EAo das demais faixas etárias e etiologias, poderemos considerar esta doença valvar como uma questão de saúde pública, aumentando ainda mais o interesse em seu estudo. 


\subsection{Estenose da valva aórtica: aspectos relevantes}

A EAo é uma doença valvar que acomete a valva aórtica, e que se caracteriza pela obstrução à passagem do fluxo sanguíneo da via de saída do ventrículo esquerdo para a aorta.

Tem como principais etiologias a doença reumática, degenerativa, também denominada aterosclerótica, e congênita ${ }^{3}$.

Nos países desenvolvidos a EAo degenerativa e congênita são as mais prevalentes, enquanto que em países em desenvolvimento, como o Brasil, além das duas anteriores, a EAo reumática torna-se frequente ${ }^{4}$.

Qualquer que seja a causa da EAo, a via final é o processo de calcificação, e redução progressiva do orifício valvar. Na evolução da EAo, esta redução progressiva da área valvar determina hipertrofia ventricular esquerda (HVE), inicialmente com manutenção da função sistólica. A hipertrofia é o mecanismo adaptativo mais importante do miocárdio em resposta à sobrecarga hemodinâmica imposta pela EAo. O aumento da massa miocárdica garante uma maior eficiência contrátil, fundamental neste contexto ${ }^{5}$.

A hipertrofia ventricular esquerda permite que o paciente seja assintomático por um período variável de tempo. Entende-se que nesta fase, o miocárdio adaptado impede que haja aumento da tensão sistólica e diastólica na parede ventricular, apesar da resistência imposta pela EAo.

Entretanto, com o passar do tempo, ocorre um desbalanço entre os compartimentos muscular, intersticial e vascular, resultando em isquemia e dano miocárdico. Há progressiva disfunção ventricular, inicialmente diastólica, observando- 
se déficit de relaxamento ventricular e consequente aumento da tensão diastólica da parede. $\mathrm{Na}$ fase final, observa-se disfunção sistólica.

O início dos sintomas geralmente está associado à mudança da fase adaptada para a fase desadaptada da doença, não necessariamente representada pela disfunção ventricular sistólica. Na realidade, a maioria dos pacientes com EAo que desenvolvem sintomas apresentam função ventricular sistólica normal, e disfunção diastólica evidente ${ }^{6}$.

$\mathrm{Na}$ história natural da EAo, o advento de sintomas (dispnéia, angina ou síncope) é um marcador de gravidade, com implicações drásticas na curva de sobrevida destes pacientes ${ }^{7 ; 8}$.

O diagnóstico da EAo baseia-se na anamnese, exame físico, e avaliação complementar. Na avaliação complementar, o ecocardiograma com Doppler (ECO) tem papel fundamental. O ECO permite a confirmação diagnóstica e a estratificação de gravidade da EAo, que pode ser leve, moderada ou grave. A Tabela 1 apresenta os critérios ecocardiográficos utilizado para definir a gravidade da EAo de acordo com a American Heart Association? . 


\section{Tabela 1 - Classificação da gravidade da estenose aórtica}

\begin{tabular}{|c|c|c|c|}
\hline & Área valvar & $\begin{array}{l}\text { Gradiente médio de } \\
\text { pressão transvalvar } \\
\text { aórtica }\end{array}$ & $\begin{array}{l}\text { Velocidade máxima de } \\
\text { fluxo transvalvar } \\
\text { aórtico }\end{array}$ \\
\hline Leve & $1,5 \mathrm{~cm}^{2}$ & $<25 \mathrm{mmHg}$ & $<3 \mathrm{~m} / \mathrm{s}$ \\
\hline Moderada & $1,0-1,5 \mathrm{~cm}^{2}$ & $25-40 \mathrm{mmHg}$ & $3,0-4,0 \mathrm{~m} / \mathrm{s}$ \\
\hline Grave & $<1,0 \mathrm{~cm}^{2}$ & $>40 \mathrm{mmHg}$ & $>4 \mathrm{~m} / \mathrm{s}$ \\
\hline
\end{tabular}

A avaliação do estado funcional do paciente com EAo é um grande desafio para o médico, visto que os sintomas têm importância prognóstica e definem o tratamento neste grupo de pacientes.

\subsection{Peptídeos natriuréticos}

Em 1981, de Bold e colaboradores observaram que a infusão de extratos de tecido atrial em ratos produzia grande volume de diurese ${ }^{10}$. Esta observação levou à descoberta do peptídeo natriurético atrial (ANP), que apresentava propriedades diuréticas, natriuréticas e vasodilatadoras, o primeiro membro da família dos peptídeos a ser identificado. Estudos subsequentes permitiram a identificação de outros peptídeos natriuréticos $(\mathrm{PN})$, seus receptores, mecanismos celulares de ação e seu papel na homeostase fisiológica ${ }^{11}$.

Os PN constituem uma família de hormônios com uma estrutura química similar composta por uma sequência de 17 aminoácidos, dispostos em forma de anel, estabilizados por uma ponte de cisteína, com duas porções terminais, sendo uma com radical carboxila e a outra com radical amino $\mathrm{N}$ terminal ${ }^{12}$. Apresentam funções 
biológicas semelhantes e atuam principalmente no sistema cardiovascular, estão envolvidos no controle volêmico e pressórico desse sistema ${ }^{13}$, sendo que mais recentemente, surgiram evidências de que desempenham papel autócrino e parácrino no controle da estrutura e função do miocárdio ${ }^{13 ; 14}$.

\subsection{Peptídeo natriurético tipo B}

O Peptídeo natriurético tipo B foi inicialmente identificado em 1988, a partir de estudo em cérebro porcino, daí recebendo a nomenclatura de "brain natriuretic peptide $^{\text {} 15 ; 16}$. Estudos seguintes revelaram que o coração, e não o cérebro, é o principal responsável pela produção e liberação deste peptídeo na circulação sanguínea ${ }^{17}$.

\subsubsection{Estrutura molecular, síntese e secreção}

O Peptídeo natriurético tipo $\mathrm{B}$ é produzido principalmente nos átrios e ventrículos. Sua expressão gênica é maior nos átrios, entretanto, dada a maior massa ventricular, observa-se que $70 \%$ a $88 \%$ deste peptídeo é proveniente dos ventrículos $^{13 ; 18 ; 19}$.

O gene responsável pela codificação do peptídeo natriurético tipo B está localizado no braço curto do cromossomo $1^{13 ; 20 ; 21}$. Este gene, que apresenta três exons e dois introns, origina um produto inicial, denominado pré-proBNP, composto por 134 aminoácidos. Rapidamente, em nível celular, ocorre a remoção de 26 aminoácidos considerados sinalizadores, restando o proBNP, composto por 108 aminoácidos. Em seguida, através da ação das enzimas proteolíticas furina e corina, o 
proBNP é clivado em um fragmento terminal, denominado NT-proBNP, composto por 76 aminoácidos, sem atividade biológica, e um fragmento biologicamente ativo, o BNP ativo (BNP), composto por um total de 32 aminoácidos $^{22}$. Na corrente sanguínea circulam o BNP ativo e o NT-proBNP. A Figura 3 ilustra o processo de geração e liberação do BNP e do NT-proBNP.

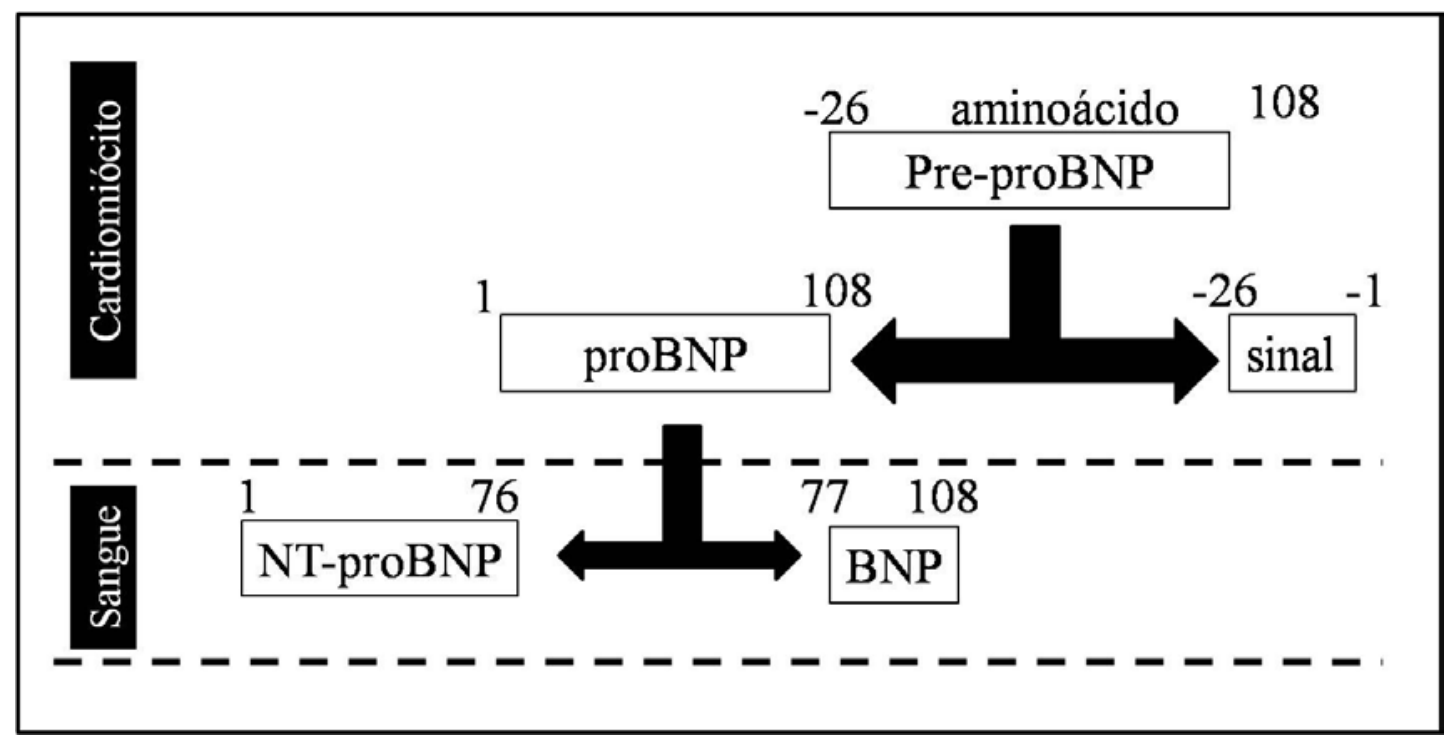

Figura 3. Síntese do BNP e NT-proBNP

Fonte: Vanderheyden M, Bartunek J, Goethals M. Brain and other natriuretic peptides: molecular aspects. Eur J Heart Fail 2004 Mar 15;6(3):261-8.

Os principais estímulos para a geração de BNP são ${ }^{22}$ :

- mecânicos (aumento da tensão sistólica e diastólica da parede ventricular),

- isquemia,

- endotelina-1, angiotensina II, interleucina-1,

- estimulação alfa e beta adrenérgica.

Destes mecanismos, o mais importante é o aumento da tensão da parede ventricular $^{17 ; 23}$. 
Após a estimulação, ocorre ativação do gene responsável pela produção do BNP, com liberação direta do hormônio para a circulação. O BNP, diferentemente do ANP não é estocado, e, portanto, a expressão gênica acelerada é o fator modulador dos níveis circulantes deste peptídeo ${ }^{17}$.

Em situações fisiológicas as concentrações plasmáticas de NT-proBNP e BNP ativo são similares. Ambos são liberados pelos átrios e ventrículos de forma contínua, sendo que a meia vida do BNP é de 22 minutos no sangue, enquanto a meia vida do NT-ProBNP é de 120 minutos. Em pacientes com disfunção ventricular esquerda, sistólica ou diastólica, a concentração de NT-ProBNP aumenta em duas a dez vezes a concentração do $\mathrm{BNP}^{22}$.

\subsubsection{Receptores, mecanismos de ação e depuração}

Existem pelo menos três tipos de receptores para os peptídeos natriuréticos (RPN): tipo A, tipo B, e tipo C. O receptor tipo A tem predileção pelo ANP e BNP, enquanto o receptor tipo $\mathrm{B}$ interage com o CNP. O receptor tipo $\mathrm{C}$ está relacionado com a depuração dos PN. Cada um desses receptores contém um domínio transmembrana e um domínio ligante extracelular ${ }^{12}$.

O BNP ativo, na corrente sanguínea, exerce efeitos biológicos através da ligação com o receptor tipo A. Esse receptor, presente na superfície de células alvo, principalmente em coração, vasos, rins e glândulas adrenais, exerce suas funções através do sistema sinalizador monofosfato de guanosina cíclica (GMPc).

Os principais efeitos biológicos do BNP são natriurese e diurese, diminuição da resistência vascular periférica, inibição do sistema renina-angiotensinaaldosterona (SRAA) e da atividade nervosa simpática. Sua atividade tem como 
objetivo modular o controle pressórico e volêmico do sistema cardiovascular, contrabalanceando a atividade do $\mathrm{SRAA}^{24}$. A Figura 4 ilustra os principais efeitos biológicos do BNP ativo.

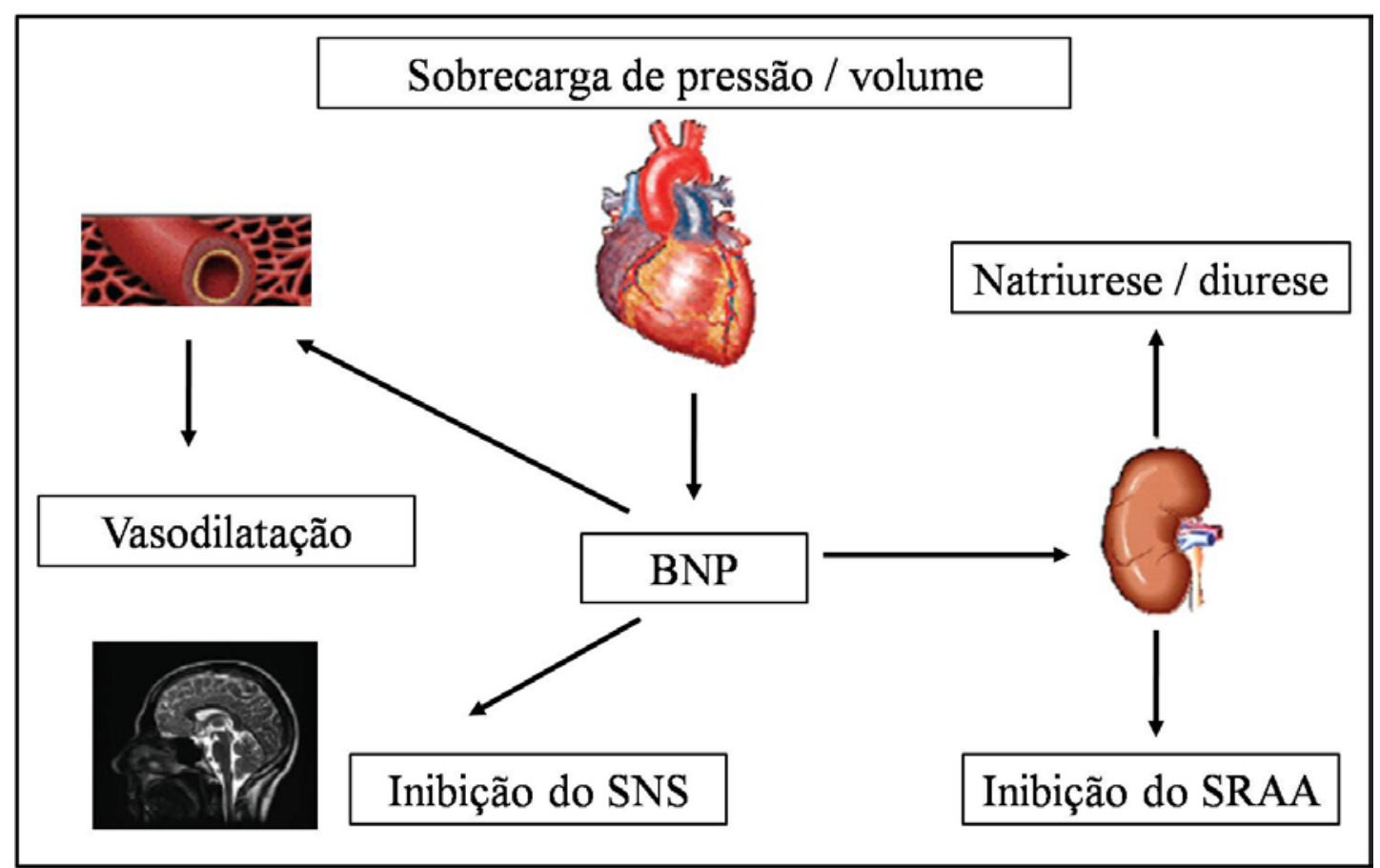

Figura 4. Efeitos sistêmicos do BNP

Legenda: SNS = sistema nervoso simpático, $\mathrm{SRAA}=$ sistema renina-angiotensina-aldosterona Fonte: Weber M, Hamm C. Role of B-type natriuretic peptide (BNP) and NT-proBNP in clinical routine. Heart 2006 Jun;92(6):843-9.

O BNP é depurado da corrente sanguínea através de três mecanismos principais $^{13 ; 22 ; 25 ; 26}$ :

- ligação com o receptor tipo C, presente no endotélio vascular, em célula muscular lisa, coração, glândulas adrenais e rins,

- proteólise direta realizada por endopeptidases presentes na circulação,

- excreção passiva pelos rins.

O NT-proBNP, por outro lado, não apresenta mecanismos ativos de depuração, sendo que sua eliminação ocorre de forma passiva através de órgãos 
dotados de alto fluxo sanguíneo, como músculos, fígado e os rins ${ }^{13}$. O Quadro 1 apresenta as principais diferenças entre o BNP ativo e o NT-proBNP ${ }^{27}$.

\section{Quadro 1 - BNP vs. NT-proBNP}

\begin{tabular}{|c|c|c|}
\hline & BNP & NT-proBNP \\
\hline Aminoácidos & 32 & 76 \\
\hline Peso molecular (Kd) & 3,5 & 8,5 \\
\hline Meia-vida (minutos) & 22 & 120 \\
\hline Depuração: & & \\
\hline Mecanismo primário & Endopeptidases & Eliminação passiva ( rins, músculos e fígado) \\
\hline Receptor para depuração & RPN tipo $\mathrm{C}$ & Não tem receptor específico \\
\hline Eliminação em hemodiálise & Não & Não \\
\hline Influência da função renal & Moderada & Forte \\
\hline Atividade biológica & Sim & Não \\
\hline Limites de dosagem (pg/mL) & $0-5000$ & $0-35000$ \\
\hline
\end{tabular}

Fonte: Adaptado de Daniels LB, Maisel AS. Natriuretic peptides. J Am Coll Cardiol 2007 Dec 18;50(25):2357-68.

O BNP e o NT-proBNP têm demonstrado importância diagnóstica e prognóstica em diversas situações clínicas. Na síndrome coronariana aguda, o BNP e o NT-proBNP são preditores independentes de mortalidade ${ }^{17}$. Também são relevantes nos casos de embolia pulmonar ${ }^{28}$. Na insuficiência cardíaca congestiva, correlacionam-se com classe funcional, função sistólica e diastólica ventricular, sendo preditores independentes de mortalidade ${ }^{17 ; 29}$. Também auxiliam no manejo do tratamento da insuficiência cardíaca descompensada ${ }^{17 ; 30 ; 31}$ e no diagnóstico diferencial da dispnéia em ambiente de emergência e pronto atendimento ${ }^{32-34}$. 


\subsection{Peptídeo natriurético tipo B na estenose aórtica: o racional para sua}

\section{utilização}

O diagnóstico de EAo grave baseia-se na avaliação clínica e complementação ecocardiográfica. Até o presente momento, de acordo com as principais diretrizes e consensos $^{9 ; 35}$, o tratamento é cirúrgico nos casos de EAo grave sintomática ou com disfunção sistólica ventricular esquerda. Como a disfunção sistólica ocorre em uma fase tardia da evolução da doença, a maioria dos pacientes elegíveis para o tratamento cirúrgico terão como embasamento para essa indicação a presença de sintomas.

Entretanto, muitos dos pacientes não valorizam o início da sintomatologia, muitas vezes negam a existência de sintomas, autolimitando-se em suas atividades cotidianas.

A elucidação do real estado funcional dos pacientes é de extrema relevância, particularmente em estenose aórtica, já que sintomas definem a conduta e o prognóstico $^{8}$.

O "como conduzir" o paciente assintomático com EAo grave é um tema bastante discutido na literatura. Em 2005, Pellikka et $\mathrm{al}^{6}$ apresentaram o resultado de um grande estudo em que 622 pacientes assintomáticos com EAo grave foram acompanhados prospectivamente por 5 anos. Nesse estudo, a probabilidade de pacientes não operados permanecer livre de sintomas foi de apenas 33\% em 5 anos. O risco de morte súbita, não precedida por sintomas, foi de aproximadamente $1 \%$ ao ano. Neste trabalho, a partir de dois anos de seguimento, o paciente assintomático passa a ter prognóstico pior do que a da população em geral, mesmo sem apresentar sintomas. 
O paradigma anterior a este estudo era o de que pacientes assintomáticos com EAo grave teriam sobrevida semelhante à da população em geral $^{8}$. O que se observa, na realidade, é que com o passar do tempo, em média dois anos, o paciente assintomático tem risco maior de desenvolver sintomas, e de morrer subitamente.

Surge a hipótese de indicar a "cirurgia profilática" para pacientes assintomáticos com EAo grave. Seria uma forma de eximir o paciente do risco de morte súbita. Entretanto, essa não é uma estratégia viável ${ }^{7 ; 36 ; 37}$, principalmente quando analisamos sob o ponto de vista populacional. Imaginando que a "cirurgia profilática" fosse a rotina, estaríamos expondo $100 \%$ dos pacientes com EAo grave assintomáticos a um risco de 3 a 4\% relacionado ao procedimento cirúrgico, somado a um risco de $1 \%$ ao ano relacionado à presença de prótese valvar ${ }^{38}$, beneficiando apenas $1 \%$ desta população que teria o risco de morte súbita.

Então permaneceriam duas preocupações principais no manejo destes pacientes:

- O paciente é realmente assintomático, ou na realidade está autolimitado?

- Qual o risco de morte súbita desse paciente ao se adotar conduta clínica expectante?

Em alguns casos o teste de esforço pode auxiliar na estratificação funcional dos pacientes ${ }^{35 ; 39-41}$, entretanto, na prática, o teste é pouco realizado ${ }^{42}$. A baixa taxa de utilização do teste de esforço na avaliação de pacientes com EAo grave assintomáticos se deve à preocupação com a segurança do teste por parte de quem realiza o exame, à dificuldade na interpretação dos resultados e particularmente às características dos pacientes, em alguns casos idosos, incapazes de realizar o teste por apresentarem outras comorbidades, por exemplo doenças osteoarticulares ${ }^{43}$. 
Mas além do paciente assintomático, também entre os sintomáticos há espaço para um maior aprofundamento na análise dos pacientes, sendo desejável associar ferramentas diagnósticas que auxiliem na estratificação mais fina destes pacientes. A ferramenta ideal seria aquela que aliada à anamnese, ao exame físico e à ecocardiografia, permitisse responder as seguintes questões:

- Qual é a real gravidade do paciente portador de estenose aórtica?

- Posso quantificar o incremento no risco de óbito deste paciente?

A partir da identificação do BNP, e dos primeiros resultados avaliando o papel do BNP e do NT-proBNP no diagnóstico e na estratificação de pacientes com insuficiência cardíaca, especulou-se a utilidade desses marcadores no contexto da EAo. A hipótese seria de que em complementação à avaliação clínica e ecocardiográfica, os peptídeos BNP e NT-proBNP pudessem responder às questões apresentadas acima.

No final da década de 90 surgem dois estudos importantes que correlacionam níveis de BNP com a gravidade da $\mathrm{EAo}^{44 ; 45}$. Entretanto, é somente a partir do início dos anos 2000 que são publicados os principais estudos avaliando o papel do BNP e NT-proBNP em pacientes com estenose aórtica ${ }^{46-57}$. Esses estudos envolvem, em sua maioria, poucos pacientes, e os resultados são conflitantes. Também não há grande seguimento e por mais que haja inferências sobre a utilidade prognóstica dos peptídeos em EAo grave, os dados são insuficientes.

Postulamos que em um acompanhamento prospectivo de pacientes com estenose aórtica grave poderíamos determinar se os peptídeos natriuréticos, de fato tem importância como marcadores prognósticos de sobrevida nesta população específica. Como em literatura não há análise prospectiva de longo prazo envolvendo 
EAo grave e NT-proBNP e, em relação ao BNP, ainda são poucos estudos, nosso estudo tem caráter original. 


\section{OBJETIVOS}

\subsection{Objetivo primário}

- Determinar o papel prognóstico de sobrevida dos peptídeos natriuréticos BNP e NT-proBNP no acompanhamento prospectivo de uma população de pacientes com estenose aórtica grave.

\subsection{Objetivos secundários}

- Comparar os níveis séricos de BNP e NT-proBNP entre pacientes com EAo grave assintomáticos e sintomáticos.

- Analisar os níveis dos peptídeos natriuréticos BNP e NT-proBNP em relação à classe funcional dos pacientes.

- Comparar os níveis séricos de BNP e NT-proBNP em pacientes com EAo grave sintomáticos nos momentos pré e pós-operatório. 


\section{MATERIAIS E MÉTODOS}

\subsection{Casuística}

Foram incluídos de outubro de 2004 a dezembro de 2007, de forma consecutiva, 66 pacientes pertencentes ao ambulatório de valvopatias, da Unidade Clínica de Valvopatias do InCor - HCFMUSP, portadores de estenose aórtica grave, definidos de acordo com os critérios da American Heart Association ${ }^{9}$. Dos 66 pacientes, 16 pacientes eram assintomáticos, e 50 pacientes sintomáticos no momento da inclusão. Todos os pacientes foram orientados quanto à natureza e objetivos do estudo, e assinaram termo de consentimento livre e esclarecido.

\subsection{Critérios de exclusão}

Os critérios de exclusão utilizados foram:

- Fibrilação atrial

- Outras valvopatias (exceto leve)

- Cardiopatia associada

- Infecções ativas

- Neoplasias

- Doenças auto-imunes ou inflamatórias

- Insuficiência renal (creatinina $>1,4 \mathrm{mg} / \mathrm{dL}$ )

- Obesidade $^{58}$ (IMC superior a $30 \mathrm{Kg} / \mathrm{m}^{2}$ ) 


\subsection{Protocolo de seguimento}

Uma vez incluídos no protocolo, todos os pacientes eram submetidos a uma avaliação inicial que consistia em anamnese, exame físico, a realização de um ECO inicial, e a dosagem sérica dos peptídeos natriuréticos BNP e NTproBNP.

Os pacientes eram classificados em sintomáticos e assintomáticos. Os sintomáticos eram aqueles que apresentavam dispnéia, síncope ou angina. Foi utilizada classificação funcional de acordo com a New York Heart Association $(\text { NYHA })^{59 ; 60}$.

Os pacientes sintomáticos, por apresentarem indicação cirúrgica de troca de valva aórtica, seguindo fluxo de atendimento ambulatorial, eram submetidos à cirurgia. Os pacientes assintomáticos eram mantidos em observação clínica, seguindo fluxo de atendimento ambulatorial, até que se tornassem sintomáticos, quando recebiam indicação cirúrgica.

Os pacientes submetidos à cirurgia eram reavaliados após oito meses do procedimento. Nesta fase, era realizada nova avaliação clínica, composta por anamnese, e exame físico, e dosagem sérica dos peptídeos natriuréticos BNP e NT-proBNP.

Todos os pacientes foram seguidos da data de inclusão até o dia 31/07/2008. No último semestre do acompanhamento, todos os pacientes foram submetidos à nova avaliação clínica, composta por anamnese, e exame físico, a realização de um ECO, e a dosagem sérica dos peptídeos natriuréticos BNP e NTproBNP. 
Em caso de óbito durante o acompanhamento, computávamos o tempo de seguimento até o óbito, assim como sua causa. Definimos como óbito cardiovascular a morte súbita, a morte relacionada à insuficiência cardíaca congestiva, e a morte no período peri-operatório de cirurgia de troca de valva aórtica (intra-operatório e período pós-operatório em que o paciente estivesse internado). A Figura 5 representa a ficha de inclusão utilizada no protocolo. A Figura 6 representa o protocolo de seguimento dos pacientes. 
Exclusão: FA, valvoptia (menos IAO e IMI discretas), cardiopatia associada, atividade reumática, infecçōes, insuficiência renal, neoplasias, doenças autoimunes ou inflamatórias.

1)

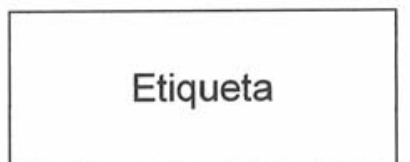

Ficha de avaliação dos pacientes incluídos

Fone de contato:

Sexo

DN

2) Diagnóstico etiológico da Estenose Aórtica:

3) Tempo de conhecimento da valvopatia:

4) Sintomas na inclusäo: assinalar com " $X$ " data:

Assintomático ( )

Dispnéia aos esforços extra habituais ( )

Palpitação ( )

Dispnéia aos esforços habituais ( )

Dispnéia aos mínimos esforços ( )

Dispnéia em repouso ( )

Tontura ( )

Dor precordial ( )

Síncope ( )

Outros ( )

ICC CF (NYHA) :

4) Exame Físico: PA: FC: Edema MMII: sim ( ) näo ( )

Congestão pulmonar: sim ( ) não ( ) Hepatomegalia: sim ( ) não ( )

Ausculta cardiaca:

5) Medicação na consulta:

6) $\mathrm{ECO}: \mathrm{S}$ PP DD DS $\mathrm{AE}$ $\mathrm{AO}$ FE $\% \mathrm{D}$

Sup. corp Conclusão:

7) Cirurgia: data:

8) Avaliação na consulta após a cirurgia (para os pacientes que forem operados): data:

Assintomático ( )

Dispnéia aos esforços extra habituais ( )

Dispnéia aos esforços habituais ( )

Dispnéia aos mínimos esforços ( )

Dispnéia em repouso ( )

Palpitação ( )

Tontura ( )

Dor precordial ( )

Sincope ( )

Outros:

ICC CF (NYHA) :

Figura 5. Ficha de avaliação inicial utilizada na inclusão dos pacientes 


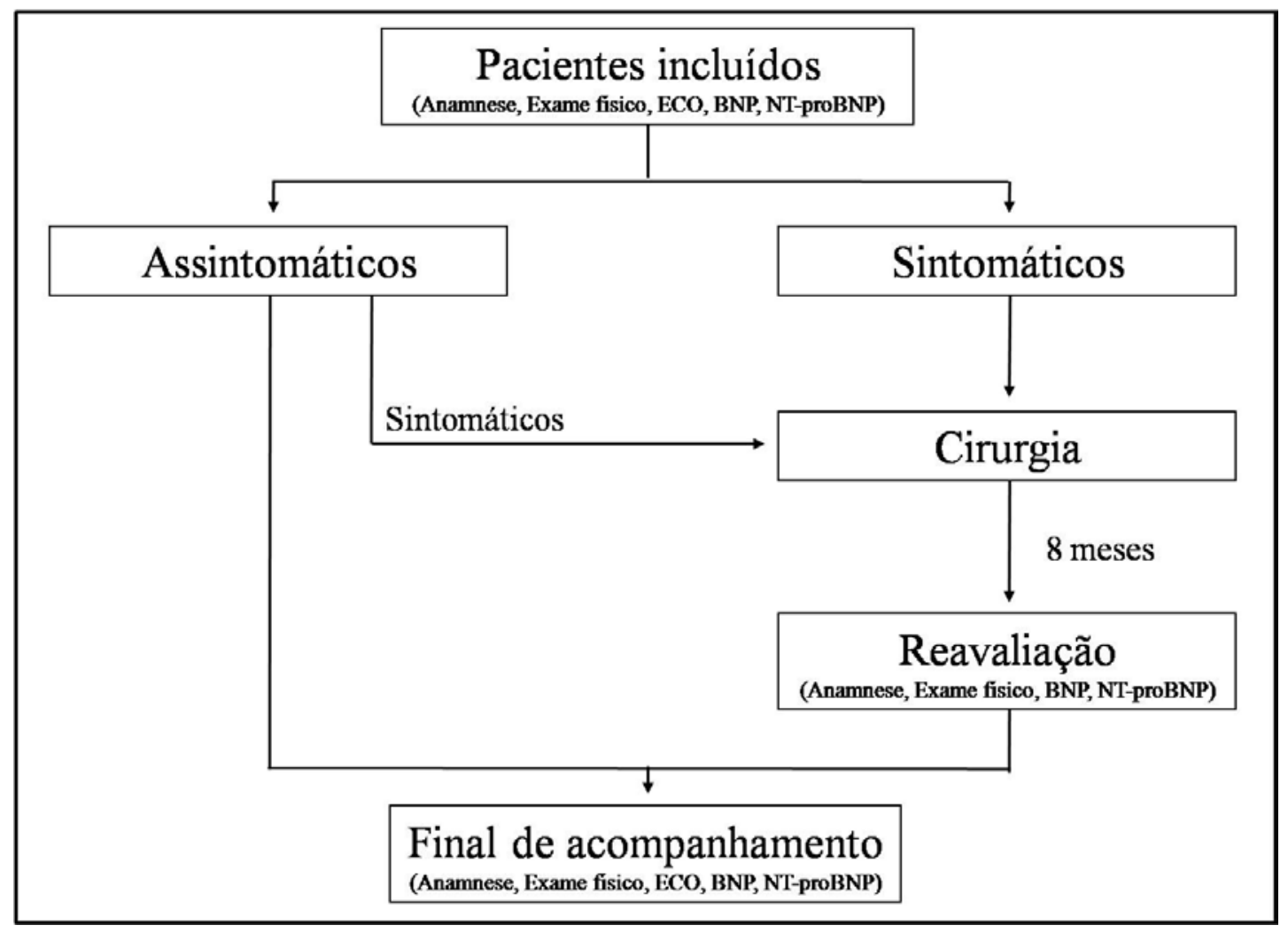

Figura 6. Fluxo de atendimento dos pacientes incluídos

\subsection{Dosagem do BNP}

Todos os pacientes foram submetidos à dosagem sérica do BNP de acordo com o protocolo de seguimento. O sangue para o estudo foi colhido da veia antecubital. $\mathrm{O}$ sangue era colocado em tubos contendo ácido etilenediaminotetraacético (EDTA). Após centrifugação, o plasma era congelado a $70^{\circ} \mathrm{C}$ negativos para análise posterior dos níveis de BNP. Para dosagem de BNP, foi utilizado o kit da marca Bayer HealthCare LLC/ Bayer Corp em equipamento automatizado ADVIA CENTAUR BNP. O teste consistia em um imunoensaio automatizado "tipo sanduíche" com dois lados, e tecnologia da quimiluminescência direta, que utiliza quantidades constantes de anticorpos monoclonais. O primeiro, no reagente Lite, um éster de acridina marcado com o 
fragmento de BNP monoclonal anti-humano de rato, específico para a estrutura anelar do BNP. O segundo anticorpo, na fase sólida, um anticorpo monoclonal anti-humano de rato específico para a porção C-terminal do BNP, que está acoplado a partículas magnéticas de estreptavidina. O sistema executa automaticamente os seguintes passos:

- coloca $100 \mu \mathrm{L}$ da amostra em uma cubeta,

- coloca $100 \mu \mathrm{L}$ de reagente Lite e incuba por 5 minutos a $37^{\circ} \mathrm{C}$,

- coloca $200 \mu \mathrm{L}$ de fase sólida e incuba por 2,5 minutos a $37^{\circ} \mathrm{C}$,

- separa, aspira e lava as cubetas com reagente de lavagem,

- coloca $300 \mu \mathrm{L}$ de reagente ácido e de reagente base para iniciar a reação de quimiluminescência,

- relata os resultados do BNP em $\mathrm{pg} / \mathrm{mL}$.

A sensibilidade do sistema ADVIA CENTAUR BNP é menor que 2,0 pg/mL, enquanto que o limite superior do teste é de 5.000,00 pg/mL. Os resultados são apresentados na unidade $\mathrm{pg} / \mathrm{mL}$. Para valores de normalidade utilizamos os controles orientados pelo fabricante ${ }^{61}$ e apresentados na Tabela 2. 
Tabela 2 - Valores de normalidade do BNP em pg/mL

\begin{tabular}{lcccccc}
\hline Idade (anos) & Total & $\mathbf{4 4 5}$ & $\mathbf{4 5 - 5 4}$ & $\mathbf{5 5 - 6 4}$ & $\mathbf{6 4 - 7 4}$ & $\mathbf{2 7 5}$ \\
\hline $\mathbf{N}$ & 1521 & 317 & 291 & 403 & 365 & 145 \\
Média & 23,2 & 11,9 & 15,6 & 19,5 & 28,3 & 60,3 \\
$\mathbf{D P}$ & 32,5 & 12,9 & 15,9 & 22,6 & 25,4 & 73 \\
Mediana & 14,4 & 8,6 & 10,4 & 13,8 & 22,1 & 43,7 \\
95\% percentil & 70,8 & 33,3 & 46,7 & 53,2 & 72,3 & 176 \\
\hline
\end{tabular}

Legenda: $\mathrm{DP}=$ desvio-padrão, $\mathrm{N}=$ número de pacientes

Fonte: Freire EMM. BNP: ADVIA CENTAUR BNP [bula de Kit para dosagem do BNP]. Tarrytown: Bayer HealthCare LLC/ Bayer Corp.; 2005-06.

\subsection{Dosagem do NT-proBNP}

Todos os pacientes foram submetidos à dosagem sérica do NT-proBNP de acordo com o protocolo de seguimento. O sangue para o estudo foi colhido da veia antecubital. O sangue era colocado em tubos contendo EDTA. Após centrifugação, o plasma era congelado a $70^{\circ} \mathrm{C}$ negativos para análise posterior dos níveis de NTproBNP.

Para dosagem do NT-proBNP foi utilizado o kit Elecsys proBNP da marca Roche Diagnostics GmbH. Trata-se de um imunoensaio de eletroquimiluminescência para determinação quantitativa do NT-proBNP com utilização da técnica de "sanduíche". As etapas do teste são:

- incubação 1: o antígeno da amostra $(20 \mu \mathrm{L})$, um anticorpo policlonal biotinilado específico anti-NT-proBNP e um anticorpo policlonal 
específico anti-NT-proBNP marcado com complexo de rutênio reagem entre si e formam um complexo "sanduíche",

- incubação 2: após a incorporação de micro partículas revestidas de estreptavidina, o complexo liga-se à forma sólida pela interação da biotina e da estreptavidina,

- a mistura da reação é aspirada para a célula de leitura, onde as micro partículas são fixadas magneticamente à superfície do eletrodo. Os elementos não ligados são removidos com ProCell. A aplicação de uma corrente elétrica ao eletrodo induz a uma emissão quimiluminescente que é medida por um fotomultiplicador,

- os resultados são determinados com base numa curva de calibração.

Os resultados são apresentados na unidade $\mathrm{pg} / \mathrm{mL}$. O intervalo de medição varia de 5,00 pg/mL a 35.000,00 pg/mL. Para valores de normalidade utilizamos os controles orientados pelo fabricante ${ }^{62}$ e apresentados nas Tabelas 3. 
Tabela 3 - Valores de normalidade do NT-proBNP em pg/mL

\begin{tabular}{lcccccc}
\hline Idade (anos) & Total & $\mathbf{< 4 5}$ & $\mathbf{4 5 - 5 4}$ & $\mathbf{5 5 - 6 4}$ & $\mathbf{6 4 - 7 4}$ & $\mathbf{2 7 5}$ \\
\hline $\mathbf{N}$ & 2264 & 1323 & 408 & 398 & 102 & 33 \\
Média & 50,3 & 35,6 & 49,3 & 72,6 & 107 & 211 \\
$\mathbf{D P}$ & 62,4 & 30,2 & 63,3 & 84,4 & 85,9 & 152 \\
Mediana & 27,9 & 20,4 & 30,7 & 47,3 & 85,1 & 174 \\
$\mathbf{9 5 \%}$ percentil & 149 & 97,3 & 121 & 198 & 285 & 526 \\
\hline
\end{tabular}

Legenda: $\mathrm{DP}=$ desvio-padrão, $\mathrm{N}=$ número de pacientes

Fonte: Roche Diagnostics GmbH. NT-proBNP: Elecsys 1010/2010 e modular analytics E 170 [bula de Kit para dosagem do NT-proBNP]. Mannheim: Roche Diagnostics GmbH; 2005-06.

\subsection{Ecocardiografia}

Os exames foram realizados no Serviço de Ecocardiografia do InCorHCFMUSP. Os pacientes foram submetidos à avaliação ecocardiográfica completa, que incluía modo-M, ecocardiograma bidimensional, Doppler pulsátil, Doppler contínuo e mapeamento de fluxo em cores. Para o cálculo da massa ventricular esquerda foi utilizada a fórmula de Deveraux modificada ${ }^{63}$. O índice de massa foi obtido dividindo-se a massa ventricular esquerda pela superfície corpórea dos pacientes. Os gradientes de pressão transvalvar aórtico de pico e médio foram calculados através da equação de Bernoulli simplificada ${ }^{64}$. A área valvar aórtica foi calculada pela equação de continuidade ${ }^{65 ; 66}$. A função ventricular esquerda foi avaliada através da fórmula de Teicholz ${ }^{67}$. 


\subsection{Análise estatística}

Os dados clínicos, laboratoriais e ecocardiográficos coletados no estudo foram tabulados e armazenados em banco de dados elaborado no programa Excel versão 2003 do Windows.

Inicialmente todas as variáveis foram analisadas descritivamente. Para as variáveis quantitativas esta análise foi feita através do cálculo de médias e desviospadrão ou mediana e diferença entre quartis (primeiro e terceiro quartis). Para as variáveis qualitativas calcularam-se frequências absolutas e relativas.

Para a comparação de médias ou medianas de dois grupos foi utilizado o teste t de Student ${ }^{68}$. Para a comparação de médias ou medianas de três ou mais grupos foi utilizada a Analise de Variância a um fator ${ }^{68}$, com comparações múltiplas realizadas através do teste de Bonferroni.

Para se testar a homogeneidade entre as proporções foi utilizado o teste quiquadrado $^{68}$ ou o teste exato de Fisher ${ }^{68}$ (quando ocorreram freqüências esperadas menores de 5).

Para o estudo da correlação entre duas variáveis foi utilizado o coeficiente de correlação de Pearson ${ }^{68}$.

Para a obtenção do ponto de corte do BNP e do NT-proBNP foi utilizado o ajuste da regressão logística ${ }^{69}$ e a curva ROC.

Para o estudo da sobrevida foi utilizada a curva de Kaplan-Meier na análise univariada e a análise multivariada realizada através do modelo de $\operatorname{Cox}^{70}$.

Os testes foram realizados com os valores de BNP e NT-proBNP transformados através do log, pois os valores brutos não apresentavam distribuição normal. 
O nível de significância estatística utilizado para os testes foi de 5\%.

\subsection{Considerações éticas}

O estudo foi aprovado pela Comissão Científica e de Ética do Instituto do Coração - HCFMUSP na sessão 458/04/16 em 16/09/2004, sob o Protocolo de Pesquisa SDC 2509/04/129. O estudo foi aprovado pela Comissão de Ética para análise de Projetos de Pesquisa - CAPPesq da Diretoria Clínica do Hospital das Clínicas e da Faculdade de Medicina da Universidade de São Paulo em sessão de 13/10/2004, sob protocolo de pesquisa 825/04. O Termo de Consentimento Livre e Esclarecido foi igualmente aprovado nesta mesma sessão. Todos os pacientes foram orientados quanto à natureza e objetivos do estudo, e assinaram termo de consentimento livre e esclarecido. 


\section{RESULTADOS}

\subsection{Dados clínicos}

Foram incluídos 66 pacientes no protocolo. Em 60 pacientes a causa da EAo era degenerativa. Seis pacientes apresentavam valva aórtica bicúspide como causa da EAo. Nenhum paciente apresentava doença reumática. Do total de pacientes, 16 eram assintomáticos e 50 eram sintomáticos no momento da inclusão. Dos pacientes sintomáticos, $92 \%$ apresentavam sintomas de insuficiência cardíaca congestiva, 30\% angina induzida pelo esforço e 16\% síncope induzida pelo esforço. Entre os pacientes com insuficiência cardíaca congestiva, 43\% estavam em classe funcional II (NYHA), 48\% em classe funcional III e 9\% em classe funcional IV. Outras características clínicas são apresentadas na Tabela 4. Os grupos não apresentavam diferença significativa em relação à idade, sexo, índice de massa ventricular esquerda, diâmetro diastólico do ventrículo esquerdo, espessura do septo interventricular, espessura da parede posterior do ventrículo esquerdo, gradiente de pressão transvalvar aórtico de pico e médio e hipertensão arterial sistêmica. Os grupos diferiam em relação à fração de ejeção do ventrículo esquerdo. 
Tabela 4 - Características dos pacientes

\begin{tabular}{lcccc}
\hline & $\begin{array}{c}\text { Total } \\
(\mathbf{n = 6 6 )}\end{array}$ & $\begin{array}{c}\text { Assintomáticos } \\
(\mathbf{n = 1 6 )}\end{array}$ & $\begin{array}{c}\text { Sintomáticos } \\
(\mathbf{n}=\mathbf{5 0})\end{array}$ & $\boldsymbol{p}$ \\
\hline Idade (em anos) & $65,62 \pm 12,35$ & $67,11 \pm 8,11$ & $65,14 \pm 13,47$ & $0,584^{(1)}$ \\
Sexo Feminino & $35(53,0 \%)$ & $6(37,5 \%)$ & $29(58,0 \%)$ & $0,153^{(2)}$ \\
IMVE & $142,20 \pm 32,38$ & $143,33 \pm 36,85$ & $141,83 \pm 31,22$ & $0,877^{(1)}$ \\
Gradiente pico (mmHg) & $99,96 \pm 21,87$ & $103,40 \pm 18,34$ & $98,68 \pm 23,14$ & $0,481^{(1)}$ \\
Gradiente médio (mmHg) & $62,04 \pm 16,21$ & $63,20 \pm 14,59$ & $61,59 \pm 16,95$ & $0,747^{(1)}$ \\
HAS & $46(69,7 \%)$ & $12(75,0 \%)$ & $34(68,0 \%)$ & $0,596^{(2)}$ \\
FE & $0,62 \pm 0,14$ & $0,70 \pm 0,08$ & $0,60 \pm 0,15$ & $0,019^{(1)}$ \\
FE $<0,50$ & $10(15,9 \%)$ & $0(0,0 \%)$ & $10(20,8 \%)$ & $0,100^{(3)}$ \\
Septo interventricular & $1,33 \pm 0,21$ & $1,32 \pm 0,23$ & $1,33 \pm 0,21$ & $0,806^{(1)}$ \\
Parede posterior VE & $1,25 \pm 0,18$ & $1,28 \pm 0,20$ & $1,24 \pm 0,17$ & $0,533^{(1)}$ \\
Diâmetro diastólico VE & $4,76 \pm 0,62$ & $4,64 \pm 0,55$ & $4,80 \pm 0,64$ & $0,380^{(1)}$ \\
\hline
\end{tabular}

Legenda: $\mathrm{HAS}=$ hipertensão arterial sistêmica, $\mathrm{FE}=$ fração de ejeção do ventrículo esquerdo, $\mathrm{IMVE}=$ índice de massa ventricular esquerda, $\mathrm{VE}=$ ventrículo esquerdo. Valores expressos em média \pm desvio-padrão ou n (\%); (1) nível descritivo de probabilidade do teste t de Student; (2) nível descritivo de probabilidade do teste qui-quadrado; (3) nível descritivo de probabilidade do teste exato de Fisher

A Tabela 5 apresenta as medicações utilizadas pelos pacientes incluídos no protocolo. Como podemos observar, não há diferença significativa em relação às medicações utilizadas nos dois grupos. Entre os assintomáticos, os diuréticos e vasodilatadores foram utilizados para controle de hipertensão arterial sistêmica associada. Entre os sintomáticos, a indicação das medicações listadas embasou-se na presença de hipertensão arterial sistêmica e na necessidade de controle dos sintomas de insuficiência cardíaca congestiva. 
Tabela 5 - Frequências absolutas e relativas das medicações utilizadas

\begin{tabular}{lccccc}
\hline \multirow{2}{*}{ Medicamento } & \multicolumn{2}{c}{ Assintomáticos } & \multicolumn{2}{c}{ Sintomáticos } & \multirow{2}{*}{$\boldsymbol{p}$} \\
\cline { 2 - 5 } & $\mathbf{n}$ & $\mathbf{\%}$ & $\mathbf{n}$ & $\%$ & \\
\hline Diurético & 10 & 62,5 & 36 & 72,0 & $0,538^{(1)}$ \\
Vasodilatador & 3 & 18,8 & 17 & 34,0 & $0,353^{(1)}$ \\
Betabloqueador & 0 & 0,0 & 1 & 2,0 & $1,000^{(2)}$ \\
Digital & 0 & 0,0 & 2 & 4,0 & $1,000^{(2)}$ \\
\hline
\end{tabular}

Legendas: (1) nível descritivo de probabilidade do teste qui-quadrado; (2) nível descritivo de probabilidade do teste exato de Fisher

\subsection{Dados evolutivos dos pacientes}

Acompanhamos os pacientes por $869 \pm 397$ dias. Neste período, houve 11 óbitos, todos cardiovasculares, sendo 2 óbitos entre os pacientes assintomáticos e 9 óbitos entre os sintomáticos. Dos 16 pacientes assintomáticos na inclusão, 11 se tornaram sintomáticos ao longo do acompanhamento. A Figura 7 ilustra os dados evolutivos dos pacientes durante o acompanhamento e a Tabela 6 apresenta as características dos óbitos. 


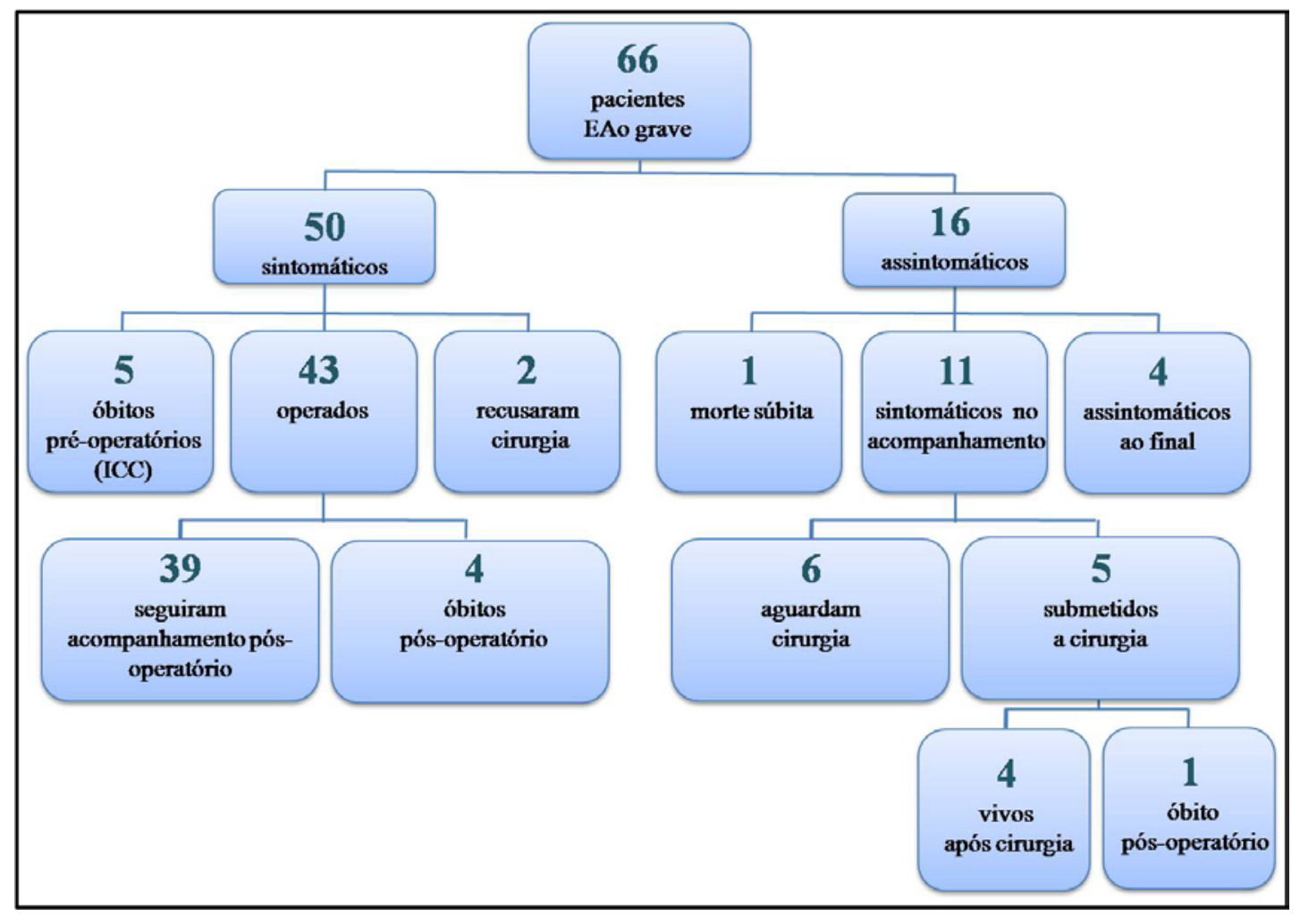

Figura 7. Dados evolutivos dos pacientes durante o acompanhamento 
Tabela 6 - Características dos óbitos

\begin{tabular}{lcccccccc}
\hline & Causa & Sexo & $\begin{array}{c}\text { Idade } \\
\text { (anos) }\end{array}$ & NYHA & $\begin{array}{c}\text { BNP } \\
(\mathbf{p g} / \mathbf{m L})\end{array}$ & $\begin{array}{c}\text { NT- } \\
\text { proBNP } \\
(\mathbf{p g} / \mathbf{m L})\end{array}$ & $\begin{array}{c}\text { Gradiente } \\
\text { médio } \\
(\mathbf{m m H g})\end{array}$ & Vmax \\
\hline 1 & MS & F & 77 & As & 72 & 1315 & 81 & 5.6 \\
2 & ICC & F & 79 & 3 & 270 & 3504 & 47 & 4.5 \\
3 & ICC & F & 69 & 4 & 2467 & 17786 & 80 & 5.4 \\
4 & PO & M & 73 & 3 & 129 & 1651 & 66 & 5.2 \\
5 & PO & F & 72 & 3 & 401 & 4709 & 65 & 5.2 \\
6 & PO & M & 57 & 1 & 180 & 1356 & 55 & 4.5 \\
7 & ICC & F & 83 & 4 & 1037 & 6608 & 40 & 4.1 \\
8 & ICC & M & 50 & 4 & 2787 & 13697 & 48 & 4.6 \\
9 & PO & M & 81 & 3 & 342 & 4073 & 56 & 5.1 \\
10 & PO & F & 69 & 3 & 289 & 1808 & 43 & 4.4 \\
11 & ICC & M & 70 & 2 & 33 & 216 & 72 & 5.1 \\
\hline
\end{tabular}

Legendas: MS: morte súbita, ICC: insuficiência cardíaca congestiva, PO: pós-operatório, As: paciente assintomático, Gradiente médio: gradiente médio de pressão transvalvar aórtico, Vmax: velocidade máxima de fluxo transvalvar aórtico.

\subsection{Níveis de BNP e sintomas dos pacientes na inclusão}

\subsubsection{Comparação dos níveis de BNP entre assintomáticos e sintomáticos}

Não houve diferença significativa em relação aos níveis de BNP quando comparamos pacientes assintomáticos e sintomáticos no momento da inclusão no protocolo. A Tabela 7 apresenta os resultados desta comparação. 
Tabela 7 - BNP em assintomáticos vs. sintomáticos na inclusão do protocolo

\begin{tabular}{lccc}
\hline & Assintomáticos & Sintomáticos & $\boldsymbol{p}$ \\
\hline $\mathbf{N}$ & 15 & 49 & \\
BNP $(\mathbf{p g} / \mathbf{m L})$ & $72(41-175)$ & $104(46-270)$ & $0,275^{*}$ \\
\hline
\end{tabular}

Legenda: $\mathrm{N}=$ número de pacientes, ${ }^{*}=$ nível descritivo de probabilidade do teste $\mathrm{t}$ de Student. Valores expressos em mediana e variação interquartil.

Mesmo ajustando para sexo e idade, não houve diferença significativa dos níveis de BNP entre assintomáticos e sintomáticos.

\subsubsection{BNP e classe funcional (NYHA)}

A Figura 8 e o Quadro 2 apresentam os níveis de BNP em relação à classe funcional (NYHA) dos pacientes na inclusão.

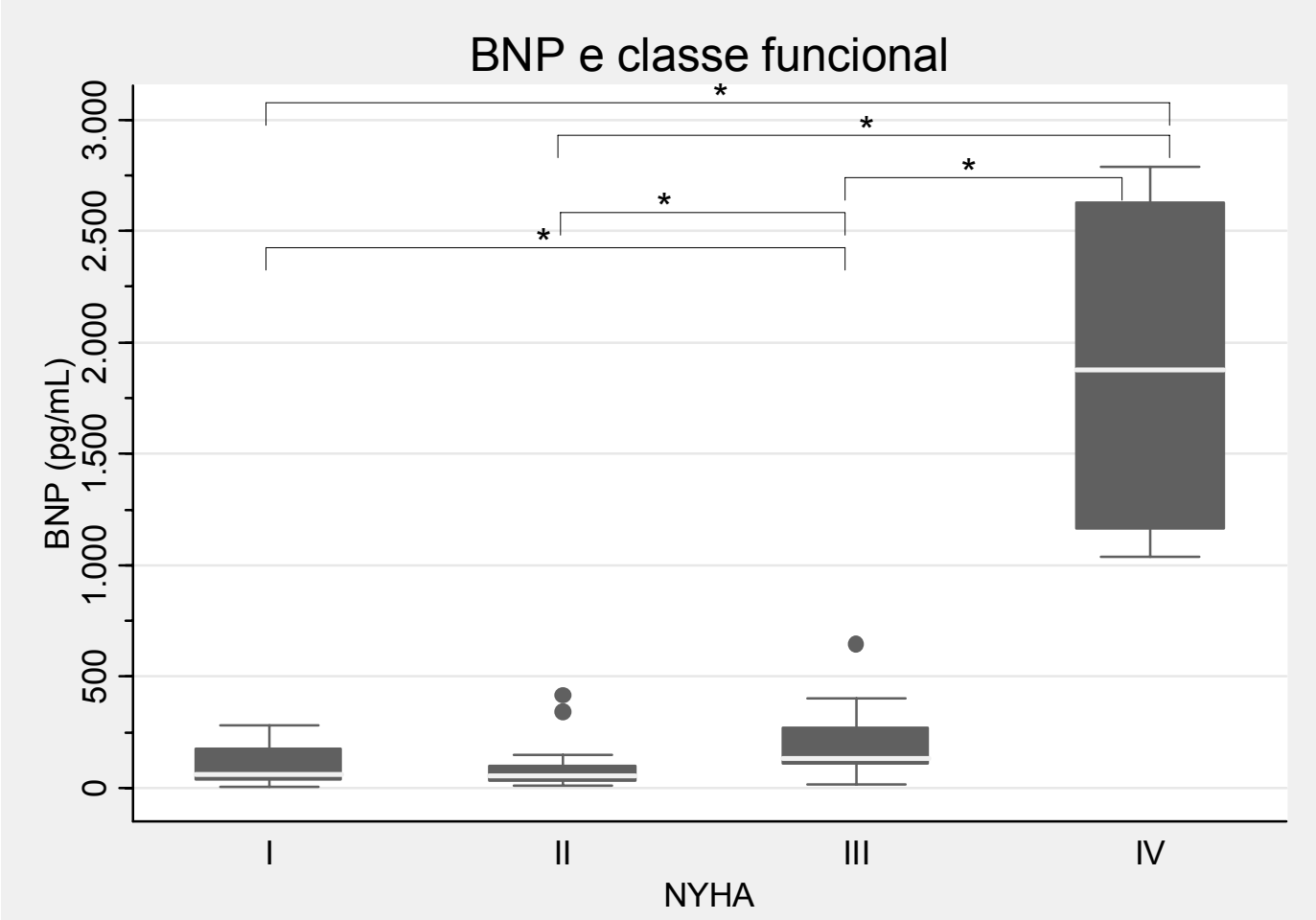

Figura 8. BNP vs. classe funcional (NYHA) na inclusão

Legenda: NYHA= New York Heart Association, * = significância estatística pelo teste de Bonferroni. 
Quadro 2 - BNP vs. classe funcional (NYHA) na inclusão

\begin{tabular}{|c|c|c|c|}
\hline Classe & N & Nível sérico de BNP & \multirow{2}{*}{$\boldsymbol{p}$} \\
(mediana e variação interquartil) & & \\
\hline I & 19 & $62 \mathrm{pg} / \mathrm{mL}(36-175)$ & \multirow{2}{*}{$0,001^{*}$} \\
\hline II & 20 & $54 \mathrm{pg} / \mathrm{mL}(29-101)$ & \\
\hline III & 21 & $134 \mathrm{pg} / \mathrm{mL}(95-279)$ & \\
\hline IV & 4 & $1879 \mathrm{pg} / \mathrm{mL}(1101-2707)$ & \\
\hline
\end{tabular}

Legenda: $\mathrm{N}=$ número de pacientes, ${ }^{*}=$ nível descritivo de probabilidade da ANOVA a um fator

Houve associação significativa entre os grupos de classe funcional (CF) em relação ao BNP. Através do teste de Bonferroni observamos que a CF I não difere da CF II $(p=1,000)$ e difere das CF III $(p=0,038)$ e IV $(p<0,001)$, a CF II difere das CF III $(p=0,007)$ e IV $(p<0,001)$ e a CF III difere da CF IV $(p<0,001)$.

Dentro de cada classe funcional, os níveis de BNP não eram mais elevados naqueles pacientes com síncope ou angina, quando comparados aos pacientes de mesma classe sem estes sintomas.

Quando agrupamos os pacientes em classe funcional I e II ou classe funcional III e IV, observamos diferença significativa entre os grupos (Quadro 3). 
Quadro 3 - BNP vs. classe funcional (NYHA) na inclusão

\begin{tabular}{|c|c|c|c|}
\hline $\begin{array}{l}\text { Classe } \\
\text { Funcional }\end{array}$ & $\mathbf{N}$ & $\begin{array}{c}\text { Nível sérico de BNP } \\
\text { (mediana e variação interquartil) }\end{array}$ & $\mathbf{p}$ \\
\hline I e II & 39 & $58 \mathrm{pg} / \mathrm{mL}(30-124)$ & \multirow[b]{2}{*}{$<0,001^{*}$} \\
\hline III e IV & 25 & $174 \mathrm{pg} / \mathrm{mL}(103,5-373,5)$ & \\
\hline
\end{tabular}

Legenda: $\mathrm{N}=$ número de pacientes, ${ }^{*}=$ nível descritivo de probabilidade do teste $\mathrm{t}$ de Student

\subsection{BNP como preditor de classe funcional III e IV na inclusão}

Construímos uma curva ROC (BNP vs. CF III e IV) com o objetivo de identificar um valor de BNP que pudesse marcar CF avançada. Através da curva ROC (Figura 9), o valor de BNP que discriminou as classes foi $105 \mathrm{pg} / \mathrm{mL}$, com sensibilidade de $76,0 \%$, especificidade de $74,4 \%$, acurácia de $75,0 \%$, valor preditivo positivo de $65,5 \%$ e valor preditivo negativo de $82,9 \%$. A área calculada abaixo da curva foi de 0,806 .

Pacientes com valor de BNP igual ou superior a $105 \mathrm{pg} / \mathrm{mL}$ apresentaram 9,18 vezes maior chance de estarem em classe funcional III ou IV (IC 95\%: 2,8629,46) no momento da inclusão. 


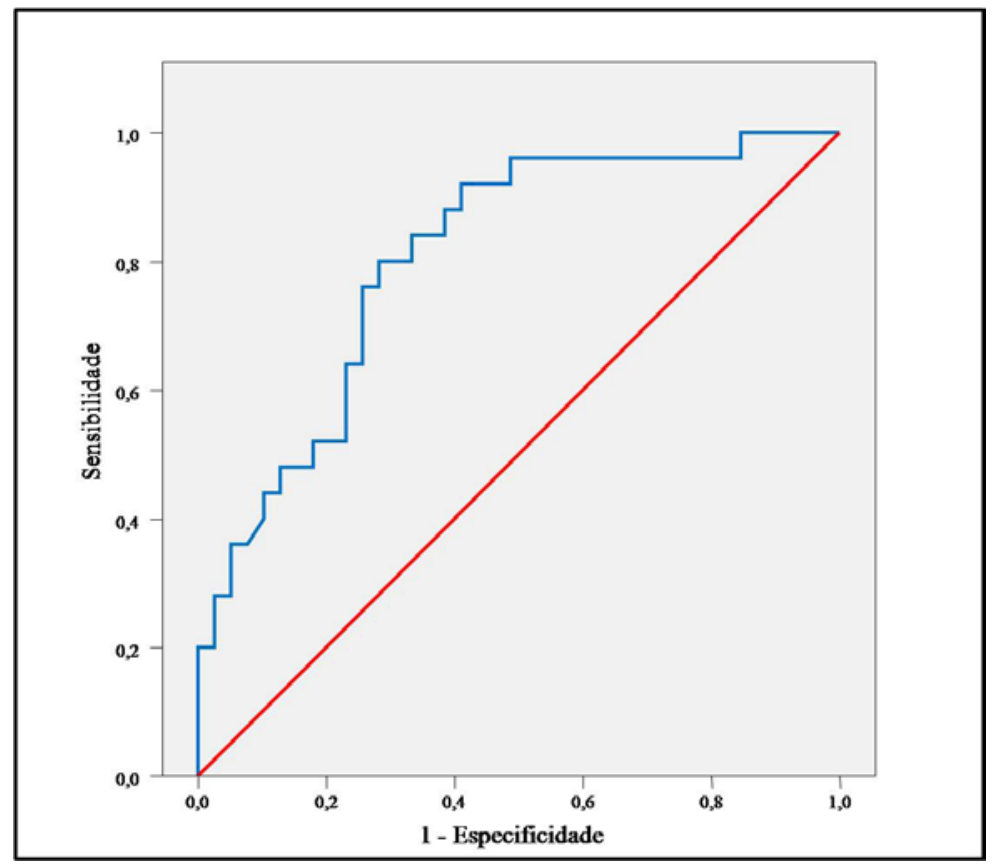

Figura 9. Curva ROC para BNP e classe funcional III e IV

\subsection{BNP como preditor de sobrevida}

Acompanhamos prospectivamente os pacientes e a partir dos níveis iniciais do BNP pudemos avaliar sua capacidade em predizer sobrevida ao longo do acompanhamento. No longo período de acompanhamento houve 11 óbitos cardiovasculares e estes foram considerados na construção de uma curva de KaplanMeier. O valor de corte estabelecido para o BNP foi de $105 \mathrm{pg} / \mathrm{mL}$. Utilizamos este valor a partir dos resultados obtidos na análise do BNP como marcador de classe funcional avançada. Através da análise da curva de Kaplan-Meier pudemos observar que o valor de BNP $105 \mathrm{pg} / \mathrm{mL}$ discriminou sobrevida. O passo seguinte foi testar se o BNP seria preditor de mortalidade de forma independente. Ajustamos um modelo de Cox com processo de seleção de variáveis "stepwise", sendo que as variáveis utilizadas no modelo foram: idade, sexo, índice de massa ventricular esquerda, diâmetro do átrio esquerdo, diâmetro da aorta, gradientes de pressão transvalvar 
aórtico pico e médio, fração de ejeção de ventrículo esquerdo, classe funcional (NYHA) e BNP. Através deste modelo pudemos observar que o único preditor independente de mortalidade foi o BNP, e que o risco de um paciente falecer era 6,31 vezes maior quando ele apresentava BNP maior ou igual a $105 \mathrm{pg} / \mathrm{mL}$ (IC 95\%: 1,36 - 29,25) com sensibilidade de $82 \%$, especificidade de $62 \%$, valor preditivo positivo de $31 \%$, valor preditivo negativo de $94 \%$ e acurácia de $66 \%$. A Figura 10 apresenta a curva de sobrevida dos pacientes em relação ao BNP.

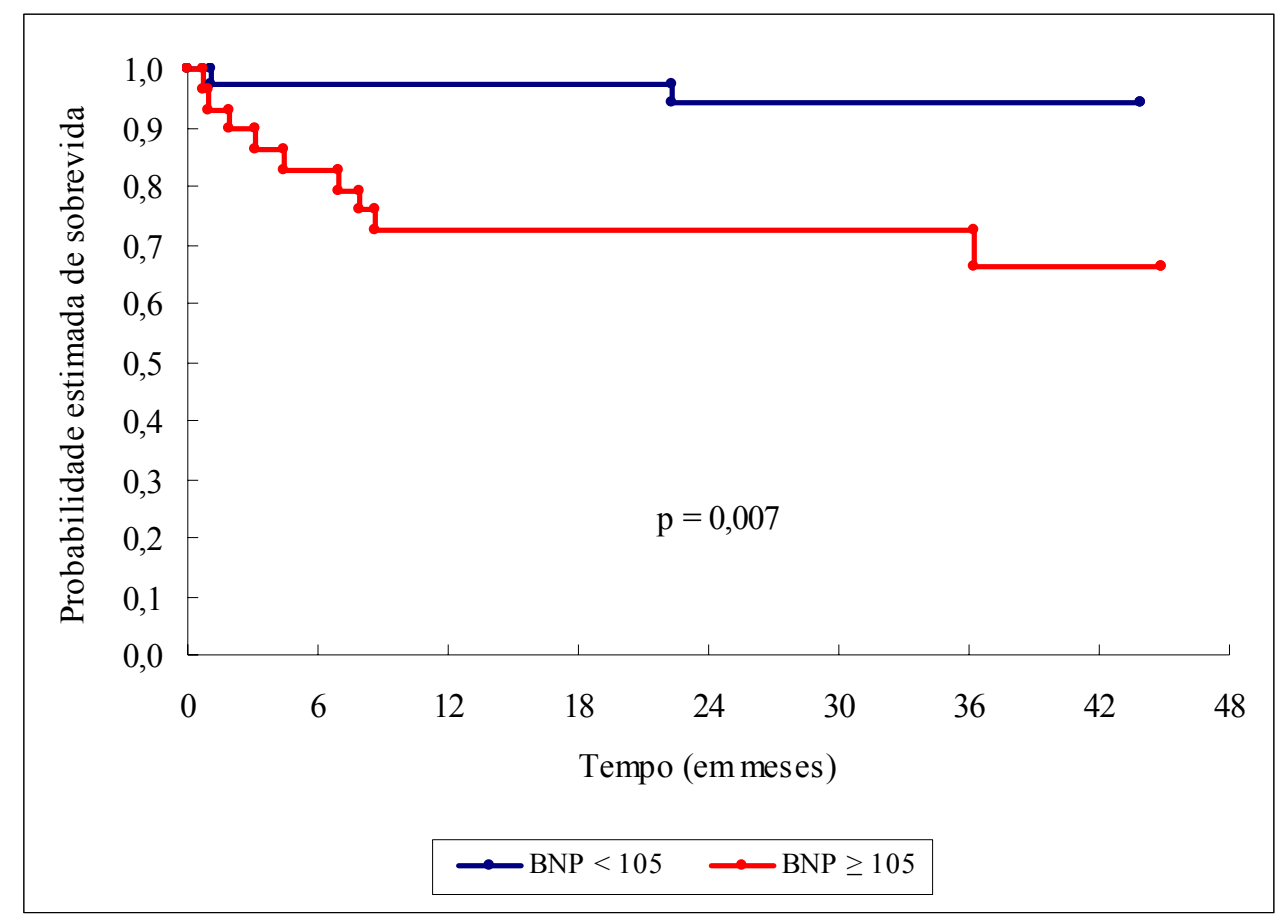

Figura 10. Curva de sobrevida dos pacientes (total) em relação ao $\mathrm{BNP}<105$ $\mathrm{pg} / \mathrm{mL}(\mathrm{n}=35)$ e $\geq 105 \mathrm{pg} / \mathrm{mL}(\mathrm{n}=29)$

Realizamos ainda a análise de Kaplan-Meier utilizando os valores de BNP subdivididos em tercis, sendo o primeiro tercil correspondente ao valor de BNP menor ou igual a $58 \mathrm{pg} / \mathrm{mL}$ ( 21 pacientes), segundo tercil com BNP entre 59 e 136 $\mathrm{pg} / \mathrm{mL}$ (21 pacientes) e terceiro tercil com BNP maior ou igual a $137 \mathrm{pg} / \mathrm{mL}$ (22 
pacientes). A Figura 11 representa a curva de sobrevida dos pacientes de acordo com estes tercis de BNP.

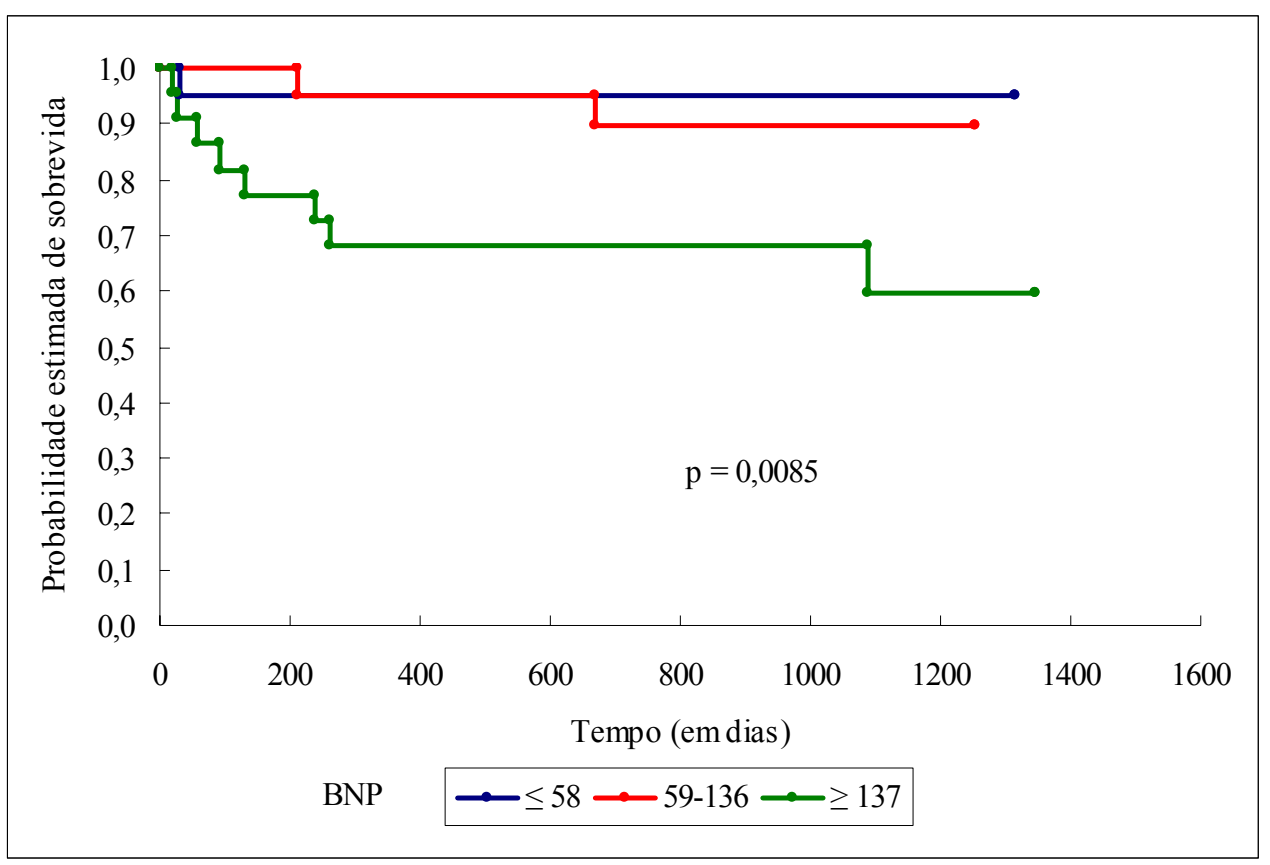

Figura 11. Curva de sobrevida dos pacientes (total) em relação aos valores de BNP em tercis

Portanto os grupos em tercis de BNP diferiram em relação ao óbito. O grupo com BNP mais elevado apresentou menor probabilidade de sobrevida do que os demais grupos.

Separamos os pacientes em sintomáticos e assintomáticos para analisar o papel prognóstico do BNP nestes subgrupos. A Figura 12 ilustra a curva de sobrevida dos sintomáticos em relação ao BNP. O risco de óbito para os pacientes sintomáticos com BNP maior ou igual a $105 \mathrm{pg} / \mathrm{mL}$ foi 9,4 vezes maior que os sintomáticos com BNP menor que $105 \mathrm{pg} / \mathrm{mL}$ (IC 95\%: 1,2- 75,3), de forma independente. Não obtivemos número de óbitos suficientes entre os pacientes assintomáticos para avaliação prognóstica do BNP neste subgrupo. 


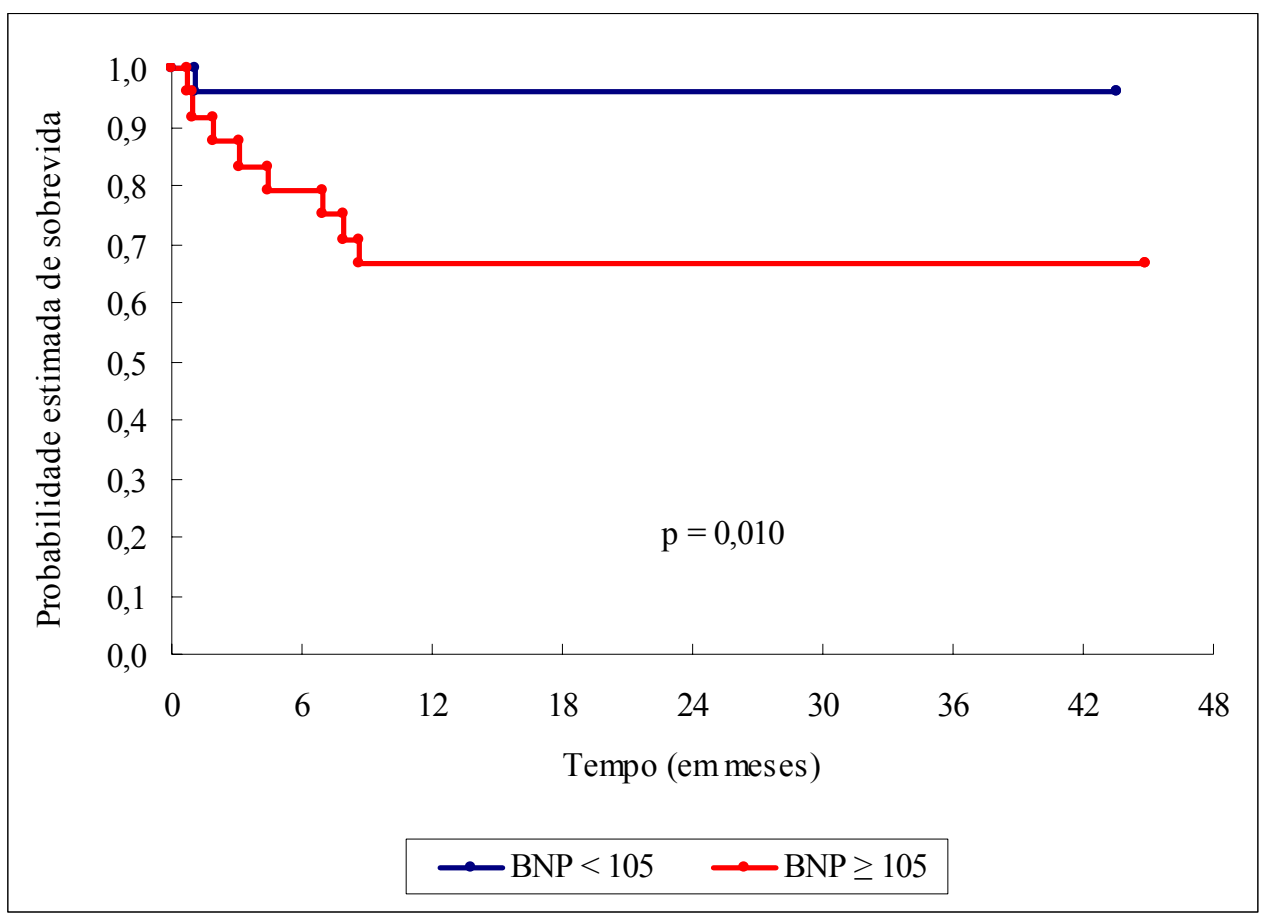

Figura 12. Curva de sobrevida dos pacientes sintomáticos em relação ao BNP $<105 \mathrm{pg} / \mathrm{mL}(\mathrm{n}=25)$ e $\geq 105 \mathrm{pg} / \mathrm{mL}(\mathrm{n}=24)$

4.6 Níveis de NT-proBNP e sintomas dos pacientes na inclusão

4.6.1 Comparação dos níveis de NT-proBNP entre assintomáticos e sintomáticos

Não houve diferença significativa em relação aos níveis de NT-proBNP quando comparamos pacientes assintomáticos e sintomáticos no momento da inclusão. A Tabela 8 apresenta os resultados desta comparação. 
Tabela 8 - NT-proBNP em assintomáticos vs. sintomáticos na inclusão do protocolo

\begin{tabular}{lccc}
\hline & Assintomáticos & Sintomáticos & $p$ \\
\hline N & 15 & 49 & \\
NT-proBNP $(\mathbf{p g} / \mathbf{m L})$ & $676(235-1356)$ & $871(310-2230)$ & $0,226^{*}$ \\
\hline
\end{tabular}

Legenda: $\mathrm{N}=$ número de pacientes, ${ }^{*}=$ nível descritivo de probabilidade do teste $\mathrm{t}$ de Student. Valores expressos em mediana e variação interquartil.

Mesmo ajustando para sexo e idade, não houve diferença significativa dos níveis de NT-proBNP entre assintomáticos e sintomáticos.

\subsubsection{NT-proBNP e classe funcional (NYHA)}

A Figura 13 e o Quadro 4 apresentam os níveis de NT-proBNP em relação à classe funcional (NYHA) dos pacientes na inclusão. 


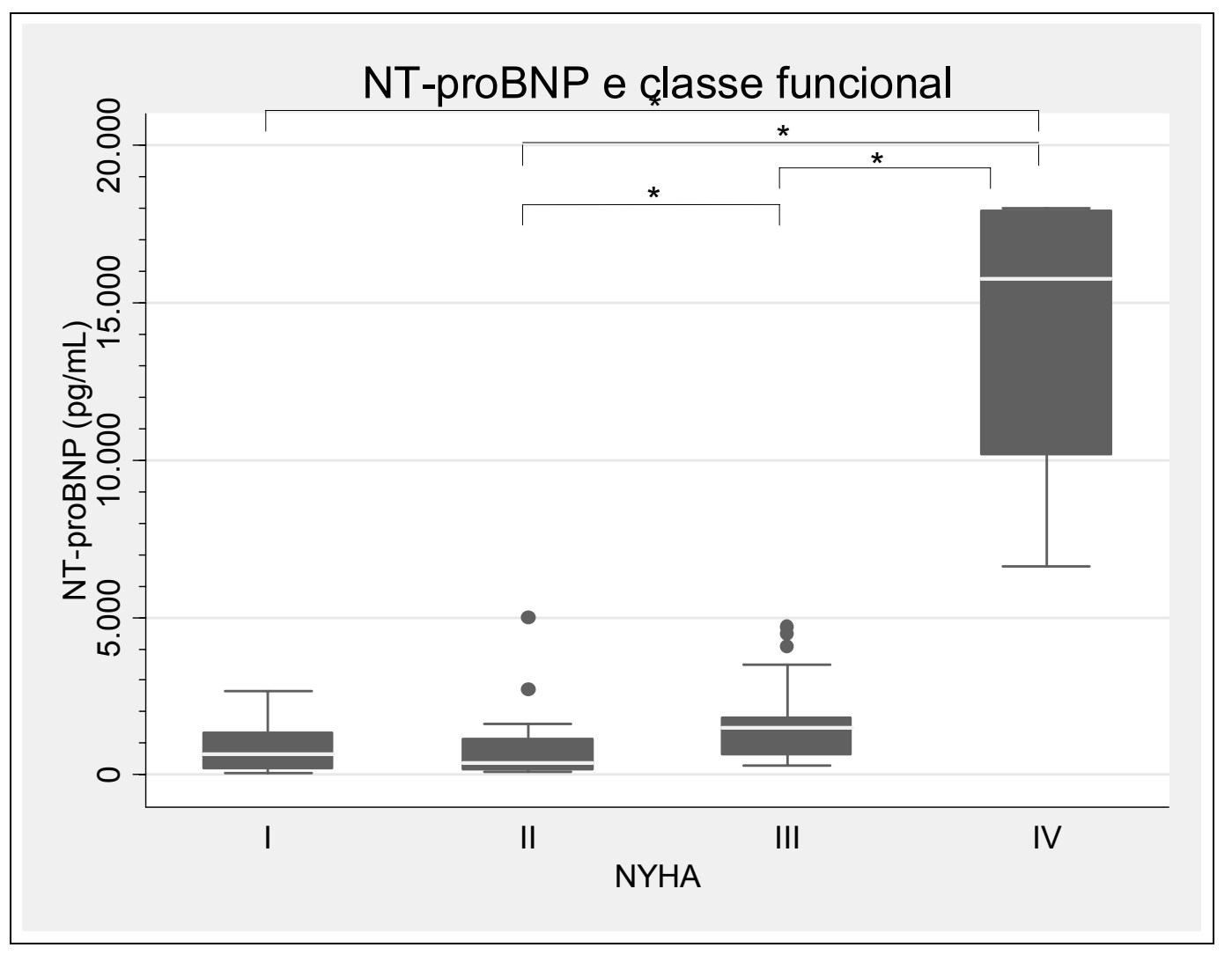

Figura 13. NT-proBNP vs. classe funcional (NYHA) na inclusão

Legenda: NYHA= New York Heart Association, * = significância estatística pelo teste de Bonferroni.

Quadro 4 - NT-proBNP vs. classe funcional (NYHA) na inclusão

\begin{tabular}{|c|c|c|c|}
\hline Classe & N & Nível sérico de NT-proBNP & \multirow{2}{*}{ (mediana e variação interquartil) } \\
II & 19 & $675,9 \mathrm{pg} / \mathrm{mL}(227-1356)$ & \multirow{2}{*}{$<0,001^{*}$} \\
\hline II & 20 & $362 \mathrm{pg} / \mathrm{mL}(182-1219)$ & \\
\hline III & 21 & $1500 \mathrm{pg} / \mathrm{mL}(657-2447)$ & \\
\hline IV & 4 & $15741 \mathrm{pg} / \mathrm{mL}(8380-17937)$ & \\
\hline
\end{tabular}

Legenda: $\mathrm{N}=$ número de pacientes, ${ }^{*}=$ nível descritivo de probabilidade da ANOVA a um fator 
Houve associação significativa entre os grupos de classe funcional em relação ao NT-proBNP. Através do teste de Bonferroni observamos que o grupo I difere significativamente do grupo IV ( $p<0,001)$ e não difere dos grupos II $(p=1,000)$ e III $(p=0,108)$. O grupo II difere significativamente dos grupos III $(p=0,007)$ e IV $(p<$ 0,001). O grupo III difere significativamente do grupo IV $(\mathrm{p}<0,001)$.

Dentro de cada classe funcional, os níveis de NT-proBNP não eram mais elevados naqueles pacientes com síncope ou angina, quando comparados aos pacientes de mesma classe sem estes sintomas.

Quando agrupamos os pacientes em classe funcional I e II ou classe funcional III e IV, observamos diferença significativa entre os grupos (Quadro 5).

Quadro 5 - NT-proBNP vs. classe funcional (NYHA) na inclusão

\begin{tabular}{|c|c|c|c|}
\hline $\begin{array}{c}\text { Classe } \\
\text { Funcional }\end{array}$ & $\mathbf{N}$ & $\begin{array}{c}\text { Nível sérico de NT-proBNP } \\
\text { (mediana e variação interquartil) }\end{array}$ & $p$ \\
\hline I e II & 39 & $523 \mathrm{pg} / \mathrm{mL}(216-1315)$ & \\
\hline III e IV & 25 & $1574 \mathrm{pg} / \mathrm{mL}(709-4259)$ & $<0,001^{*}$ \\
\hline
\end{tabular}

Legenda: $\mathrm{N}=$ número de pacientes, $*$ = nível descritivo de probabilidade do teste $\mathrm{t}$ de Student

\subsection{NT-proBNP como preditor de classe funcional III e IV na inclusão}

Construímos uma curva ROC (NT-proBNP vs. CF III e IV) com o objetivo de identificar um valor de NT-proBNP que pudesse marcar CF avançada. Através da curva ROC (Figura 14), pudemos obter um ponto de corte para o NT-proBNP, relacionando-o à classe funcional. O valor de NT-proBNP que discriminou as classes 
foi $1500 \mathrm{pg} / \mathrm{mL}$, com sensibilidade de $60 \%$, especificidade de $84,6 \%$, acurácia de $75,0 \%$, valor preditivo positivo de $71,4 \%$ e valor preditivo negativo de $76,7 \%$. A área calculada abaixo da curva foi de 0,786.

Pacientes com valor de NT-proBNP igual ou superior a $1500 \mathrm{pg} / \mathrm{mL}$ apresentaram 8,25 vezes maior chance de estarem em classe funcional III ou IV (IC 95\%: 2,53 - 26,90) no momento da inclusão.

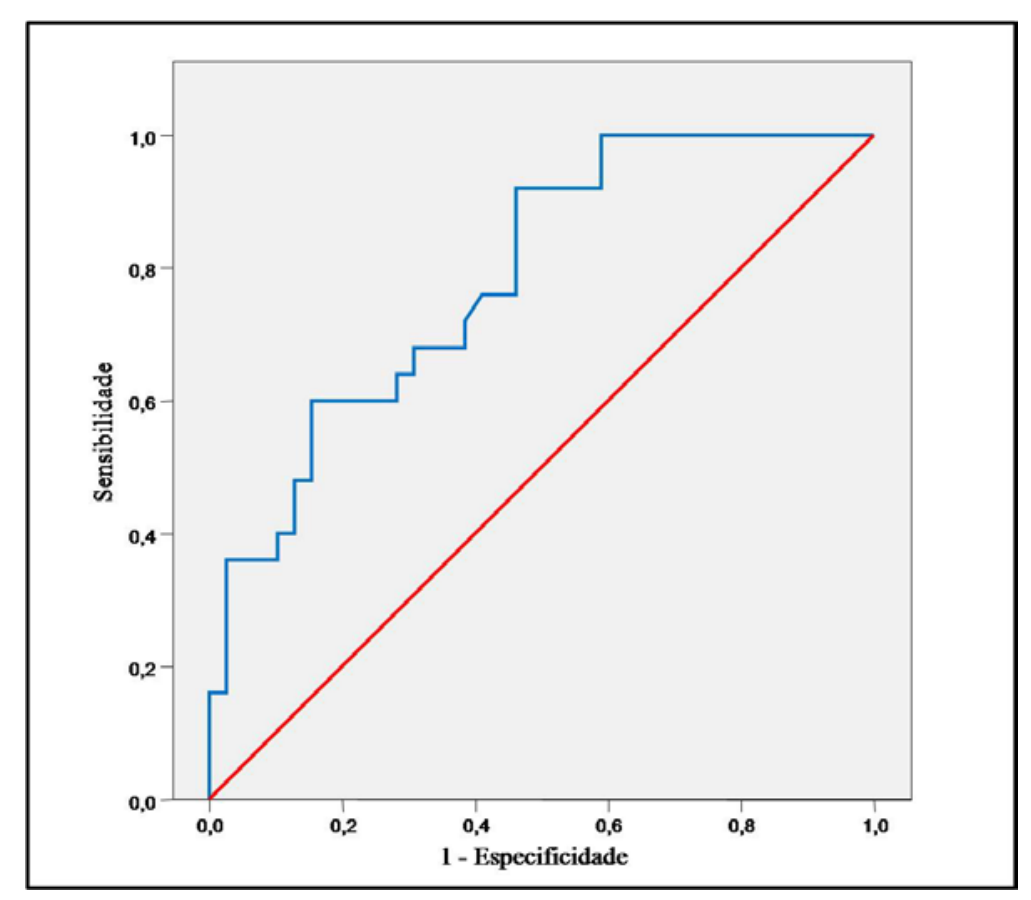

Figura 14. Curva ROC para NT-proBNP e classe funcional III e IV

\subsection{NT-proBNP como preditor de sobrevida}

Utilizamos para o NT-proBNP o valor de corte de $1500 \mathrm{pg} / \mathrm{mL}$ obtido a partir da curva ROC para classe funcional avançada e testamos esse valor em uma curva de sobrevida.Através da análise da curva de Kaplan-Meier pudemos observar que o valor de $1500 \mathrm{pg} / \mathrm{mL}$ para o NT-proBNP discriminou sobrevida. O passo seguinte foi 
testar se o NT-proBNP seria preditor de mortalidade de forma independente. Ajustamos um modelo de Cox com processo de seleção de variáveis "stepwise", sendo que as variáveis utilizadas no modelo foram idade, sexo, índice de massa ventricular esquerda, diâmetro do átrio esquerdo, diâmetro da aorta, gradientes de pressão transvalvar aórtico pico e médio, fração de ejeção de ventrículo esquerdo, classe funcional (NYHA) e NT-proBNP. Através deste modelo pudemos observar que o único preditor independente de mortalidade foi o NT-proBNP, e que o risco de um paciente falecer era 6,52 vezes maior quando ele apresentava NT-proBNP maior ou igual a $1500 \mathrm{pg} / \mathrm{mL}$ (IC 95\%: 1,73 - 24,63) com sensibilidade de 73\%, especificidade de $75 \%$, valor preditivo positivo de $38 \%$, valor preditivo negativo de 93\% e acurácia de 75\%. A Figura 15 apresenta a curva de sobrevida dos pacientes em relação ao NTproBNP.

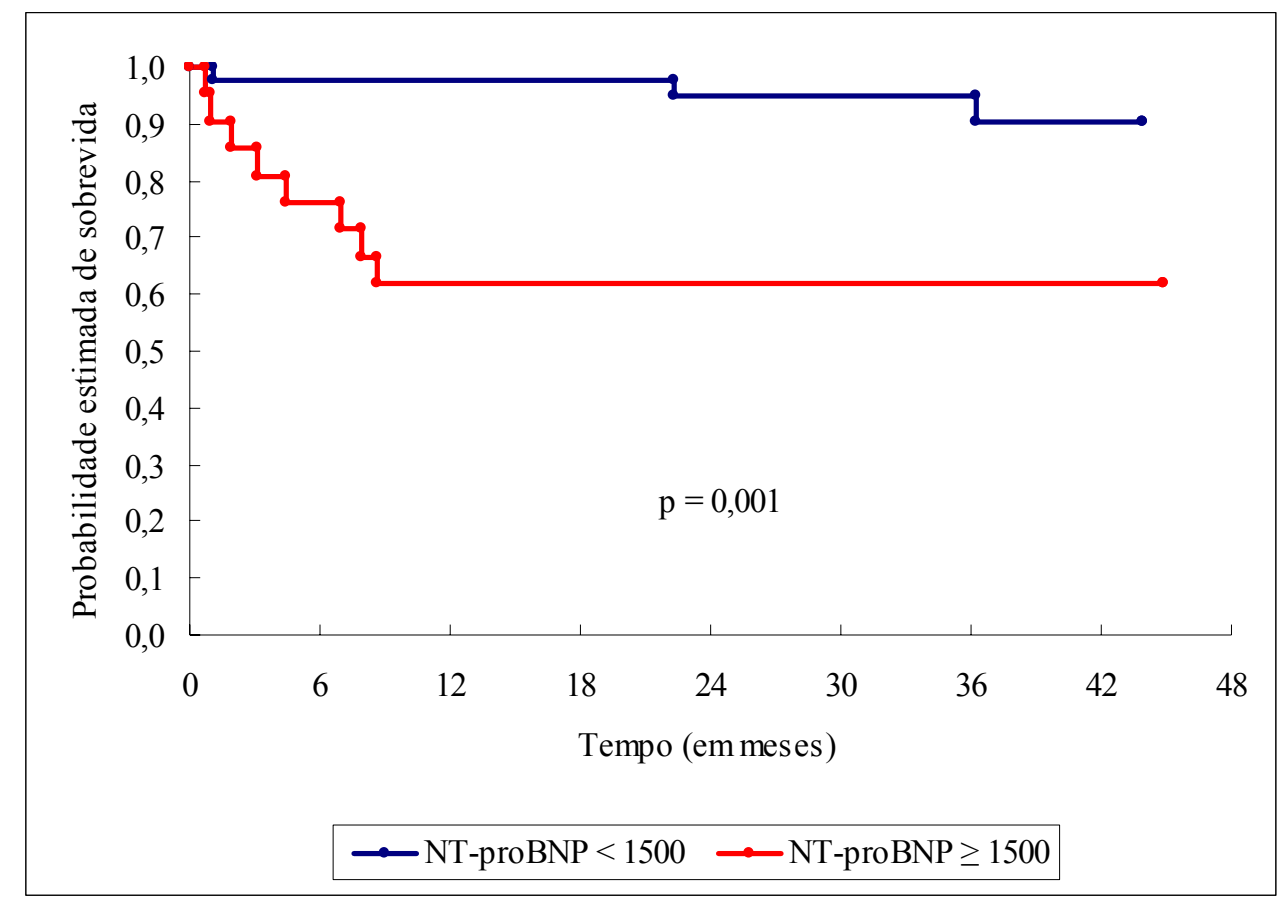

Figura 15. Curva de sobrevida dos pacientes (total) em relação ao NT-proBNP $<1500 \mathrm{pg} / \mathrm{mL}(\mathrm{n}=43)$ e $\geq 1500 \mathrm{pg} / \mathrm{mL}(\mathrm{n}=21)$ 
Realizamos ainda análise de Kaplan-Meier utilizando os valores de NTproBNP subdivididos em tercis, sendo o primeiro tercil correspondente ao valor de NT-proBNP menor ou igual a $413 \mathrm{pg} / \mathrm{mL}$ (21 pacientes), segundo tercil com NTproBNP entre 414 e $1406 \mathrm{pg} / \mathrm{mL}$ (21 pacientes), e terceiro tercil com NT-proBNP maior ou igual a $1407 \mathrm{pg} / \mathrm{mL}$ (22 pacientes). A Figura 16 representa a curva de sobrevida pdos pacientes de acordo com estes tercis de NT-proBNP.

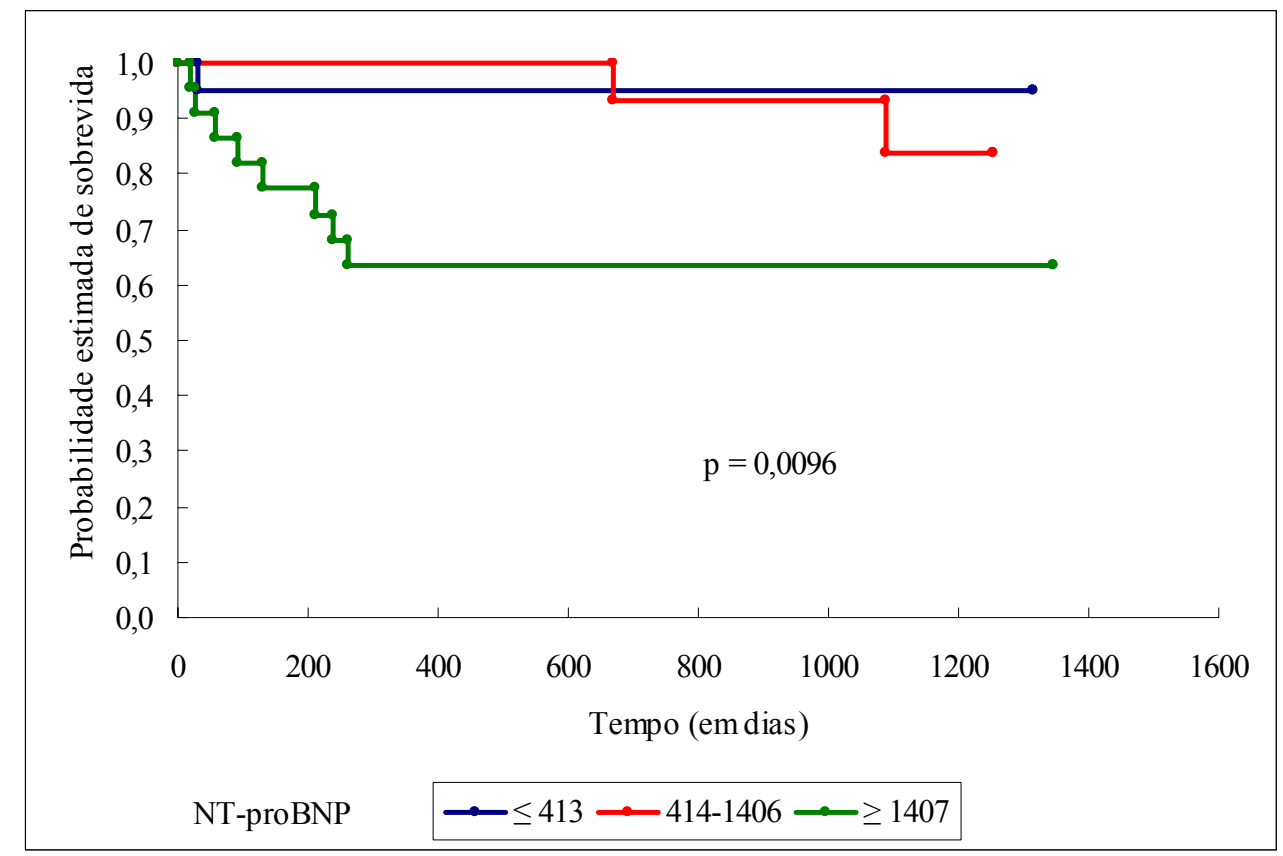

Figura 16. Curva de sobrevida dos pacientes (total) em relação aos valores de NT-proBNP em tercis

Portanto os grupos em tercis de NT-proBNP diferiram em relação ao óbito. O grupo com NT-proBNP mais elevado apresentou menor probabilidade de sobrevida do que os demais grupos. 
Separamos os pacientes em sintomáticos e assintomáticos para analisar o papel prognóstico do NT-proBNP nestes subgrupos. A figura 17 ilustra a curva de sobrevida dos sintomáticos em relação ao NT-proBNP. O risco de óbito para os pacientes sintomáticos com NT-proBNP maior ou igual a $1500 \mathrm{pg} / \mathrm{mL}$ foi 15,1 (IC a 95\%: 1,9; 120,9) vezes maior que os sintomáticos com NT-proBNP menor, de forma independente. Não obtivemos número de óbitos suficientes entre os pacientes assintomáticos para avaliação prognóstica do NT-proBNP neste subgrupo.

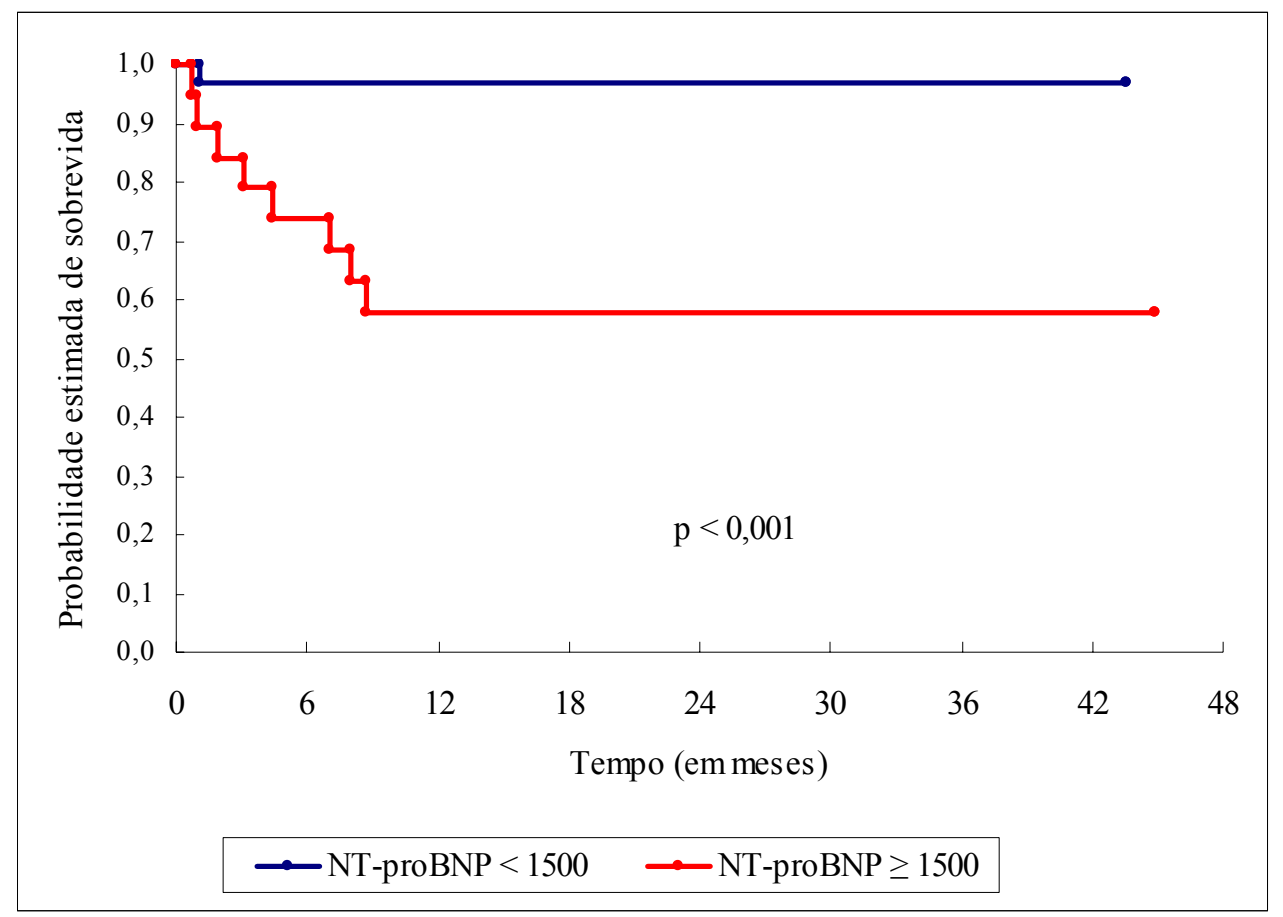

Figura 17. Curva de sobrevida dos pacientes sintomáticos em relação ao NTproBNP $<1500 \mathrm{pg} / \mathrm{mL}(\mathrm{n}=30)$ e $\geq 1500 \mathrm{pg} / \mathrm{mL}(\mathrm{n}=19)$

\subsection{Correlação entre os parâmetros ecocardiográficos e nível sérico de BNP}

As Tabelas 9, 10 e 11 apresentam resultados da correlação de Pearson entre o $\log (\mathrm{BNP})$ e parâmetros ecocardiográficos na inclusão dos pacientes. 


\section{Tabela 9 - Correlação de Pearson entre log (BNP) e parâmetros ecocardiográficos no grupo todo (sintomáticos e assintomáticos)}

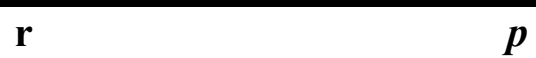

\begin{tabular}{lcc}
\hline AE & 0,207 & 0,116 \\
AO & 0,036 & 0,789 \\
Gradiente de pico & 0,054 & 0,699 \\
Gradiente médio & 0,098 & 0,486 \\
IMVE & 0,361 & 0,005 \\
FE & $-0,543$ & $<0,001$ \\
\hline
\end{tabular}

Legenda: $\mathrm{r}=$ coeficiente de correlação. $\mathrm{AE}=$ átrio esquerdo, $\mathrm{AO}=$ aorta, Gradiente de pico $=$ gradiente de pressão transvalvar aórtico no pico da sístole, Gradiente médio $=$ gradiente de pressão transvalvar aórtico médio, IMVE = índice de massa ventricular esquerda, $\mathrm{FE}=$ fração de ejeção do ventrículo esquerdo.

Pela Tabela 9 observamos que no grupo geral houve correlação negativa e significativa entre BNP e fração de ejeção de ventrículo esquerdo, e correlação positiva e significativa entre BNP e índice de massa ventricular esquerda. 


\section{Tabela 10 - Correlação de Pearson entre log (BNP) e parâmetros ecocardiográficos no grupo assintomáticos}

r p

\begin{tabular}{lcc}
\hline AE & 0,511 & 0,074 \\
AO & 0,059 & 0,847 \\
Gradiente de pico & 0,245 & 0,398 \\
Gradiente médio & 0,363 & 0,202 \\
IMVE & 0,332 & 0,246 \\
FE & $-0,013$ & 0,966 \\
\hline
\end{tabular}

Legenda: $\mathrm{r}=$ coeficiente de correlação. $\mathrm{AE}=$ átrio esquerdo, $\mathrm{AO}=$ aorta, Gradiente de pico $=$ gradiente de pressão transvalvar aórtico no pico da sístole, Gradiente médio $=$ gradiente de pressão transvalvar aórtico médio, IMVE = índice de massa ventricular esquerda, $\mathrm{FE}=$ fração de ejeção do ventrículo esquerdo.

Pela Tabela 10 observamos que no grupo assintomáticos não houve correlação significativa entre BNP e os parâmetros ecocardiográficos. 


\section{Tabela 11 - Correlação de Pearson entre log (BNP) e parâmetros ecocardiográficos no grupo sintomáticos}

r P

\begin{tabular}{lcc}
\hline AE & 0,159 & 0,291 \\
AO & 0,031 & 0,839 \\
Gradiente de pico & 0,035 & 0,828 \\
Gradiente médio & 0,056 & 0,736 \\
IMVE & 0,390 & 0,007 \\
FE & $-0,581$ & $<0,001$ \\
\hline
\end{tabular}

Legenda: $\mathrm{r}=$ coeficiente de correlação. $\mathrm{AE}=$ átrio esquerdo, $\mathrm{AO}=$ aorta, Gradiente de pico $=$ gradiente de pressão transvalvar aórtico no pico da sístole, Gradiente médio $=$ gradiente de pressão transvalvar aórtico médio, IMVE = índice de massa ventricular esquerda, $\mathrm{FE}=$ fração de ejeção do ventrículo esquerdo.

Pela Tabela 11 observamos que no grupo sintomáticos houve correlação negativa e significativa entre BNP e fração de ejeção de ventrículo esquerdo e correlação positiva e significativa entre BNP índice de massa ventricular esquerda.

\subsection{Correlação entre os parâmetros ecocardiográficos e nível sérico de} NT-proBNP

As Tabelas 12, 13 e 14 apresentam resultados da correlação de Pearson entre o $\log$ (NT-proBNP) e parâmetros ecocardiográficos na inclusão dos pacientes. 
Tabela 12 - Correlação de Pearson entre log (NT-proBNP) e parâmetros ecocardiográficos no grupo todo (sintomáticos e assintomáticos)

r p

\begin{tabular}{lcc}
\hline AE & 0,076 & 0,566 \\
AO & 0,052 & 0,696 \\
Gradiente de pico & 0,199 & 0,149 \\
Gradiente médio & 0,244 & 0,078 \\
IMVE & 0,466 & $<0,001$ \\
FE & $-0,458$ & $<0,001$ \\
\hline
\end{tabular}

Legenda: $\mathrm{r}=$ coeficiente de correlação. $\mathrm{AE}=$ átrio esquerdo, $\mathrm{AO}=$ aorta, Gradiente de pico $=$ gradiente de pressão transvalvar aórtico no pico da sístole, Gradiente médio $=$ gradiente de pressão transvalvar aórtico médio, IMVE = índice de massa ventricular esquerda, $\mathrm{FE}=$ fração de ejeção do ventrículo esquerdo.

Pela Tabela 12 observamos que no grupo geral houve correlação negativa e significativa entre NT-proBNP e fração de ejeção de ventrículo esquerdo, e correlação positiva e significativa entre NT-proBNP e índice de massa ventricular esquerda. 
Tabela 13 - Correlação de Pearson entre log (NT-proBNP) e parâmetros ecocardiográficos no grupo assintomáticos

r p

\begin{tabular}{lcc}
\hline AE & 0,324 & 0,280 \\
AO & $-0,133$ & 0,665 \\
Gradiente de pico & 0,472 & 0,088 \\
Gradiente médio & 0,554 & 0,040 \\
IMVE & 0,455 & 0,102 \\
FE & 0,339 & 0,236 \\
\hline
\end{tabular}

Legenda: $\mathrm{r}=$ coeficiente de correlação. $\mathrm{AE}=$ átrio esquerdo, $\mathrm{AO}=$ aorta, Gradiente de pico $=$ gradiente de pressão transvalvar aórtico no pico da sístole, Gradiente médio $=$ gradiente de pressão transvalvar aórtico médio, IMVE = índice de massa ventricular esquerda, $\mathrm{FE}=$ fração de ejeção do ventrículo esquerdo.

Pela Tabela 13 observamos que no grupo assintomáticos houve correlação significativa entre NT-proBNP e gradiente médio. 
Tabela 14 - Correlação de Pearson entre log (NT-proBNP) e parâmetros ecocardiográficos no grupo sintomáticos

r p

\begin{tabular}{lcc}
\hline AE & 0,028 & 0,853 \\
AO & 0,095 & 0,531 \\
Gradiente de pico & 0,170 & 0,294 \\
Gradiente médio & 0,192 & 0,243 \\
IMVE & 0,497 & $<0,001$ \\
FE & $-0,520$ & $<0,001$ \\
\hline
\end{tabular}

Legenda: $\mathrm{r}=$ coeficiente de correlação. $\mathrm{AE}=$ átrio esquerdo, $\mathrm{AO}=$ aorta, Gradiente de pico $=$ gradiente de pressão transvalvar aórtico no pico da sístole, Gradiente médio $=$ gradiente de pressão transvalvar aórtico médio, ÍMVE = índice de massa ventricular esquerda, $\mathrm{FE}=$ fração de ejeção do ventrículo esquerdo.

Pela Tabela 14 observamos que no grupo sintomáticos houve correlação negativa e significativa entre NT-proBNP e fração de ejeção de ventrículo esquerdo e correlação positiva e significativa entre NT-proBNP e índice de massa ventricular esquerda.

\subsection{Comparação dos níveis de BNP e NT-proBNP no pré e pós-operatório}

Os pacientes submetidos à cirurgia foram reavaliados no pós-operatório. Esta avaliação incluiu nova coleta de BNP e NT-proBNP. As dosagens foram realizadas em média 11,3 meses após a cirurgia. A Tabela 15 apresenta os resultados da comparação entre os níveis de BNP e NT-proBNP no pré e no pós-operatório. Para efeito de análise consideramos apenas os pacientes sintomáticos na inclusão do protocolo. Os pacientes assintomáticos que se tornaram sintomáticos e operaram 
foram excluídos da análise uma vez que não realizamos nova dosagem dos peptídeos após a mudança do status funcional.

Tabela 15 - BNP e NT-proBNP pré e pós-operatório de pacientes sintomáticos

\begin{tabular}{lcccc}
\hline & N & Pré-operatório & Pós-operatório & $\boldsymbol{p}^{*}$ \\
\hline BNP (pg/mL) & 38 & $97(38-167)$ & $43(15-137)$ & 0,005 \\
NT-proBNP (pg/mL) & 37 & $744(296-1504)$ & $181,6(102-627)$ & $<0,001$ \\
\hline
\end{tabular}

Legenda: $\mathrm{N}=$ número de pacientes, ${ }^{*}=$ Nível descritivo de probabilidade do teste $\mathrm{t}$ de Student pareado. Variável analisada com a transformação logarítmica.Valores expressos em mediana e variação interquartil.

Como podemos observar, os níveis de BNP e NT-proBNP caem significativamente na avaliação pós-operatória.

\subsection{Comparação entre os níveis de BNP e NT-proBNP e classe funcional}

\section{(NYHA) após a cirurgia}

Os pacientes submetidos à cirurgia foram reavaliados no pós-operatório, em média 11,3 meses após a cirurgia. Nesta avaliação, além de coleta dos PN, foram obtidos dados relacionados ao status funcional dos pacientes. Os Quadros 6 e 7 relacionam os níveis dos PN e a classe funcional dos pacientes nesta fase. Como podemos observar, no pós-operatório, o BNP foi significativamente menor nos pacientes em classe funcional I (NYHA) quando comparado aos pacientes em classe funcional II-III. Em relação ao NT-proBNP, não houve diferença significativa quando comparamos classe I e classe II-III. 
Quadro 6 - BNP vs. classe funcional (NYHA) no pós-operatório

\begin{tabular}{|c|c|c|c|}
\hline Classe & N & Nível sérico de BNP & \multirow{2}{*}{ (mediana e variação interquartil) } \\
\cline { 1 - 2 } I & 24 & $30 \mathrm{pg} / \mathrm{mL}(12-63)$ & \multirow{2}{*}{$0,024^{*}$} \\
\hline II-III & 18 & $102 \mathrm{pg} / \mathrm{mL}(28-153)$ & \\
\hline
\end{tabular}

Legenda: $\mathrm{N}$ = número de pacientes, * = nível descritivo de probabilidade do teste $\mathrm{t}$ de Student

Quadro 7 - NT-proBNP vs. classe funcional (NYHA) no pós-operatório

\begin{tabular}{|c|c|c|c|}
\hline Classe & N & Nível sérico de NT-proBNP & \multirow{2}{*}{ (mediana e variação interquartil) } \\
\hline I & 23 & $151 \mathrm{pg} / \mathrm{mL}(96-341)$ & \multirow{2}{*}{$0,064^{*}$} \\
\hline II-III & 18 & $376 \mathrm{pg} / \mathrm{mL}(115-955)$ & \\
\hline
\end{tabular}

Legenda: $\mathrm{N}=$ número de pacientes, ${ }^{*}=$ nível descritivo de probabilidade do teste $\mathrm{t}$ de Student

\subsection{Comparação dos níveis de BNP e NT-proBNP entre pacientes}

assintomáticos na inclusão vs. pacientes no pós-operatório

As Tabelas 16 e 17 apresentam a comparação dos níveis de BNP e NT-proBNP entre pacientes assintomáticos na inclusão vs. pacientes no pós-operatório. 
Tabela 16 - BNP em assintomáticos na inclusão vs. pós-operatório

\begin{tabular}{lccc}
\hline & Assintomáticos & Pós-operatório & $\boldsymbol{p}^{*}$ \\
& $\mathbf{N}=\mathbf{1 5}$ & $\mathbf{N}=\mathbf{4 2}$ & \\
\hline BNP (pg/mL) & $72(41-175)$ & $43(19-137)$ & 0,07 \\
\hline
\end{tabular}

Legenda: $\mathrm{N}=$ número de pacientes, $*=$ Nível descritivo de probabilidade do teste $\mathrm{t}$ de Student pareado. Variável analisada com a transformação logarítmica. Valores expressos em mediana e variação interquartil.

Tabela 17 - NT-proBNP em assintomáticos na inclusão vs. pós-operatório

\begin{tabular}{lccc}
\hline & Assintomáticos & Pós-operatório & \multirow{2}{*}{$\boldsymbol{p}^{*}$} \\
& $\mathbf{N}=\mathbf{1 5}$ & $\mathbf{N}=\mathbf{4 1}$ & \\
\hline NT-proBNP $(\mathbf{p g} / \mathbf{m L})$ & $676(235-1356)$ & $188(106-727)$ & 0,015 \\
\hline
\end{tabular}

Legenda: $\mathrm{N}=$ número de pacientes, $*=$ Nível descritivo de probabilidade do teste $\mathrm{t}$ de Student pareado. Variável analisada com a transformação logarítmica. Valores expressos em mediana e variação interquartil.

\subsection{Evolução ecocardiográfica durante o estudo}

Os pacientes realizaram ecocardiograma na inclusão e ao final do acompanhamento. As Tabelas 18 e 19 apresentam os parâmetros ecocardiográficos no início do acompanhamento e ao final. Para efeito de análise, consideramos pacientes operados e pacientes não operados. 
Tabela 18 - Comparação entre Ecocardiograma inicial e no final do acompanhamento de pacientes operados

\section{Pacientes operados}

\begin{tabular}{|c|c|c|c|}
\hline & Início & Final & $P^{*}$ \\
\hline $\mathrm{AE}(\mathrm{cm})$ & $4,04 \pm 0,47$ & $3,85 \pm 0,64$ & 0,148 \\
\hline $\mathrm{AO}(\mathrm{cm})$ & $3,19 \pm 0,47$ & $3,22 \pm 0,35$ & 0,616 \\
\hline FE & $0,63 \pm 0,11$ & $0,63 \pm 0,05$ & 0,822 \\
\hline IMVE $\left(\mathrm{g} / \mathrm{m}^{2}\right)$ & $142,03 \pm 29,72$ & $112,59 \pm 23,29$ & $<0,001$ \\
\hline G. pico (mmHg) & $95,00 \pm 21,06$ & $26,56 \pm 9,74$ & $<0,001$ \\
\hline G.medio (mmHg) & $58,74 \pm 14,37$ & $13,87 \pm 6,09$ & $<0,001$ \\
\hline
\end{tabular}

Legenda: $\mathrm{AE}=$ átrio esquerdo, $\mathrm{AO}=$ aorta, $\mathrm{FE}=$ fração de ejeção do ventrículo esquerdo, IMVE = índice de massa ventricular esquerda, $\mathrm{G}$ pico = gradiente transvalvar aórtico de pressão no pico da sístole, G. médio = gradiente médio transvalvar aórtico. * = Nível descritivo de probabilidade do teste t de Student pareado Valores expressos em média \pm desvio padrão.

Tabela 19 - Comparação entre Ecocardiograma inicial e no final do acompanhamento de pacientes não operados

Pacientes não operados

\begin{tabular}{lccc} 
& Início & Final & P* \\
\cline { 2 - 4 } AE (cm) & $4,05 \pm 0,57$ & $4,26 \pm 0,77$ & 0,346 \\
AO (cm) & $3,22 \pm 0,54$ & $3,22 \pm 0,51$ & 0,393 \\
FE & $0,68 \pm 0,06$ & $0,62 \pm 0,07$ & 0,104 \\
IMVE (g/m $\mathbf{2})$ & $149,10 \pm 40,22$ & $166,50 \pm 42,76$ & 0,135 \\
G. pico (mmHg) & $109,56 \pm 16,26$ & $89,00 \pm 33,80$ & 0,143 \\
G.medio (mmHg) & $61,00 \pm 14,95$ & $57,89 \pm 13,12$ & 0,616 \\
\hline
\end{tabular}

Legenda: $\mathrm{AE}=$ átrio esquerdo, $\mathrm{AO}=$ aorta, $\mathrm{FE}=$ fração de ejeção do ventrículo esquerdo, IMVE = índice de massa ventricular esquerda, $\mathrm{G}$ pico = gradiente transvalvar aórtico de pressão no pico da sístole, G. médio = gradiente médio transvalvar aórtico. $*=$ Nível descritivo de probabilidade do teste t de Student pareado Valores expressos em média \pm desvio padrão. 


\subsection{BNP vs. NT-proBNP}

Usando o $\log$ das duas variáveis e calculando a correlação de Pearson obtivemos o coeficiente de correlação igual a $0,914(\mathrm{p}<0,001)$. Portanto há correlação positiva e significativa entre o os valores obtidos de BNP e NT-proBNP. A Figura 18 ilustra essa correlação.

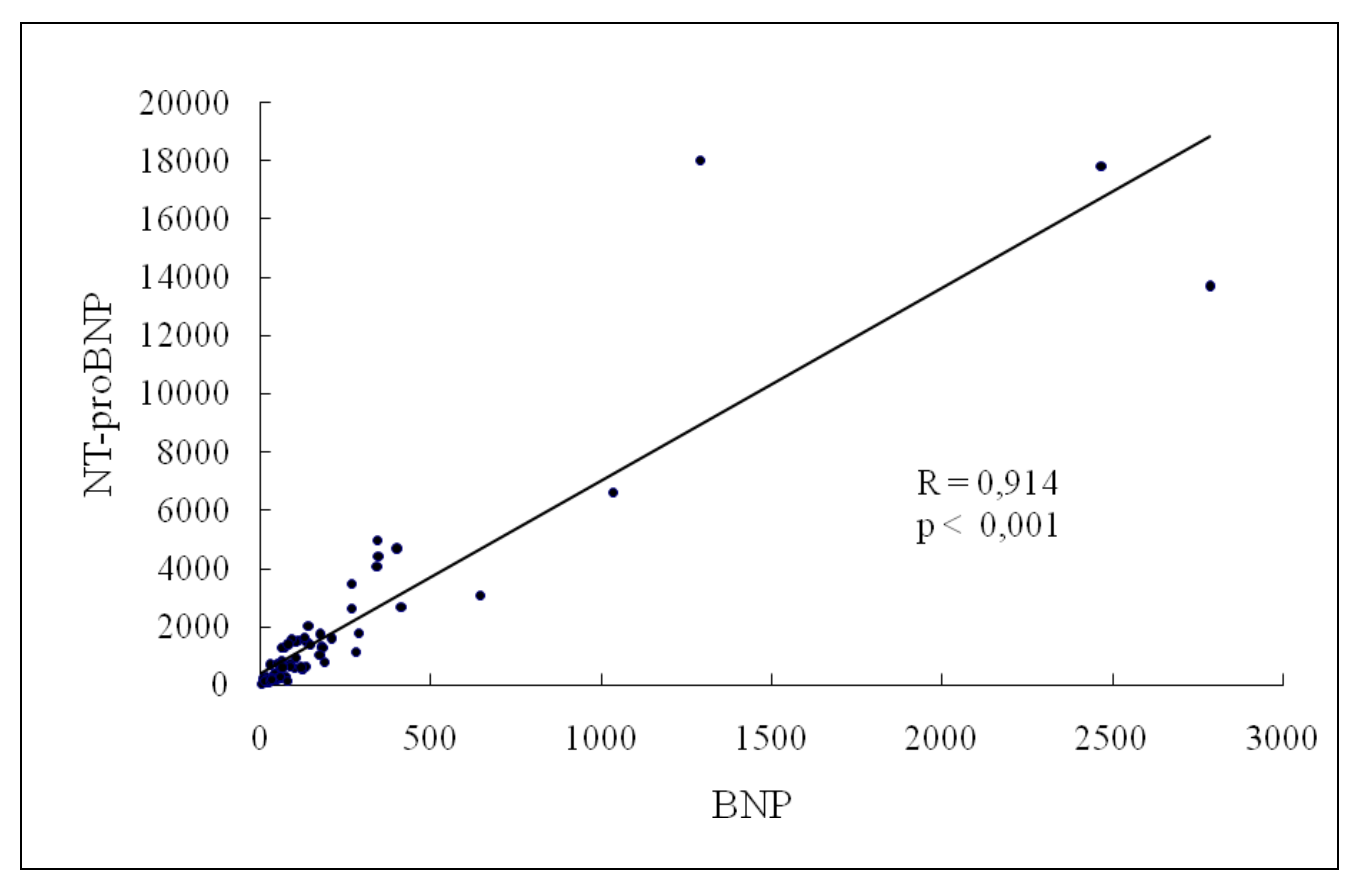

Figura 18. Correlação entre os níveis de BNP e NT-proBNP

Através de uma curva ROC, fizemos a comparação da capacidade do BNP vs. NT-proBNP em predizer óbito na população total de nosso estudo. Como observado, tanto o BNP como o NT-proBNP foram preditores independentes de mortalidade, mas houve pequena vantagem do NT-proBNP em relação ao BNP (área abaixo da curva 0,83 e 0,80 respectivamente, Figura 19). 


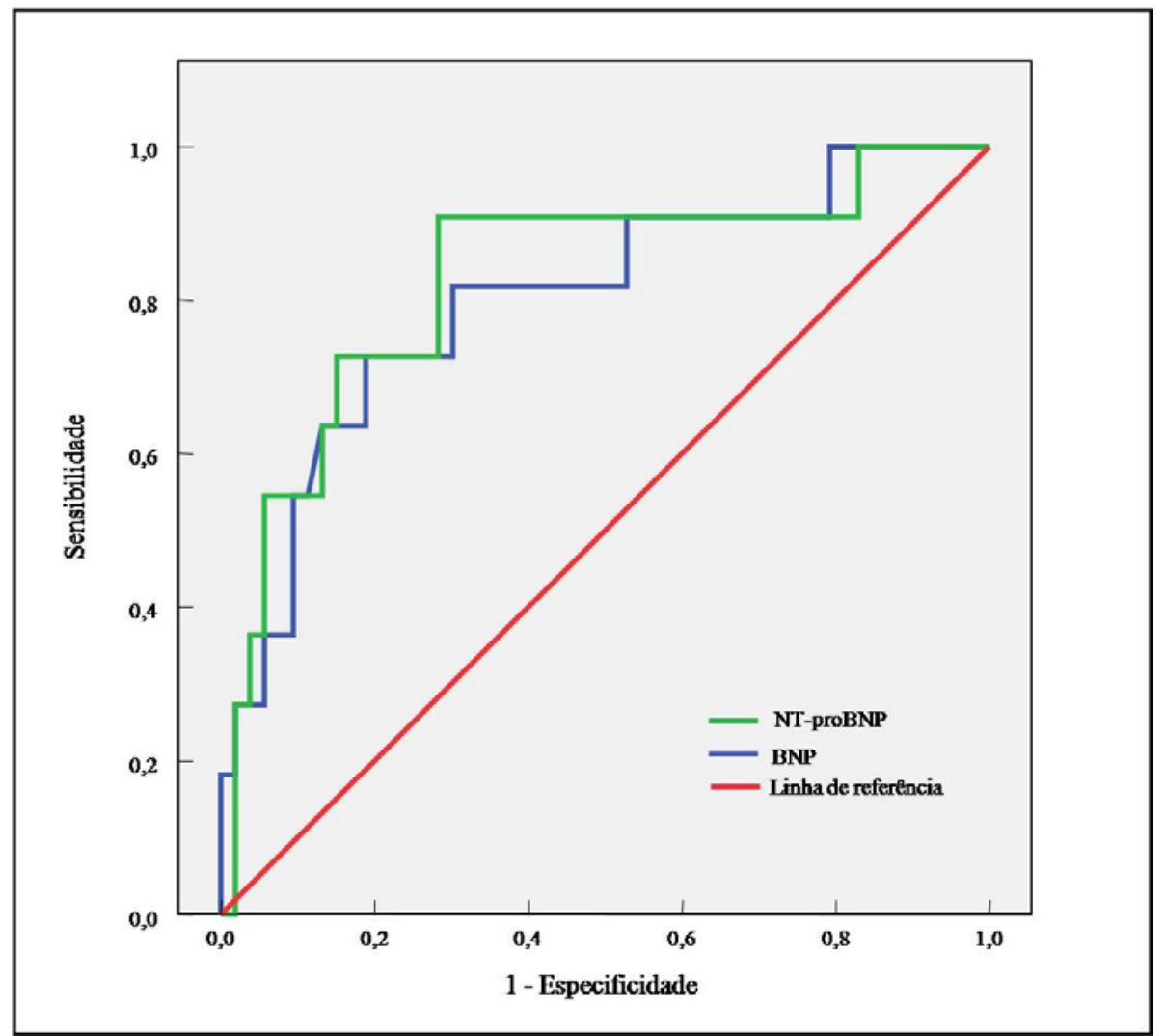

Figura 19. Curva ROC de BNP vs. NT-proBNP como preditores de mortalidade 


\section{DISCUSSÃO}

Nosso estudo avaliou pacientes com estenose aórtica, doença valvar cuja prevalência tende a aumentar. Selecionamos pacientes com EAo grave, pertencentes ao ambulatório de valvopatias do InCor, hospital de alta complexidade, parte integrante do complexo Hospital das Clínicas da Faculdade de Medicina da Universidade de São Paulo.

Analisamos os níveis dos peptídeos natriuréticos BNP e NT-proBNP neste grupo de pacientes, e acompanhamos os pacientes prospectivamente, permitindo análises de prognóstico relacionadas a esses marcadores. Pudemos ainda comparar os níveis dos peptídeos entre assintomáticos e sintomáticos em uma fase pré-operatória, assim como avaliar o comportamento dos peptídeos na fase pós-operatória.

\subsection{Valores considerados "normais" para o BNP e NT-proBNP}

A definição de valores normais para o BNP e NT-proBNP é uma questão relativa. Sabe-se que, idade e sexo influenciam os níveis dos peptídeos. A função renal também exerce influência, assim como a composição corporal. Em obesos, com índice de massa corpórea superior a $30 \mathrm{~kg} / \mathrm{m}^{2}$, os níveis de BNP e NT-proBNP são menores quando comparados a não obesos ${ }^{71 ; 72}$.

Por outro lado, valores de corte dependem da situação clínica em questão. E mesmo tomando-se como base um determinado contexto clínico, pode haver dúvida em relação aos níveis dos $\mathrm{PN}$ considerados seguros para se fazer um diagnóstico. Exemplos desta afirmativa são os estudos de Maisel et $\mathrm{al}^{32}$ e Januzzi et $\mathrm{al}^{34}$, que 
estudaram respectivamente o BNP e o NT-proBNP na sala de emergência. Suas observações levaram à constatação da chamada zona cinza ou zona de penumbra, que para o BNP é definida como valores entre $100 \mathrm{pg} / \mathrm{mL}$ e $500 \mathrm{pg} / \mathrm{mL}$ e para o NTproBNP de $300 \mathrm{pg} / \mathrm{mL}$ até $900 \mathrm{pg} / \mathrm{mL}^{73 ; 74}$. Valores acima do limite superior confirmam o diagnóstico de insuficiência cardíaca congestiva descompensada, enquanto valores abaixo do limite inferior afastam essa possibilidade. Mas os valores intermediários não permitem diagnóstico de certeza, caem na faixa da zona de penumbra $^{27}$.

Outro aspecto que deve ser considerado na definição de referências é o fato de existir diversos kits disponíveis para dosagem de BNP e NT-proBNP. Cada kit, de acordo com seu fabricante, tem uma metodologia específica, com características próprias, e consequentes valores de normalidade particulares. Por esses motivos, os valores considerados normais podem variar ${ }^{27}$.

De um modo geral, levando-se em conta os diferentes ensaios de diferentes fabricantes, um adulto jovem, saudável, deverá ter como valor sérico um BNP menor do que $25 \mathrm{pg} / \mathrm{mL}$ e um NT-proBNP menor do que $70 \mathrm{pg} / \mathrm{mL}^{27 ; 75}$.

No caso específico de nosso estudo, realizamos a dosagem do BNP e do NTproBNP utilizando respectivamente os ensaios ADVIA CENTAUR BNP marca Bayer HealthCare LLC e Elecsys proBNP da marca Roche Diagnostics GmbH .Os resultados aqui obtidos devem ser considerados no contexto específico destes ensaios utilizados $^{76}$.

As recomendações quanto aos valores de referência para o BNP e NTproBNP, de acordo com os fabricantes Bayer HealthCare LLC e Roche Diagnostics GmbH estão apresentadas nas Tabelas 2 e 3. Para se estabelecer a referência na 
população geral, o BNP foi determinado em 1521 indivíduos saudáveis e o NTproBNP foi determinado em 2264 indivíduos saudáveis. Considerando os resultados, o valor que poderia ser considerado normal para o BNP seria de $23,2 \mathrm{pg} / \mathrm{mL}$ e de NT-proBNP 50,3 pg/mL (médias das populações de referência) ou 14,4 pg/mL para o BNP e 27,9 pg/mL para o NT-proBNP (medianas das populações de referência) ${ }^{61 ; 62}$

\subsection{BNP e NT-proBNP para avaliação de status funcional}

As principais questões que podem ser levantadas neste tópico são:

- $\mathrm{O}$ BNP e o NT-proBNP permitem diferenciar pacientes com EAo grave sintomáticos de assintomáticos?

- O BNP e o NT-proBNP se correlacionam com a classe funcional do paciente com EAo grave?

Em nosso estudo, não encontramos diferença significativa dos níveis de BNP e NT-proBNP em pacientes assintomáticos quando comparados aos sintomáticos. Vale ressaltar que tanto os pacientes assintomáticos como os sintomáticos apresentavam EAo verdadeiramente grave. Quando estratificamos os resultados por sexo e idade, também não encontramos diferenças entre sintomáticos e assintomáticos. A estratificação é importante porque diversos estudos mostram que os níveis de BNP e NT-proBNP estão relacionados ao sexo, sendo maiores em mulheres, e à idade, sendo maiores com o aumento da idade. Recentemente surgiram evidências de que os andrógenos, particularmente a testosterona, suprima parcialmente a secreção de BNP e NT-proBNP, justificando o menor nível dos PN em homens ${ }^{77}$. No caso da idade, o aumento dos peptídeos em pacientes idosos pode 
refletir alterações estruturais e funcionais pré-clínicas do miocárdio, não detectáveis em exames diagnósticos ${ }^{17 ; 78}$.

Embora não tenhamos demonstrado diferença significativa entre assintomáticos e sintomáticos, observamos que houve diferença dos níveis dos peptídeos em relação à classe funcional, a partir da CF II. Além disso, em nosso estudo, o BNP e o NT-proBNP foram marcadores de classe funcional III e IV (NYHA) na inclusão dos pacientes. Através da construção de curvas ROC, obtivemos o ponto de corte de $105 \mathrm{pg} / \mathrm{mL}$ para o BNP e $1500 \mathrm{pg} / \mathrm{mL}$ para o NTproBNP. Esses pontos de corte levaram em consideração sensibilidade e especificidade otimizadas. Valores de BNP e NT-proBNP acima deste corte foram capazes de marcar classe funcional avançada.

A informação de que os peptídeos BNP e NT-proBNP predizem classe funcional avançada em estenose aórtica grave é de extrema relevância clínica. Sabese que muitos pacientes com EAo grave são idosos (em nosso estudo $79 \%$ dos pacientes eram idosos), incapazes de deambular efetivamente, quer seja por uma impossibilidade osteoarticular, quer seja por outra comorbidade associada. Nestes casos a avaliação do status funcional fica prejudicada. Mesmo o teste de esforço, que pode agregar informações funcionais no paciente assintomático, na prática é pouco realizado, fato corroborado por Lung et $\mathrm{al}^{42}$, que descreve a baixa taxa de realização do teste de esforço para avaliação de pacientes com EAo. Neste contexto, o BNP e o NT-proBNP poderiam ser utilizados como ferramentas auxiliares na elucidação do status funcional dos pacientes, particularmente nos pacientes em classe funcional avançada. 
Bergler-Klein et $\mathrm{al}^{49}$, avaliando 130 pacientes com EAo grave, à semelhança de nossos resultados, também não encontraram diferença significativa para os níveis de BNP e NT-proBNP entre assintomáticos e sintomáticos. Porém, mostraram correlação significativa entre os níveis dos PN e classe funcional a partir da classe II (NYHA).

Dois estudos anteriores, diferentemente de nossos achados, concluíram que os peptídeos poderiam diferenciar pacientes com EAo grave sintomáticos de assintomáticos, entretanto ambos com algumas ressalvas. Gerber et $\mathrm{al}^{48}$, avaliando o papel do BNP e do NT-proBNP em pacientes com EAo, encontraram diferença significativa nos níveis dos peptídeos entre assintomáticos e sintomáticos, sugerindo que esses peptídeos seriam capazes de marcar o início dos sintomas em pacientes com EAo grave. Também demonstraram correlação entre os níveis dos peptídeos e o incremento de classe funcional (NYHA). A crítica a este trabalho reside no critério de inclusão definido pelos autores: velocidade de fluxo transvalvar aórtico no pico da sístole maior que $2,5 \mathrm{~m} / \mathrm{s}$. Sabe-se que estenose aórtica leve é definida como velocidade de fluxo transvalvar aórtico menor que $3 \mathrm{~m} / \mathrm{s}$. O critério adotado por Gerber et al, portanto, foi pouco rígido no que diz respeito à gravidade da EAo, e permitiu que pacientes com EAo leve, moderada e grave fossem incluídos, o que não combinou com o objetivo dos autores, que era de avaliar somente pacientes com EAo grave. Neste caso, possivelmente a presença de EAo leve e moderada entre os assintomáticos influenciou os resultados menores dos peptídeos neste grupo.

Lim et $\mathrm{al}^{57}$, estudando o BNP em uma população de pacientes com EAo grave, também encontraram diferença em relação aos níveis de BNP em pacientes assintomáticos, quando comparados aos sintomáticos, mas os pacientes 
assintomáticos apresentavam área valvar aórtica significativamente maior do que os sintomáticos e além disso, foi utilizado um radioimunoensaio para dosagem do BNP, e esta metodologia está associada a níveis menores de BNP quando comparada à tecnologia convencional de imunofluorescência. Neste estudo o NT-proBNP não foi avaliado.

Desta, forma, baseados em nossos resultados, apoiados pelo estudo de Bergler-Klein et al e levando em consideração as ressalvas em relação aos estudos de Gerber et al e Lim et al, entendemos que o BNP e o NT-proBNP não auxiliam na diferenciação de pacientes com EAo grave sintomáticos e assintomáticos. Por outro lado, permitem a identificação de pacientes em classe funcional mais avançada, com valor de corte estabelecido em nosso estudo.

\subsection{BNP e NT-proBNP como marcadores prognósticos de sobrevida}

A utilidade prognóstica dos peptídeos natriuréticos BNP e NT-proBNP é objeto mais recente de avaliação em literatura médica. Em diversas situações clínicas foram testados como ferramentas prognósticas, preditores de eventos cardiovasculares. Alguns exemplos de estudos prognósticos envolvendo os peptídeos podem ser visualizados no Quadro 8. 


\section{Quadro 8 - Exemplos de estudos envolvendo PN e prognóstico}

\begin{tabular}{|c|c|c|c|}
\hline Contexto clínico & $\begin{array}{l}\text { Valor de corte do } \\
\text { BNP e NT-proBNP }\end{array}$ & Desfecho & $\begin{array}{c}\text { Tempo de } \\
\text { seguimento }\end{array}$ \\
\hline $\begin{array}{c}\text { Insuficiência cardíaca } \\
\text { congestiva }^{79}\end{array}$ & $\mathrm{BNP}<200 \mathrm{pg} / \mathrm{mL}$ & $\begin{array}{l}\text { Desfecho } \\
\text { combinado } \\
\text { (mortalidade) }\end{array}$ & 90 dias \\
\hline $\begin{array}{c}\text { Insuficiência cardíaca } \\
\text { congestiva }^{80}\end{array}$ & $\begin{array}{c}\text { NT-proBNP }=1767 \\
\text { pg/mL }\end{array}$ & Mortalidade & 29 meses \\
\hline Insuficiência coronariana ${ }^{81}$ & $\mathrm{BNP}>80 \mathrm{pg} / \mathrm{mL}$ & Mortalidade & 10 meses \\
\hline Insuficiência coronariana $^{82}$ & $\mathrm{BNP}>100 \mathrm{pg} / \mathrm{mL}$ & Mortalidade & 2,5 anos \\
\hline Embolia pulmonar ${ }^{28}$ & $\mathrm{BNP}>90 \mathrm{pg} / \mathrm{mL}$ & $\begin{array}{c}\text { Eventos cardíacos } \\
\text { adversos }\end{array}$ & Durante internação \\
\hline Embolia pulmonar $^{83}$ & $\begin{array}{c}\text { NT-proBNP }>500 \\
\mathrm{pg} / \mathrm{mL}\end{array}$ & Eventos adversos & Durante internação \\
\hline
\end{tabular}

Fonte: Daniels LB, Maisel AS. Natriuretic peptides. J Am Coll Cardiol 2007 Dec 18;50(25):2357-68.

Particularmente em modelos de disfunção diastólica, dois estudos recentes ratificam a função prognóstica dos peptídeos. Em estudo conduzido por Grewal et $\mathrm{al}^{84}$, o BNP e o NT-proBNP foram testados como marcadores prognósticos em uma população de pacientes com função sistólica ventricular preservada e disfunção diastólica evidente. Através de análise multivariada, valores de BNP acima de 100 $\mathrm{pg} / \mathrm{mL}$ e NT-proBNP acima de $600 \mathrm{pg} / \mathrm{mL}$ foram preditores independentes de eventos cardiovasculares adversos, definidos no estudo como morte cardiovascular, internação por insuficiência cardíaca descompensada ou infarto agudo do miocárdio. Em um segundo estudo, envolvendo pacientes com hipertrofia ventricular esquerda e 
função sistólica ventricular normal o NT-proBNP também foi marcador prognóstico de sobrevida ${ }^{85}$.

Em nosso estudo, um dos destaques foi o tempo de seguimento dos pacientes. Com um tempo de seguimento próximo aos quatro anos, nosso trabalho passa a ser o de maior seguimento quando se considera o estudo conjunto do BNP e NT-proBNP em pacientes com EAo grave, permitindo a observação de eventos cardiovasculares (óbitos cardiovasculares) e, portanto delineando o papel dos peptídeos como marcadores prognósticos.

Analisamos óbito cardiovascular, e o nível de corte estabelecido para o BNP foi de $105 \mathrm{pg} / \mathrm{mL}$. Valores acima deste corte associaram-se ao aumento do risco de óbito em 6,3 vezes nos pacientes com EAo grave, de forma independente. Em relação ao NT-proBNP, estabelecemos o valor de corte em $1500 \mathrm{pg} / \mathrm{mL}$ e valores acima deste corte associaram-se ao aumento do risco de óbito em 6,52 vezes, também de forma independente. Quando separamos os pacientes em tercis relacionados aos níveis de BNP e NT-proBNP verificamos que os pacientes no maior tercil apresentavam risco maior de mortalidade. Portanto nossos resultados são importantes e de extrema relevância clínica porque garantem ao BNP e ao NTproBNP o papel de marcadores prognósticos de sobrevida nesta população. Apenas para efeito ilustrativo, dois pacientes sintomáticos que recusaram cirurgia e permaneceram vivos ao final do acompanhamento apresentavam respectivamente os valores de BNP 42 pg/mL e 79 pg/mL e NT-proBNP 393 pg/mL e 156,6 pg/mL.

Anteriormente, Lim et al $^{57}$ procurou determinar o papel prognóstico do BNP no seguimento de pacientes com EAo grave. O tempo de seguimento médio foi de 308 dias e após análise multivariada, o BNP associou-se de forma independente a 
mortalidade. Uma curva de sobrevida foi construída e um valor de corte de $97 \mathrm{pg} / \mathrm{mL}$ foi utilizado para discriminar maior risco ou menor risco de morte durante o acompanhamento. No estudo, o NT-proBNP não foi avaliado, e o tempo de seguimento foi mais curto, chamando a atenção, entretanto, o valor de corte estabelecido para o BNP, extremamente próximo ao obtido em nossos resultados.

Bergler-Klein et $\mathrm{al}^{49}$ também já haviam estudado o BNP e o NT-proBNP como marcadores prognósticos em EAo, entretanto o foco era na análise da sobrevida livre de sintomas em assintomáticos e na evolução pós operatória de sintomáticos. O tempo de seguimento foi relativamente curto e a análise de sobrevida na população como um todo não foi realizada. Entre os assintomáticos, o valor de BNP menor que $130 \mathrm{pg} / \mathrm{mL}$ e de NT-proBNP menor que $80 \mathrm{pmol} / \mathrm{L}(678 \mathrm{pg} / \mathrm{mL})$ foram preditores de sobrevida livre de sintomas por um períodos de 6 a 9 meses. Em relação aos sintomáticos, somente o NT-proBNP foi preditor independente de sobrevida no período pós-operatório.

Mais recentemente, Pedrazzini et $\mathrm{al}^{86}$ compararam a capacidade do BNP versus o EuroSCORE em determinar informações prognósticas de pacientes com estenose aórtica submetidos à troca valvar, em um acompanhamento de três anos. Neste estudo o NT-proBNP não foi avaliado. Este estudo mostrou que o BNP no préoperatório, assim como o EuroSCORE, forneceram dados prognósticos dos pacientes em relação à mortalidade hospitalar e tardia. $\mathrm{O}$ valor de corte encontrado para o BNP, que discriminou sobrevida foi de $312 \mathrm{pg} / \mathrm{mL}$.

Os valores de corte estabelecidos para o BNP e para o NT-proBNP em nossa casuística tiveram significância estatística na população como um todo e também no 
subgrupo de sintomáticos. A subanálise de assintomáticos não foi possível pela baixa incidência de óbitos neste subgrupo.

De forma inédita, analisamos BNP e NT-proBNP conjuntamente, por um tempo de seguimento mais prolongado. Ressaltamos que os valores de corte estabelecidos em nosso estudo são consistentes com a literatura, em outros contextos clínicos, como resumidos no Quadro 8, mas também com estudos envolvendo pacientes com disfunção diastólica e até estenose aórtica, validando nossos resultados e garantindo aos peptídeos grande utilidade na estratificação de risco dos pacientes com estenose aórtica grave.

\subsection{BNP e NT-proBNP e parâmetros ecocardiográficos}

Em nosso trabalho observamos correlação positiva significativa entre índice de massa ventricular esquerda e nível sérico de BNP. Resultado semelhante pôde ser observado por Qi et $\mathrm{al}^{46}$, Neverdal et $\mathrm{al}^{55}$, e Gerber et $\mathrm{al}^{48}$. Também o NT-proBNP correlacionou-se ao índice de massa ventricular esquerda, semelhante ao encontrado por Qi et $\mathrm{al}^{46}$, Gerber et $\mathrm{al}^{48}$ e Kupari et $\mathrm{al}^{54}$

A hipertrofia ventricular esquerda, que ocorre em resposta à sobrecarga pressórica imposta pela EAo, está associada à maior expressão de genes responsáveis pela geração dos peptídeos natriuréticos, incluindo o $\mathrm{BNP}^{87 ; 88}$. Por outro lado, conforme demonstrado em um estudo em ratos, a hipertrofia ventricular associa-se a uma diminuição da densidade de RPN tipo C no coração ${ }^{89}$. Este receptor tem como função a depuração dos PN, entre eles o BNP. Assim, a maior expressão gênica e a 
menor depuração, explicariam a correlação dos níveis de BNP com massa ventricular esquerda.

De forma interessante, quando realizamos a análise de níveis de BNP e NTproBNP em relação à massa ventricular, mas separado por grupos, sintomáticos e assintomáticos, observamos que esta correlação restringiu-se aos sintomáticos. Esse comportamento não pode ser explicado pelo grau de hipertrofia ventricular, uma vez que o índice de massa ventricular esquerda é semelhante entre assintomáticos e sintomáticos. Também não pode ser discutido à luz de outros estudos, já que não há análise por subgrupo descrita.

Não observamos correlação entre gradiente transvalvar áortico e nível sérico de BNP, o mesmo ocorrendo em relação ao NT-proBNP. Somente na análise de subgrupo, no grupo assintomático, houve correlação significativa entre NT-proBNP e gradiente médio transvalvar aórtico.

A correlação entre nível sérico de BNP e NT-proBNP e gradiente transvalvar aórtico é conflitante na literatura. Ao observarmos os nosso resultados, uma das hipóteses que o justificariam, seria o fato de nossa população ser muito homogênea no que se refere à gravidade da EAo. Embora nosso critério de inclusão fosse gradiente transvalvar áortico médio igual ou superior a $40 \mathrm{mmHg}$, o grupo como um todo apresentava este gradiente em torno de $62 \mathrm{mmHg}$. Essa homogeneidade dos pacientes fez com que não tivéssemos uma dispersão de valores encontrados para gradiente transvalvar aórtico pico e médio, possivelmente explicando a ausência da correlação. Um outro dado importante é que o gradiente transvalvar aórtico simplesmente reflete a gravidade da EAo e, per si, não é responsável pela liberação de BNP e NT-proBNP. 
Houve correlação negativa significativa entre fração de ejeção de ventrículo esquerdo e nível sérico de BNP, assim como com o NT-proBNP. Quando analisamos por grupos, observamos que esta correlação se restringiu aos sintomáticos. A disfunção sistólica esta associada com o aumento do BNP e do NT-proBNP. No caso dos assintomáticos, a ausência de correlação pode ser explicada pelo fato de que todos os pacientes neste grupo tinham função sistólica ventricular esquerda normal.

\subsection{BNP e NT-proBNP no período pós-operatório}

Em nosso estudo houve queda significativa dos níveis de BNP e NT-proBNP quando comparamos pré e pós-operatório. Resultado semelhante foi observado por Neverdal et $\mathrm{al}^{55} \mathrm{e}$ Weber et $\mathrm{al}^{51}$. Após a cirurgia, há redução da resistência ao fluxo sanguíneo, outrora imposta pela estenose aórtica. O ventrículo esquerdo, com o passar do tempo sofre um processo de remodelação reversa, em que há principalmente redução da hipertrofia ventricular esquerda. A diminuição da massa ventricular, assim como a queda da tensão diastólica da parede do ventrículo são os fatores que influenciam a queda dos peptídeos. Mesmo menores, o BNP e o NTproBNP não atingem a normalidade, quando comparamos aos valores normais apresentados pelos fabricantes dos kits ${ }^{61 ; 62}$. Esse comportamento do BNP e do NTproBNP pode ser explicado pelo fato de que mesmo havendo queda na resistência ao fluxo sanguíneo na via de saída do ventrículo esquerdo, a presença de prótese valvar gera gradiente de pressão, que embora em menor monta, reflete-se na remodelação reversa ventricular parcial e não total. 


\subsection{Evolução ecocardiográfica dos pacientes}

Os pacientes realizaram ECO no início e ao final do acompanhamento. Para efeito de análise, comparamos os pacientes, dividindo-os em dois grupos, operados e não operados. Sabemos que o ECO tem papel fundamental na EAo ${ }^{9}$. Permite o diagnóstico e estratificação de gravidade, auxiliando na decisão terapêutica. A EAo gera resistência à passagem do fluxo sanguíneo na via de saída do ventrículo esquerdo. A resposta adaptativa do miocárdio pode ser melhor observada na hipertrofia ventricular, traduzida pelo índice de massa ventricular esquerdo. Quando analisamos os pacientes operados, percebemos claramente que há redução da massa ventricular ao longo das avaliações. Esse achado é concordante Weber et $\mathrm{al}^{51}$. A redução de massa ventricular no pós-operatório reflete o processo de remodelação reversa que ocorre nesta fase. Também há redução significativa do gradiente transvalvar aórtico, máximo e médio, fenômeno que não surpreende, já que a proposta de troca valvar aórtica é justamente corrigir a resistência oferecida pela valva doente. Com a troca valvar, ocorre redução dos gradientes, mas não eliminação total, já que a presença de prótese valvar, seja ela biológica ou metálica, oferece grau de resistência superior à valva nativa saudável.

Ainda entre os pacientes operados, não há modificação significativa na fração de ejeção do ventrículo esquerdo e no tamanho do átrio esquerdo. Este fato pode ser explicado pela observação de que no pré-operatório os pacientes já apresentavam função ventricular preservada e átrio esquerdo no limite superior da normalidade.

Em relação aos pacientes não operados, não há mudança significativa nos parâmetros ecocardiográficos ao longo das avaliações. Isto se explica pelo fato dos pacientes apresentarem gradiente transvalvar aórtico elevado desde o início do 
acompanhamento, assim como hipetrofia ventricular evidente. Embora haja tendência de aumento de índice de massa ventricular, não há significância estatística.

\section{7 BNP vs. NT-proBNP}

Em nosso estudo optamos por avaliar o BNP e NT-proBNP. A intenção era adquirir experiência na utilização dessas duas ferramentas e também compará-las. O NT-proBNP, por um lado, sofre influência da função renal, já que este é seu principal mecanismo de depuração. Estudos mais recentes indicam que esta influência da função renal não seria tão evidente em disfunções renais leves ${ }^{90 ; 91}$. Outro fator relevante diz respeito à meia-vida mais longa do NT-proBNP em comparação ao BNP além da maior estabilidade in vitro, portanto, a partir da coleta de sangue do paciente, o NT-proBNP tende a ser mais estável ${ }^{90}$.

No que se refere à aplicação clínica do BNP e NT-proBNP,a literatura é conflitante em relação às vantagens e desvantagens de cada um dos peptídeos nas mais diversas situações clínicas. Por sua menor meia-vida, o BNP tenderia a ser mais efetivo como marcador de mudanças abruptas do status hemodinâmico dos pacientes, enquanto que o NT-proBNP, por sua meia-vida mais longa, seria melhor marcador de disfunção ventricular sistólica e diastólica incipientes ${ }^{90}$. Importante frisar que não há fórmula ou maneira de se converter um resultado obtido para o BNP em um correspondente NT-proBNP e vice-versa.

Para o nosso protocolo, tomamos o cuidado de assumir como critério de exclusão pacientes com insuficiência renal. Também houve rigor sob o ponto de vista laboratorial de tal forma que o critério estabilidade pouco influenciasse nos 
resultados. O que verificamos, desta forma, foi uma correlação muito forte entre os níveis séricos de BNP e NT-proBNP. Tanto um como o outro foram capazes de marcar pacientes em classe funcional avançada e também predizer mortalidade, sendo que o NT-proBNP apresentou vantagem discreta em relação ao BNP como preditor de mortalidade.

\subsection{Limitações do estudo}

Apesar do número total de pacientes incluídos ter sido suficiente para se atribuir aos peptídeos natriuréticos valor prognóstico na população como um todo, o número de pacientes assintomáticos, pela baixa incidência de óbitos neste subgrupo não permitiu análise neste subgrupo.

Não realizamos teste ergométrico para avaliação funcional dos pacientes assintomáticos, mas este fato traduziu a prática clínica, em que o teste é pouco realizado para este fim, conforme relato de Lung et al no estudo Euro Heart Survey on Valvular Heart Diseases ${ }^{42}$.

\subsection{Considerações finais}

Os estudos que envolvem BNP e NT-proBNP em estenose aórtica são conflitantes em relação à capacidade desses marcadores diferenciarem sintomáticos de assintomáticos. Também em relação aos parâmetros ecocardiográficos, embora haja maior consenso da correlação dos peptídeos com massa ventricular e função 
ventricular, a heterogeneidade das populações estudadas gera dúvidas acerca de como interpretar essas correlações.

Os peptídeos têm maior aplicabilidade na identificação de pacientes em classe funcional mais avançada e principalmente na determinação prognóstica de sobrevida. Acreditamos que o BNP ou o NT-proBNP devam ser dosados em todos os pacientes com EAo grave. A decisão terapêutica caberá ao médico, que se baseará no que já está consagrado, anamnese, exame físico e complementação ecocardiográfica. Naqueles pacientes em que se tem dúvida acerca de seu real estado funcional, o BNP e o NT-proBNP podem acrescentar informações já que, como demonstrado em nosso estudo, são capazes de identificar pacientes em classe funcional avançada. Além disso, fornecem informações adicionais prognósticas de sobrevida, refinando a estratificação de risco deste grupo de pacientes. 


\section{CONCLUSÕES}

- Os peptídeos natriuréticos BNP e NT-proBNP foram preditores independentes de mortalidade no acompanhamento prospectivo de pacientes com estenose aórtica grave.

- Os níveis séricos de BNP e o NT-proBNP não permitiram diferenciar pacientes sintomáticos de assintomáticos.

- O BNP e o NT-proBNP foram marcadores de classe funcional III e IV (NYHA) em pacientes com estenose aórtica grave.

- Os níveis séricos de BNP e NT-proBNP diminuíram significativamente no momento pós-operatório, quando comparado ao pré-operatório. 


\section{REFERÊNCIAS BIBLIOGRÁFICAS}

1. Instituto Brasileiro de Geografia e Estatística (IBGE). 2008. Disponível em http://www.ibge.gov.br/home/estatistica/populacao/projecao_da_populacao/p iramide/piramide.shtm.

2. Lindroos M, Kupari M, Heikkila J, Tilvis R. Prevalence of aortic valve abnormalities in the elderly: an echocardiographic study of a random population sample. J Am Coll Cardiol. 1993;21(5):1220-5.

3. Passik CS, Ackermann DM, Pluth JR, Edwards WD. Temporal changes in the causes of aortic stenosis: a surgical pathologic study of 646 cases. Mayo Clin Proc. 1987;62(2):119-23.

4. Soler-Soler J, Galve E. Worldwide perspective of valve disease. Heart. 2000;83(6):721-5.

5. Gould KL, Carabello BA. Why angina in aortic stenosis with normal coronary arteriograms? Circulation. 2003;107(25):3121-3.

6. Pellikka PA, Sarano ME, Nishimura RA, Malouf JF, Bailey KR, Scott CG, et al. Outcome of 622 adults with asymptomatic, hemodynamically significant aortic stenosis during prolonged follow-up. Circulation. 2005;111(24):32905.

7. Carabello BA. Evaluation and management of patients with aortic stenosis. Circulation. 2002;105(15):1746-50. 
8. Ross J, Jr., Braunwald E. Aortic stenosis. Circulation. 1968;38(1 Suppl):617.

9. Bonow RO, Carabello BA, Kanu C, de LA, Jr., Faxon DP, Freed MD, et al. ACC/AHA 2006 guidelines for the management of patients with valvular heart disease: a report of the American College of Cardiology/American Heart Association Task Force on Practice Guidelines (writing committee to revise the 1998 Guidelines for the Management of Patients With Valvular Heart Disease): developed in collaboration with the Society of Cardiovascular Anesthesiologists: endorsed by the Society for Cardiovascular Angiography and Interventions and the Society of Thoracic Surgeons. Circulation. 2006;114(5):e84-231.

10. de Bold AJ, Borenstein HB, Veress AT, Sonnenberg H. A rapid and potent natriuretic response to intravenous injection of atrial myocardial extract in rats. Life Sci. 1981;28(1):89-94.

11. Levin ER, Gardner DG, Samson WK. Natriuretic peptides. $N$ Engl J Med. 1998;339(5):321-8.

12. Woodard GE, Rosado JA. Recent advances in natriuretic peptide research. $J$ Cell Mol Med. 2007;11(6):1263-71.

13. Martinez-Rumayor A, Richards AM, Burnett JC, Januzzi JL, Jr. Biology of the natriuretic peptides. Am J Cardiol. 2008;101(3A):3-8.

14. Patel JB, Valencik ML, Pritchett AM, Burnett JC, Jr., McDonald JA, Redfield MM. Cardiac-specific attenuation of natriuretic peptide A receptor 
activity accentuates adverse cardiac remodeling and mortality in response to pressure overload. Am J Physiol Heart Circ Physiol. 2005;289(2):H777H784.

15. Sudoh T, Minamino N, Kangawa K, Matsuo H. Brain natriuretic peptide-32: N-terminal six amino acid extended form of brain natriuretic peptide identified in porcine brain. Biochem Biophys Res Commun. 1988;155(2):72632.

16. Sudoh T, Kangawa K, Minamino N, Matsuo H. A new natriuretic peptide in porcine brain. Nature. 1988;332(6159):78-81.

17. Weber M, Hamm C. Role of B-type natriuretic peptide (BNP) and NTproBNP in clinical routine. Heart. 2006;92(6):843-9.

18. Mukoyama M, Nakao K, Saito Y, Ogawa Y, Hosoda K, Suga S, et al. Human brain natriuretic peptide, a novel cardiac hormone. Lancet. 1990;335(8692):801-2.

19. Mukoyama M, Nakao K, Hosoda K, Suga S, Saito Y, Ogawa Y, et al. Brain natriuretic peptide as a novel cardiac hormone in humans. Evidence for an exquisite dual natriuretic peptide system, atrial natriuretic peptide and brain natriuretic peptide. J Clin Invest. 1991;87(4):1402-12.

20. LaPointe MC, Wu G, Garami M, Yang XP, Gardner DG. Tissue-specific expression of the human brain natriuretic peptide gene in cardiac myocytes. Hypertension. 1996;27(3 Pt 2):715-22. 
21. Tamura N, Ogawa Y, Yasoda A, Itoh H, Saito Y, Nakao K. Two cardiac natriuretic peptide genes (atrial natriuretic peptide and brain natriuretic peptide) are organized in tandem in the mouse and human genomes. $J$ Mol Cell Cardiol. 1996;28(8):1811-5.

22. Vanderheyden M, Bartunek J, Goethals M. Brain and other natriuretic peptides: molecular aspects. Eur J Heart Fail. 2004;6(3):261-8.

23. Watanabe S, Shite J, Takaoka H, Shinke T, Imuro Y, Ozawa T, et al. Myocardial stiffness is an important determinant of the plasma brain natriuretic peptide concentration in patients with both diastolic and systolic heart failure. Eur Heart J. 2006;27(7):832-8.

24. Wilkins MR, Redondo J, Brown LA. The natriuretic-peptide family. Lancet. 1997;349(9061):1307-10.

25. Richards AM, Crozier IG, Yandle TG, Espiner EA, Ikram H, Nicholls MG. Brain natriuretic factor: regional plasma concentrations and correlations with haemodynamic state in cardiac disease. Br Heart J. 1993;69(5):414-7.

26. Lainchbury JG, Nicholls MG, Espiner EA, Ikram H, Yandle TG, Richards AM. Regional plasma levels of cardiac peptides and their response to acute neutral endopeptidase inhibition in man. Clin Sci (London). 1998;95(5):54755.

27. Daniels LB, Maisel AS. Natriuretic peptides. $J$ Am Coll Cardiol. 2007;50(25):2357-68. 
28. Kucher N, Printzen G, Goldhaber SZ. Prognostic role of brain natriuretic peptide in acute pulmonary embolism. Circulation. 2003;107(20):2545-7.

29. Anand IS, Fisher LD, Chiang YT, Latini R, Masson S, Maggioni AP, et al. Changes in brain natriuretic peptide and norepinephrine over time and mortality and morbidity in the Valsartan Heart Failure Trial (Val-HeFT). Circulation. 2003;107(9):1278-83.

30. Cheng V, Kazanagra R, Garcia A, Lenert L, Krishnaswamy P, Gardetto N, et al. A rapid bedside test for B-type peptide predicts treatment outcomes in patients admitted for decompensated heart failure: a pilot study. J Am Coll Cardiol. 2001;37(2):386-91.

31. Troughton RW, Frampton CM, Yandle TG, Espiner EA, Nicholls MG, Richards AM. Treatment of heart failure guided by plasma aminoterminal brain natriuretic peptide (N-BNP) concentrations. Lancet. 2000;355(9210):1126-30.

32. Maisel AS, Krishnaswamy P, Nowak RM, McCord J, Hollander JE, Duc P, et al. Rapid measurement of B-type natriuretic peptide in the emergency diagnosis of heart failure. N Engl J Med. 2002;347(3):161-7.

33. Maisel A. B-type natriuretic peptide measurements in diagnosing congestive heart failure in the dyspneic emergency department patient. Rev Cardiovasc Med. 2002;3(Suppl 4):S10-S17. 
34. Januzzi JL, Jr., Camargo CA, Anwaruddin S, Baggish AL, Chen AA, Krauser DG, et al. The N-terminal Pro-BNP investigation of dyspnea in the emergency department (PRIDE) study. Am J Cardiol. 2005;95(8):948-54.

35. Vahanian A, Baumgartner H, Bax J, Butchart E, Dion R, Filippatos G, et al. Guidelines on the management of valvular heart disease: The Task Force on the Management of Valvular Heart Disease of the European Society of Cardiology. Eur Heart J. 2007;28(2):230-68.

36. Carabello BA. Timing of valve replacement in aortic stenosis. Moving closer to perfection. Circulation. 1997;95(9):2241-3.

37. Carabello BA. Clinical practice. Aortic stenosis. $N$ Engl J Med. 2002;346(9):677-82.

38. Hammermeister K, Sethi GK, Henderson WG, Grover FL, Oprian C, Rahimtoola SH. Outcomes 15 years after valve replacement with a mechanical versus a bioprosthetic valve: final report of the Veterans Affairs randomized trial. J Am Coll Cardiol. 2000;36(4):1152-8.

39. Amato MC, Moffa PJ, Werner KE, Ramires JA. Treatment decision in asymptomatic aortic valve stenosis: role of exercise testing. Heart. 2001;86(4):381-6.

40. Otto CM, Burwash IG, Legget ME, Munt BI, Fujioka M, Healy NL, et al. Prospective study of asymptomatic valvular aortic stenosis. Clinical, echocardiographic, and exercise predictors of outcome. Circulation. 1997;95(9):2262-70. 
41. Das P, Rimington H, Chambers J. Exercise testing to stratify risk in aortic stenosis. Eur Heart J. 2005;26(13):1309-13.

42. Lung B, Baron G, Butchart EG, et al. A prospective survey of patients with valvular heart disease in Europe: The Euro Heart Survey on Valvular Heart Disease. Eur Heart J. 2003;24:1231-43.

43. Van Pelt NC, Kerr AJ, Legget ME, Pasupati S, Whalley G, Wong S, et al. Increased B-type natriuretic peptide is associated with an abnormal blood pressure response to exercise in asymptomatic aortic stenosis. Int J Cardiol. 2008;127(3):313-20.

44. Ikeda T, Matsuda K, Itoh H, Shirakami G, Miyamoto Y, Yoshimasa T, et al. Plasma levels of brain and atrial natriuretic peptides elevate in proportion to left ventricular end-systolic wall stress in patients with aortic stenosis. Am Heart J. 1997;133(3):307-14.

45. Prasad N, Bridges AB, Lang CC, Clarkson PB, MacLeod C, Pringle TH, et al. Brain natriuretic peptide concentrations in patients with aortic stenosis. Am Heart J. 1997;133(4):477-9.

46. Qi W, Mathisen P, Kjekshus J, Simonsen S, Bjornerheim R, Endresen K, et al. Natriuretic peptides in patients with aortic stenosis. Am Heart J. 2001;142(4):725-32.

47. Talwar S, Downie PF, Squire IB, Davies JE, Barnett DB, Ng LL. Plasma Nterminal pro BNP and cardiotrophin-1 are elevated in aortic stenosis. Eur $J$ Heart Fail. 2001;3(1):15-9. 
48. Gerber IL, Stewart RA, Legget ME, West TM, French RL, Sutton TM, et al. Increased plasma natriuretic peptide levels reflect symptom onset in aortic stenosis. Circulation. 2003;107(14):1884-90.

49. Bergler-Klein J, Klaar U, Heger M, Rosenhek R, Mundigler G, Gabriel H, et al. Natriuretic peptides predict symptom-free survival and postoperative outcome in severe aortic stenosis. Circulation. 2004;109(19):2302-8.

50. Weber M, Arnold R, Rau M, Brandt R, Berkovitsch A, Mitrovic V, et al. Relation of N-terminal pro-B-type natriuretic peptide to severity of valvular aortic stenosis. Am J Cardiol. 2004;94(6):740-5.

51. Weber M, Arnold R, Rau M, Elsaesser A, Brandt R, Mitrovic V, et al. Relation of N-terminal pro B-type natriuretic peptide to progression of aortic valve disease. Eur Heart J. 2005;26(10):1023-30.

52. Nessmith MG, Fukuta H, Brucks S, Little WC. Usefulness of an elevated Btype natriuretic peptide in predicting survival in patients with aortic stenosis treated without surgery. Am J Cardiol. 2005;96(10):1445-8.

53. Gerber IL, Legget ME, West TM, Richards AM, Stewart RA. Usefulness of serial measurement of $\mathrm{N}$-terminal pro-brain natriuretic peptide plasma levels in asymptomatic patients with aortic stenosis to predict symptomatic deterioration. Am J Cardiol. 2005;95(7):898-901.

54. Kupari M, Turto H, Lommi J, Makijarvi M, Parikka H. Transcardiac gradients of $\mathrm{N}$-terminal B-type natriuretic peptide in aortic valve stenosis. Eur J Heart Fail. 2005;7(5):809-14. 
55. Neverdal NO, Knudsen CW, Husebye T, Vengen OA, Pepper J, Lie M, et al. The effect of aortic valve replacement on plasma B-type natriuretic peptide in patients with severe aortic stenosis--one year follow-up. Eur J Heart Fail. 2006;8(3):257-62.

56. Bergler-Klein J, Mundigler G, Pibarot P, Burwash IG, Dumesnil JG, Blais C, et al. B-type natriuretic peptide in low-flow, low-gradient aortic stenosis: relationship to hemodynamics and clinical outcome: results from the Multicenter Truly or Pseudo-Severe Aortic Stenosis (TOPAS) study. Circulation. 2007;115(22):2848-55.

57. Lim P, Monin JL, Monchi M, Garot J, Pasquet A, Hittinger L, et al. Predictors of outcome in patients with severe aortic stenosis and normal left ventricular function: role of B-type natriuretic peptide. Eur Heart J. 2004;25(22):2048-53.

58. World Health Organization. 2006. Disponível em: http://www.who.int/mediacentre/factsheets/fs311/en/.

59. The Criteria Committee of the New York Heart Association. Nomenclature and Criteria for Diagnosis of Diseases of the Heart and Great Vessels. In: Little Brown \& Co, editor. 9th ed. Boston: 1994. p. 253-6.

60. Goldman L, Hashimoto B, Cook EF, Loscalzo A. Comparative reproducibility and validity of systems for assessing cardiovascular functional class: advantages of a new specific activity scale. Circulation. $1981 ; 64(6): 1227-34$ 
61. Freire EMM. BNP: ADVIA CENTAUR BNP [bula de Kit para dosagem do BNP]. Tarrytown: Bayer HealthCare LLC/ Bayer Corp.; 2005-06.

62. Roche Diagnostics GmbH. NT-proBNP: Elecsys 1010/2010 e MODULAR ANALYTICS E 170 [bula de Kit para dosagem do NT-proBNP]. Mannheim: Roche Diagnostics GmbH; 2005-06.

63. Devereux RB, Alonso DR, Lutas EM, Gottlieb GJ, Campo E, Sachs I, et al. Echocardiographic assessment of left ventricular hypertrophy: comparison to necropsy findings. Am J Cardiol 1986 Feb 15;57(6):450-8.

64. Currie PJ, Seward JB, Reeder GS, Vlietstra RE, Bresnahan DR, Bresnahan JF, et al. Continuous-wave Doppler echocardiographic assessment of severity of calcific aortic stenosis: a simultaneous Doppler-catheter correlative study in 100 adult patients. Circulation. 1985;71(6):1162-9.

65. Ihlen H, Molstad P. Cardiac output measured by Doppler echocardiography in patients with aortic prosthetic valves. Eur Heart J. 1990;11(5):399-402.

66. Skjaerpe T, Hegrenaes L, Hatle L. Noninvasive estimation of valve area in patients with aortic stenosis by Doppler ultrasound and two-dimensional echocardiography. Circulation. 1985;72(4):810-8.

67. Wyatt HL, Heng MK, Meerbaum S, Gueret P, Hestenes J, Dula E, et al. Cross-sectional echocardiography. II. Analysis of mathematic models for quantifying volume of the formalin-fixed left ventricle. Circulation. 1980;61(6):1119-25. 
68. Rosner B. Fundamentals of Biostatistics . Second ed. Boston: PWS Publishers; 1986.

69. Hosmer D, Lemshow S. Applied Logistic Regression. Third ed. New York: John Wiley \& sons; 1989.

70. Lee ET, Wang JW. Statistical Methods for Survival Data Analysis. Third ed. New York: John Wiley \& sons; 2003.

71. McCord J, Mundy BJ, Hudson MP, Maisel AS, Hollander JE, Abraham WT, et al. Relationship between obesity and B-type natriuretic peptide levels. Arch Intern Med. 2004;164(20):2247-52.

72. Taylor JA, Christenson RH, Rao K, Jorge M, Gottlieb SS. B-type natriuretic peptide and $\mathrm{N}$-terminal pro B-type natriuretic peptide are depressed in obesity despite higher left ventricular end diastolic pressures. Am Heart J. 2006;152(6):1071-6.

73. Brenden CK, Hollander JE, Guss D, McCullough PA, Nowak R, Green G, et al. Gray zone BNP levels in heart failure patients in the emergency department: results from the Rapid Emergency Department Heart Failure Outpatient Trial (REDHOT) multicenter study. Am Heart J. 2006;151(5):1006-11.

74. van Kimmenade RR, Pinto YM, Bayes-Genis A, Lainchbury JG, Richards AM, Januzzi JL, Jr. Usefulness of intermediate amino-terminal pro-brain natriuretic peptide concentrations for diagnosis and prognosis of acute heart failure. Am J Cardiol. 2006;98(3):386-90. 
75. Daniels LB, Allison MA, Clopton P, Redwine L, Siecke N, Taylor K, et al. Use of natriuretic peptides in pre-participation screening of college athletes. Int J Cardiol. 2008;124(3):411-4.

76. Maeder MT, Mueller C, Pfisterer ME, Buser PT, Brunner-La Rocca HP. Use of B-type natriuretic peptide outside of the emergency department. Int $J$ Cardiol. 2008;127(1):5-16.

77. de Lemos JA, Hildebrandt P. Amino-terminal pro-B-type natriuretic peptides: testing in general populations. Am J Cardiol. 2008;101(3A):16-20.

78. Redfield MM, Rodeheffer RJ, Jacobsen SJ, Mahoney DW, Bailey KR, Burnett JC, Jr. Plasma brain natriuretic peptide concentration: impact of age and gender. J Am Coll Cardiol. 2002;40(5):976-82.

79. Maisel A, Hollander JE, Guss D, McCullough P, Nowak R, Green G, et al. Primary results of the Rapid Emergency Department Heart Failure Outpatient Trial (REDHOT). A multicenter study of B-type natriuretic peptide levels, emergency department decision making, and outcomes in patients presenting with shortness of breath. J Am Coll Cardiol. 2004;44(6):1328-33.

80. Hartmann F, Packer M, Coats AJ, Fowler MB, Krum H, Mohacsi P, et al. Prognostic impact of plasma N-terminal pro-brain natriuretic peptide in severe chronic congestive heart failure: a substudy of the Carvedilol Prospective Randomized Cumulative Survival (COPERNICUS) trial. Circulation. 2004;110(13):1780-6. 
81. de Lemos JA, Morrow DA, Bentley JH, Omland T, Sabatine MS, McCabe $\mathrm{CH}$, et al. The prognostic value of B-type natriuretic peptide in patients with acute coronary syndromes. $N$ Engl J Med. 2001;345(14):1014-21.

82. Schnabel R, Lubos E, Rupprecht HJ, Espinola-Klein C, Bickel C, Lackner $\mathrm{KJ}$, et al. B-type natriuretic peptide and the risk of cardiovascular events and death in patients with stable angina: results from the AtheroGene study. $J \mathrm{Am}$ Coll Cardiol. 2006;47(3):552-8.

83. Kucher N, Printzen G, Doernhoefer T, Windecker S, Meier B, Hess OM. Low pro-brain natriuretic peptide levels predict benign clinical outcome in acute pulmonary embolism. Circulation. 2003;107(12):1576-8.

84. Grewal J, McKelvie RS, Persson H, Tait P, Carlsson J, Swedberg K, et al. Usefulness of N-terminal pro-brain natriuretic Peptide and brain natriuretic peptide to predict cardiovascular outcomes in patients with heart failure and preserved left ventricular ejection fraction. Am J Cardiol. 2008;102(6):733-7.

85. Garcia S, Akbar MS, Ali SS, Kamdar F, Tsai MY, Duprez DA. N-terminal pro B-type natriuretic peptide predicts mortality in patients with left ventricular hypertrophy. Int J Cardiol. In press 2009.

86. Pedrazzini GB, Masson S, Latini R, Klersy C, Rossi MG, Pasotti E, et al. Comparison of brain natriuretic peptide plasma levels versus logistic EuroSCORE in predicting in-hospital and late postoperative mortality in patients undergoing aortic valve replacement for symptomatic aortic stenosis. Am J Cardiol. 2008;102(6):749-54. 
87. Sadoshima J, Jahn L, Takahashi T, Kulik TJ, Izumo S. Molecular characterization of the stretch-induced adaptation of cultured cardiac cells. An in vitro model of load-induced cardiac hypertrophy. $J$ Biol Chem. 1992;267(15):10551-60.

88. Cameron VA, Aitken GD, Ellmers LJ, Kennedy MA, Espiner EA. The sites of gene expression of atrial, brain, and C-type natriuretic peptides in mouse fetal development: temporal changes in embryos and placenta. Endocrinology. 1996;137(3):817-24.

89. Brown LA, Nunez DJ, Wilkins MR. Differential regulation of natriuretic peptide receptor messenger RNAs during the development of cardiac hypertrophy in the rat. J Clin Invest. 1993;92(6):2702-12.

90. Steiner J, Guglin M. BNP or NTproBNP? A clinician's perspective. Int $J$ Cardiol. 2008;129(1):5-14.

91. Luchner A, Hengstenberg C, Lowel H, Riegger GA, Schunkert H, Holmer S. Effect of compensated renal dysfunction on approved heart failure markers: direct comparison of brain natriuretic peptide (BNP) and N-terminal proBNP. Hypertension. 2005;46(1):118-23. 
Aprovação do protocolo de pesquisa

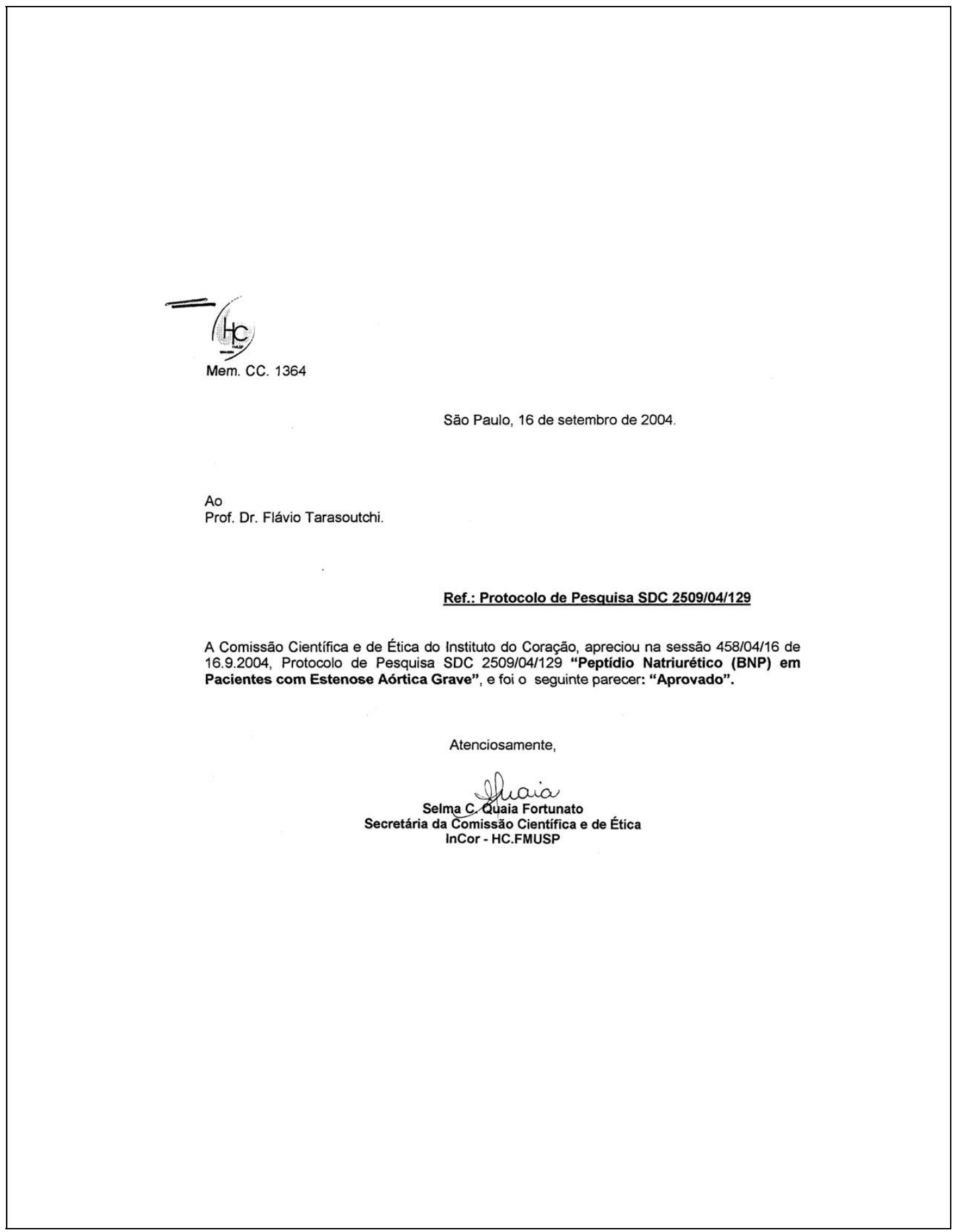


Lista de pacientes incluídos

\begin{tabular}{|c|c|c|c|c|c|c|c|}
\hline NOME & $\begin{array}{c}\text { Data } \\
\text { Inclusão }\end{array}$ & $\begin{array}{l}\text { ICC CF } \\
\text { (NYHA) }\end{array}$ & $\begin{array}{c}\text { Angina } 0 \\
\text { ou } 1\end{array}$ & $\begin{array}{c}\text { Síncope } \\
0 \text { ou } 1\end{array}$ & Sintomas & $\begin{array}{l}\mathrm{BNP} \\
\mathrm{pg} / \mathrm{mL}\end{array}$ & $\begin{array}{c}\text { NT-pro BNP } \\
\mathrm{pg} / \mathrm{mL}\end{array}$ \\
\hline VDVO & $01 / 10 / 04$ & 1 & 0 & 0 & 0 & 72 & 1315 \\
\hline AFC & $01 / 10 / 04$ & 3 & 0 & 0 & 1 & 136 & 1504 \\
\hline MPDP & $14 / 10 / 04$ & 2 & 1 & 0 & 1 & 16 & 110 \\
\hline AMG & $15 / 10 / 04$ & 2 & 0 & 0 & 1 & 343 & 4970 \\
\hline JLFS & $19 / 10 / 04$ & 3 & 1 & 0 & 1 & 18 & 324 \\
\hline RRRB & $25 / 10 / 04$ & 1 & 0 & 0 & 0 & 48 & 206 \\
\hline SFF & $26 / 10 / 04$ & 2 & 0 & 0 & 1 & 30 & 737 \\
\hline MASR & $27 / 10 / 04$ & 1 & 1 & 0 & 1 & 9 & 180 \\
\hline LG & $05 / 11 / 04$ & 4 & 0 & 0 & 1 & 1292 & 17987 \\
\hline ABSA & $05 / 11 / 04$ & 3 & 1 & 0 & 1 & 346 & 4446 \\
\hline DRL & $11 / 11 / 04$ & 1 & 0 & 0 & 0 & 56 & 523 \\
\hline PCR & $16 / 11 / 04$ & 3 & 0 & 1 & 1 & 270 & 3504 \\
\hline DMB & $23 / 11 / 04$ & 1 & 0 & 1 & 1 & 62 & 871 \\
\hline EO & $23 / 11 / 04$ & 3 & 0 & 0 & 1 & 75 & 296 \\
\hline MCF & $26 / 11 / 04$ & 2 & 0 & 0 & 1 & 50 & 744 \\
\hline ACJ & $26 / 11 / 04$ & 3 & 0 & 0 & 1 & 59 & 745 \\
\hline PRS & 29/11/04 & 1 & 0 & 0 & 0 & 141 & 2061 \\
\hline LBO & $30 / 11 / 04$ & 2 & 0 & 1 & 1 & 62 & 1302 \\
\hline JP & $07 / 12 / 04$ & 2 & 1 & 0 & 1 & 10 & 247 \\
\hline IPS & $07 / 12 / 04$ & 3 & 1 & 0 & 1 & 111 & 1574 \\
\hline AAP & $20 / 12 / 04$ & 1 & 0 & 0 & 0 & 26 & 129 \\
\hline BHG & $05 / 01 / 05$ & 2 & 1 & 0 & 1 & 124 & 582 \\
\hline MDM & $05 / 01 / 05$ & 2 & 0 & 0 & 1 & 42 & 393 \\
\hline ALS & $11 / 01 / 05$ & 3 & 0 & 0 & 1 & 105 & 1500 \\
\hline ZNS & $19 / 01 / 05$ & 4 & 0 & 0 & 1 & 2467 & 17786 \\
\hline EGC & $26 / 01 / 05$ & 2 & 1 & 0 & 1 & 58 & 254 \\
\hline LRS & $25 / 02 / 05$ & 1 & 1 & 0 & 1 & 270 & 2652 \\
\hline GB & $28 / 02 / 05$ & 1 & 0 & 0 & 0 & 41 & 413 \\
\hline AFM & $03 / 03 / 05$ & 3 & 1 & 0 & 1 & 129 & 1651 \\
\hline SFF & $07 / 03 / 05$ & 3 & 0 & 0 & 1 & 102 & 623 \\
\hline MFM & $08 / 03 / 05$ & 3 & 0 & 0 & 1 & 401 & 4709 \\
\hline WAS & 09/03/05 & 1 & 0 & 0 & 0 & 180 & 1356 \\
\hline JPR & $28 / 03 / 05$ & 1 & 0 & 0 & 0 & 175 & 1777 \\
\hline NM & $28 / 03 / 05$ & 4 & 1 & 0 & 1 & 1037 & 6608 \\
\hline MLA & $15 / 04 / 05$ & 1 & 0 & 0 & 0 & 36 & 235 \\
\hline CPS & $27 / 05 / 05$ & 3 & 1 & 0 & 1 & 183 & 1292 \\
\hline JMF & $01 / 06 / 05$ & 1 & 0 & 0 & 0 & 57 & 290 \\
\hline MARB & $08 / 06 / 05$ & 3 & 0 & 0 & 1 & 210 & 1636 \\
\hline SR & $14 / 06 / 05$ & 2 & 0 & 1 & 1 & 34 & 257 \\
\hline JSN & $15 / 08 / 05$ & 2 & 0 & 0 & 1 & 15 & 161 \\
\hline VP & $15 / 08 / 05$ & 2 & 0 & 0 & 1 & 92 & 1600 \\
\hline ITRS & $18 / 08 / 05$ & 3 & 0 & 0 & 1 & 88 & 744 \\
\hline LTOS & $28 / 09 / 05$ & 4 & 0 & 0 & 1 & 2787 & 13697 \\
\hline MJNM & $25 / 10 / 05$ & 2 & 0 & 0 & 1 & 60 & 331 \\
\hline MAF & $08 / 11 / 05$ & 3 & 0 & 0 & 1 & 134 & 674 \\
\hline
\end{tabular}




\begin{tabular}{|l|c|c|c|c|c|c|c|}
\hline NOME & $\begin{array}{c}\text { Data } \\
\text { Inclusão }\end{array}$ & $\begin{array}{c}\text { ICC CF } \\
\text { (NYHA) }\end{array}$ & $\begin{array}{c}\text { Angina 0 } \\
\text { ou 1 }\end{array}$ & $\begin{array}{c}\text { Síncope } \\
\text { 0 ou 1 }\end{array}$ & Sintomas & $\begin{array}{c}\text { BNP } \\
\text { pg/mL }\end{array}$ & $\begin{array}{c}\text { NT-pro BNP } \\
\text { pg/mL }\end{array}$ \\
\hline SAM & $06 / 01 / 06$ & 3 & 0 & 0 & 1 & 342 & 4073 \\
\hline DDX & $06 / 02 / 06$ & 2 & 0 & 0 & 1 & 79 & 156,6 \\
\hline RG & $07 / 02 / 06$ & 1 & 0 & 0 & 0 & 190 & 819,5 \\
\hline JF & $21 / 02 / 06$ & 1 & 0 & 0 & 0 & & \\
\hline LAS & $01 / 03 / 06$ & 2 & 0 & 0 & 1 & 413 & 2681 \\
\hline ICH & $22 / 03 / 06$ & 1 & 0 & 0 & 0 & 89 & 675,9 \\
\hline SI & $11 / 04 / 06$ & 1 & 0 & 0 & 0 & 82 & 1429 \\
\hline EAM & $24 / 04 / 06$ & 1 & 0 & 0 & 0 & 282 & 1154 \\
\hline WA & $27 / 04 / 06$ & 1 & 0 & 0 & 0 & 19 & 227 \\
\hline JAHCP & $05 / 06 / 06$ & 1 & 1 & 0 & 1 & 5 & 72,49 \\
\hline LRG & $10 / 07 / 06$ & 2 & 0 & 1 & 1 & 13 & 171,2 \\
\hline VXM & $17 / 07 / 06$ & 3 & 1 & 1 & 1 & 174 & 1053 \\
\hline JFS & $17 / 07 / 06$ & 2 & 0 & 0 & 1 & 29 & 164,2 \\
\hline EEMG & $07 / 08 / 06$ & 3 & 0 & 0 & 1 & 65 & 641 \\
\hline MJM & $21 / 07 / 06$ & 3 & 0 & 0 & 1 & 289 & 1808 \\
\hline ARP & $23 / 10 / 06$ & 2 & 0 & 0 & 1 & 33 & 216 \\
\hline FS & $06 / 09 / 06$ & 3 & 0 & 0 & 1 & 645 & 3087 \\
\hline FRS & $20 / 12 / 06$ & 3 & 1 & 1 & 1 & & \\
\hline MAL & $14 / 06 / 07$ & 2 & 0 & 1 & 1 & 146 & 1406 \\
\hline FMN & $14 / 06 / 07$ & 3 & 0 & 0 & 1 & 120 & 638,6 \\
\hline AVP & $10 / 12 / 07$ & 2 & 0 & 0 & 1 & 104 & 970,2 \\
\hline & & & & & & & \\
\hline
\end{tabular}

